\title{
Leveraging Collective Intelligence in Participatory Design Research Using Information and Communications Technology
}

\author{
By \\ Michael Grigoriev
}

A thesis submitted to the Faculty of Graduate and Postdoctoral Affairs in partial fulfillment of the requirements for the degree of

Master of Design
In
Industrial Design

Carleton University

Ottawa, Ontario

(C) 2013, Michael Grigoriev 


\begin{abstract}
Design is in the midst of undergoing significant changes in its potential to engage large crowds of people using information and communications technology (ICT) in participatory processes. As design becomes increasingly tasked with playing a role in improving the human condition, it must determine how to best engage existing diverse knowledge from crowds and evolve beyond traditional design approaches to solve non-traditional problems. The notion of using information and communication technologies for development (ICT4D) to aggregate diverse knowledge within participatory processes represents great promise, yet it must be better understood in an emerging design landscape. This research combines leading perspectives into a set of comprehensive guidelines to inform the use of ICT within participatory design research capable of engaging the collective intelligence of participants. It also documents the exploration and evidence of a social movement known as 'Idle No More' as potential for a future application of these guidelines.
\end{abstract}

KEYWORDS: Participatory Design, Collective Intelligence, ICT4D 


\section{ACKNOWLEDGEMENTS}

This thesis would not have been possible without the incredible support of a closeknit group of family, supporters, and friends. From the invaluable wisdom, perspectives, and scrutiny of my supervisors, to the support, inspiration, and optimism of my family, the last two years have embodied a broad range of emotions that have culminated in this document. As I progress on my journey in design, I need to stop and say thank you to some special contributors who have made the journey of learning so enjoyable.

First off, a big thank you to my two supervisors whose deep thoughts and enlightened approaches always found a way to help me dig a little deeper and think a little harder. Dr. Thomas Garvey, after 9 years of knowing you, I can attest that you have definitely shaped my mind and made me expect more from myself and those around me - in the best kind of way. Osewa ni narimashita. Dr. Gerald Grant, you brought a level of intellectual stimulus that I craved in a field I once knew so little about. Thank you for expanding my horizons.

On to my tight-knit little family. My parents - Paul and Olga - you've been incredibly supportive throughout, not that they've ever been anything but. Hearing your perspectives as you've taken similar paths helped tremendously in seeing the forest from the trees. To my sister, brother-in-law and nieces who spent their early years with an occasionally absent and surly uncle, thank you for being so understanding. Finally, Jane, you've been as much a part of this process as I have. Always encouraging, motivating, and even comforting when need be. Thank you for being who you are and for always enthusiastically lending a hand.

I've saved one last but enormous thank you to the School of Industrial Design at Carleton University, which has been home for 6 years. I want to sincerely thank everyone I've come in contact with during that time. The opportunities you've given me have surpassed anything I thought possible. Leaving may feel a little bittersweet, but I promise to be back. You're not getting rid of me this easily.

Michael Grigoriev 


\section{TABLE OF CONTENTS}

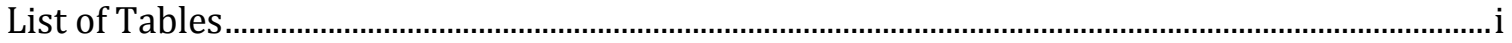

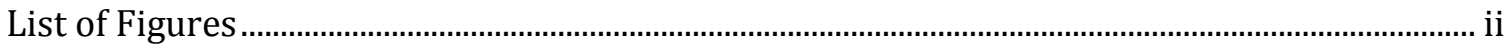

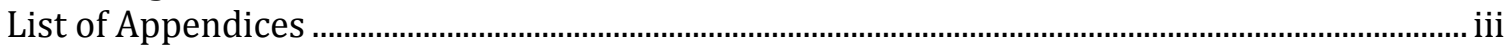

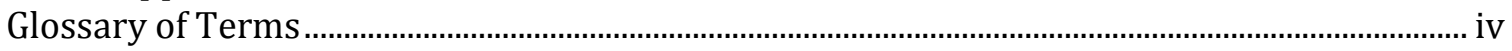

1.0 INTRODUCTION

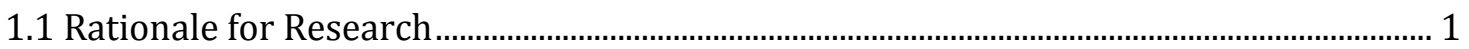

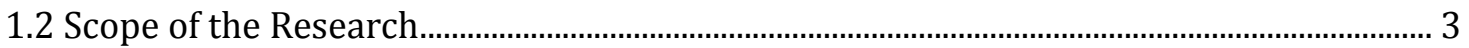

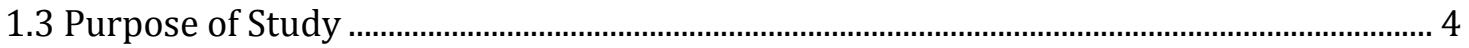

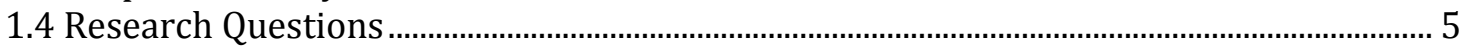

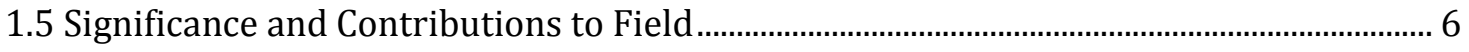

2.0 LITERATURE REVIEW

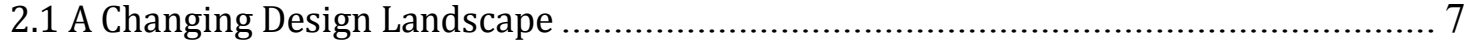

2.2 Participatory Approaches in Design and Development .......................................... 9

2.2.1 A Flawed 'Expert' ........................................................................................................ 9

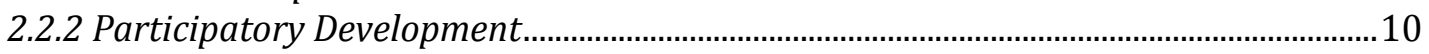

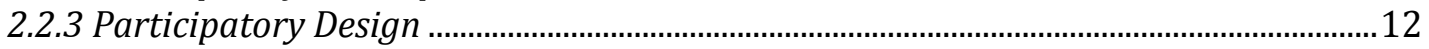

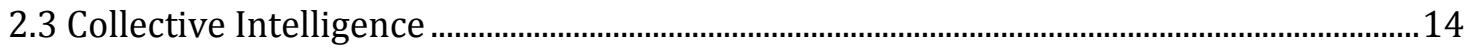

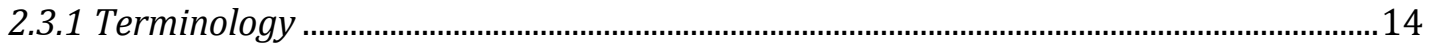

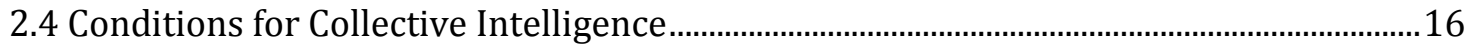

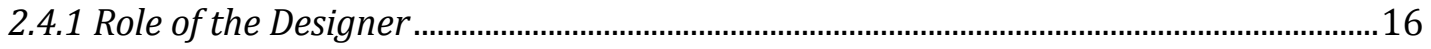

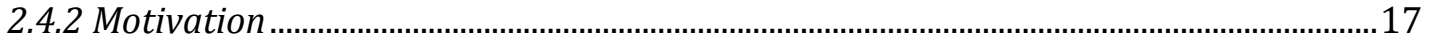

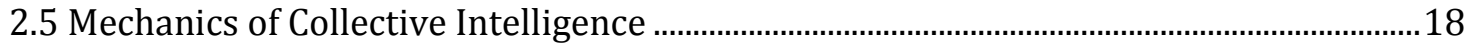

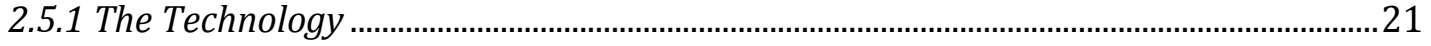

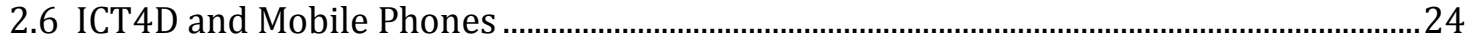

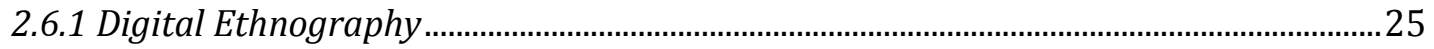

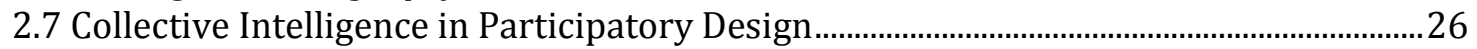

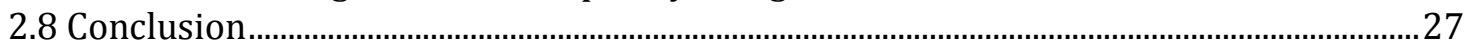

3.0 METHODS: PHASE 1 PD-ICT GUIDELINES

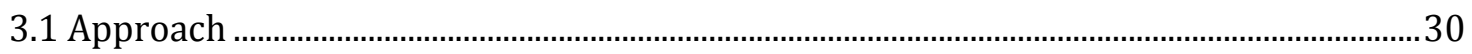

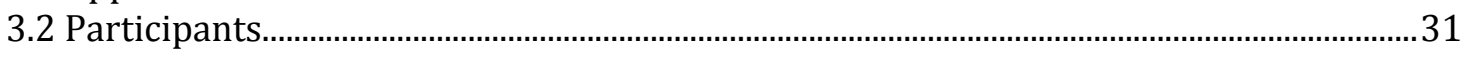

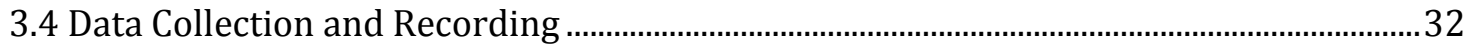

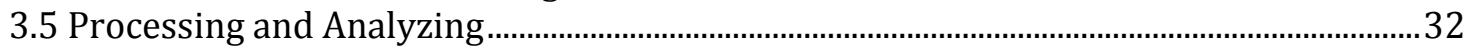

4.0 RESULTS: PHASE 1 PD-ICT GUIDELINES

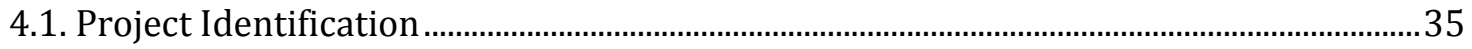

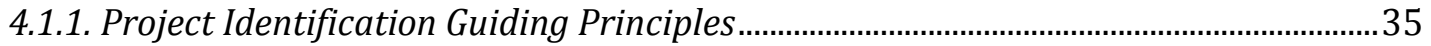

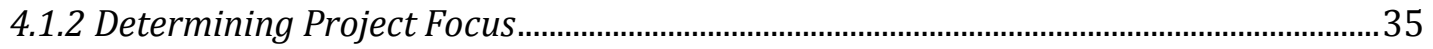

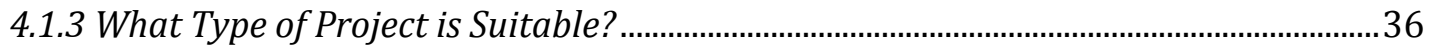

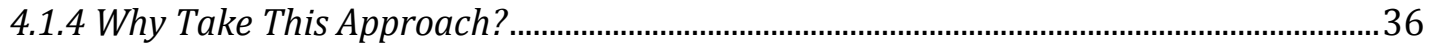

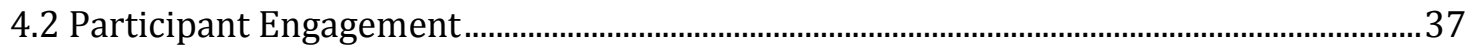

4.2.1 Participant Engagement Guiding Principles .......................................................................3

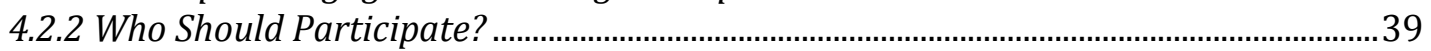

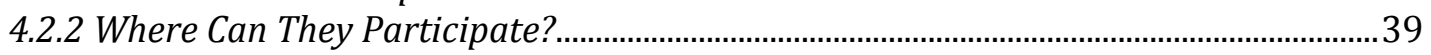

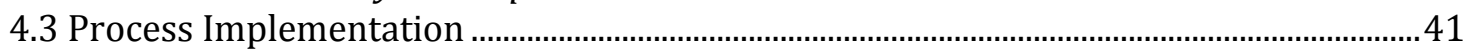

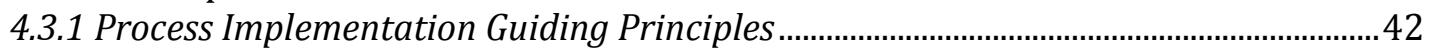

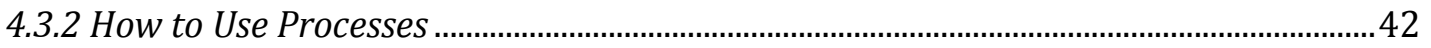

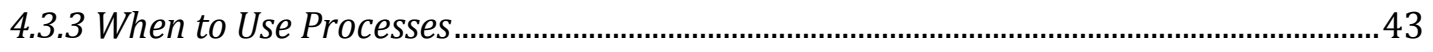

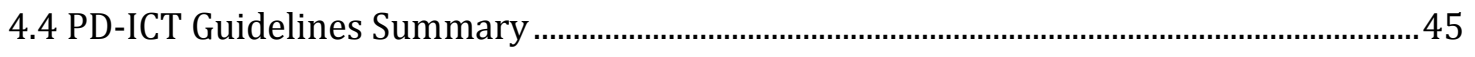




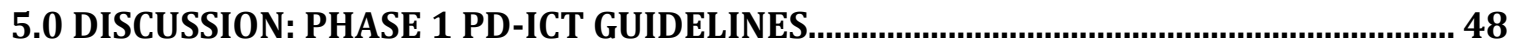

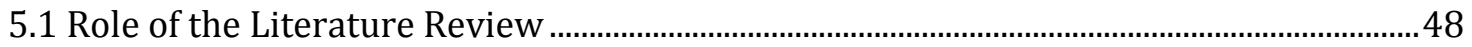

5.2 Comparison of Data to Literature

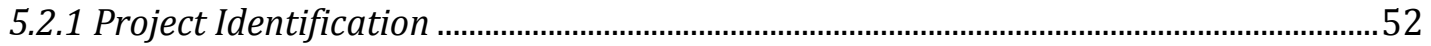

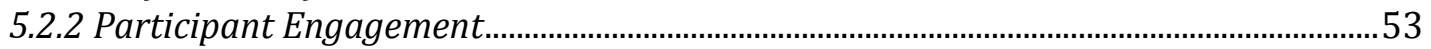

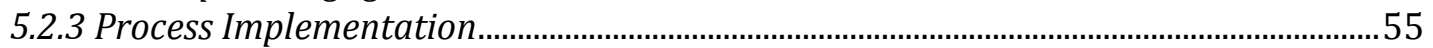

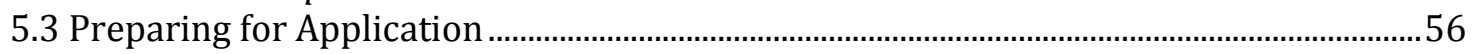

6.0 METHODS: PHASE 2 APPLICATION IDENTIFICATION

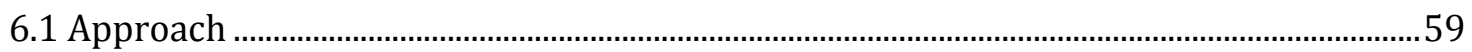

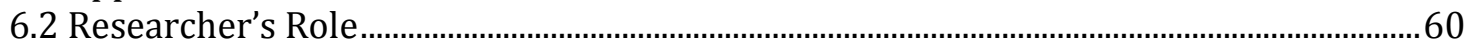

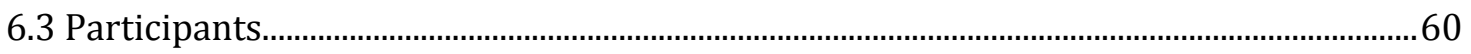

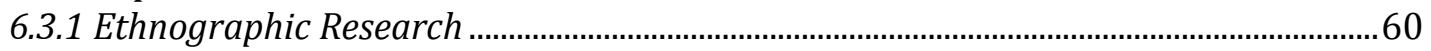

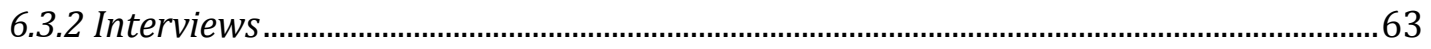

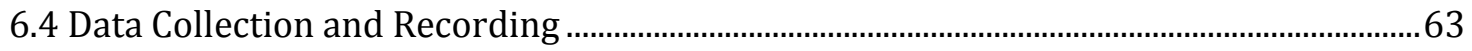

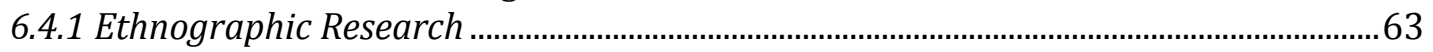

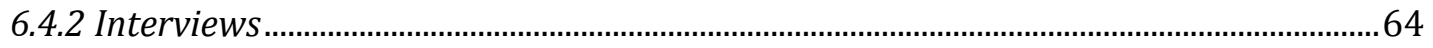

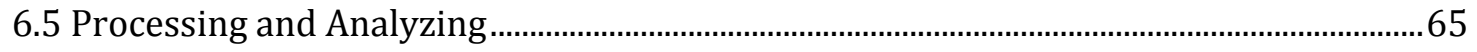

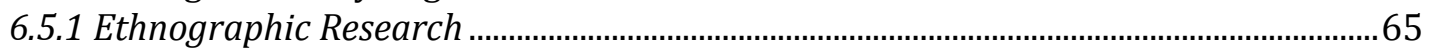

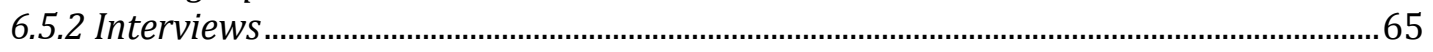

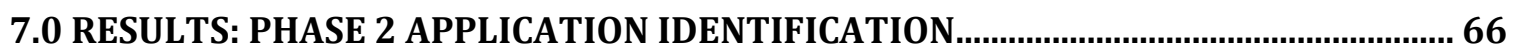

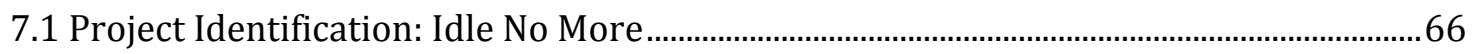

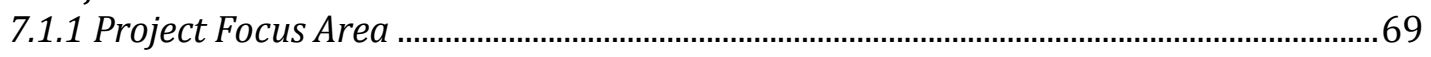

8.0 DISCUSSION: PHASE 2 APPLICATION IDENTIFICATION ............................................ 76

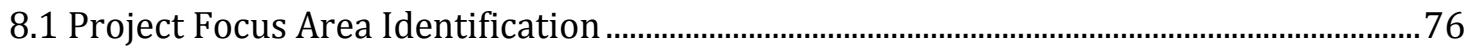

8.2 Future Guideline Category Application..................................................................................

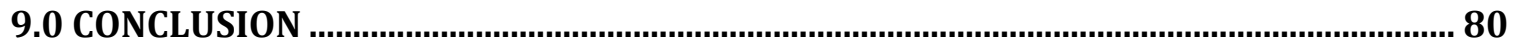

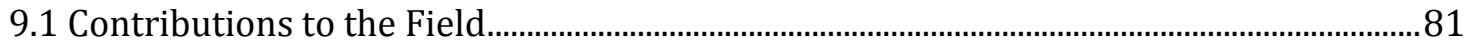

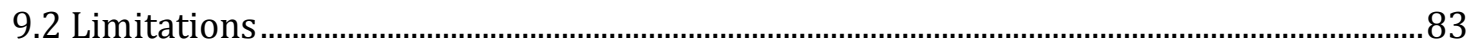

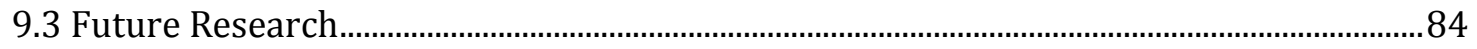

LIST OF REFERENCES 


\section{LIST OF TABLES}

Table 1. Interview participants' expertise and interview focus.......................................................31

Table 2. Sample interview coding - Project Identification ..................................................................

Table 3. Sample interview coding - Participant Engagement ...................................................... 41

Table 4. Sample interview coding - Process Implementation ........................................................... 44

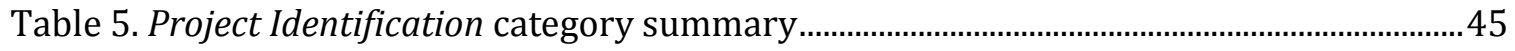

Table 6. Participant Engagement category summary ………........................................................... 46

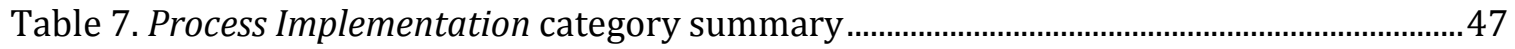

Table 8. Idle No More events attended for ethnographic research...............................................61

Table 9. Twitter volume using \#idlenomore hashtag........................................................................62

Table 10. Primary themes from in-person ethnography.................................................................

Table 11. Primary themes from interviews …………………………….......................................... 72

Table 12. Idle No More popular themes on dates of ethnographic research ...............................74

Table 13. Project research area identification using PD-ICT guidelines........................................77 


\section{LIST OF FIGURES}

Figure 1. Rationale for research: participation and use of ICT ………......................................... 3

Figure 2. Intersecting fields of research ........................................................................................

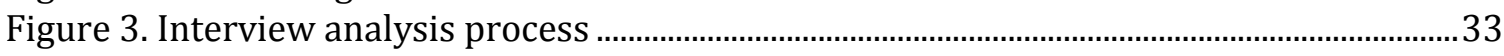

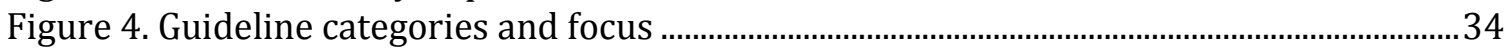

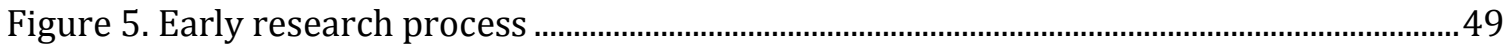

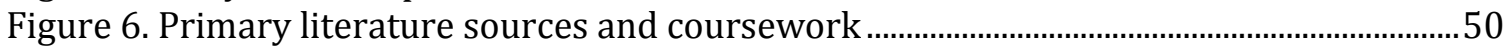

Figure 7. Process of interviews, coding and stage 2 literature review ..........................................51

Figure 8. Phase 1 research process ……………................................................................................57

Figure 9. Tweet volume of \#idlenomore hashtag adapted from Topsy ..........................................63

Figure 10. Idle No More 2012 events map sample .....................................................................67

Figure 11. \#Idlenomore tweet cluster density map as of May 6, 2013..........................................68

Figure 12. Aboriginal connectivity profiles of Ontario as of March 1, 2013 .............................69

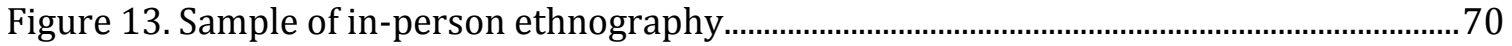

Figure 14. Sample of \#idlenomore tweets ………….....................................................................73

Figure 15. Sample of tweet processing in Excel................................................................................. 74

Figure 16. Breadth and depth of research techniques employed...................................................78 


\section{LIST OF APPENDICES}

Appendix A. Recruitment Email Interview.......................................................................

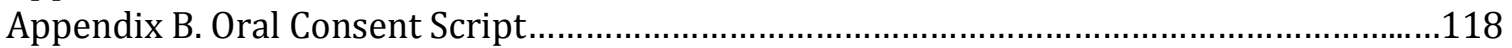

Appendix C. Organization Descriptions and Participant Biographies.................................119

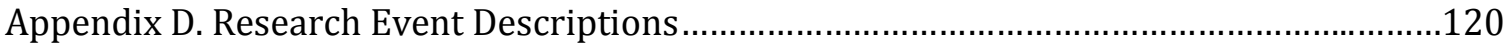

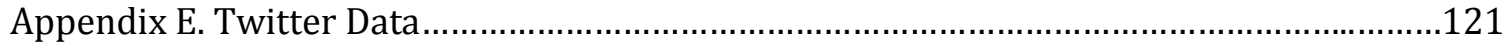




\section{GLOSSARY OF TERMS}

\section{Participatory Design}

An approach in which users and other stakeholders work with designers in the design process, and are given the role of 'expert of his/her experience'. Participants play a significant role in knowledge development, idea generation, and concept development (Sanders \& Stappers, 2008).

\section{Participatory Development}

A process of engaging local populations in development projects. It seeks to give the beneficiaries a role in initiatives designed for their benefit in the hopes that development projects will be more sustainable and successful if local populations are engaged in the development process (Cornwall, 2002).

\section{Human Development}

A process of enlarging people's choices. The most critical of these wide-ranging choices are to live a long and healthy life, to be educated and to have access to resources needed for a decent standard of living. Additional choices include political freedom, guaranteed human rights and personal self-respect It focuses on the human life component of development, rather than the solely the economic component (UNDP, 2001).

\section{Collective Intelligence}

The cognitive capacities of a society, a community or a collection of individuals (Lévy, 2013)

\section{Crowdsourcing}

An online, distributed problem-solving and production model (Brabham, 2008).

\section{Digital Ethnography}

A modern day digital equivalent of traditional ethnographic forms that employs information communication and social technologies to extend approaches like participant observation into the digital world (Murthy, 2008).

\section{Hashtag}

The \# symbol, is used to mark keywords or topics in a Tweet. Twitter users created it organically as a way to categorize messages. People use the hashtag symbol \# before a relevant keyword or phrase (no spaces) in their Tweet to categorize those Tweets and help them show more easily in Twitter Search. (Twitter, 2013). 


\subsection{INTRODUCTION}

As the world copes with complex human development challenges, new perspectives and approaches are being sought to address them. Design and its innovative approaches to problem-solving that places people at the heart of solutions, is becoming increasingly employed in development work, and interdisciplinary connections are being forged between the fields. While design's role in human development is a progressive approach to achieve new, meaningful impact, its processes must evolve to reflect the growing complexity of challenges ahead. These processes include participatory approaches that are increasingly popular and represent a significant transition from traditionally 'expert'-driven processes. By embracing these participatory approaches and expanding their breadth with information and communications technology (ICT), it is now possible to engage a wide variety of stakeholders and beneficiaries in previously impossible ways in the hope of leveraging their collective intelligence. It is this promise of leveraging the tacit collective intelligence of a local community - people who are at the core of human development challenges - in participatory design processes by using ICT that is the foundation of this research.

\subsection{Rationale for Research}

\section{Design is playing a larger role in human development work.}

While employing design approaches towards development challenges first emerged as a concept as early as the 1960's (Margolin, 2007a), the conversation is beginning to take on greater significance as development organizations and agencies look for new approaches to achieve meaningful impact. In 2012, design was recognized as a valuable tool for development by bodies such as the World Economic Forum and the Clinton Global Initiative. Design firms have become increasingly engaged in development work as well, evidenced by projects undertaken by firms such as IDEO.org, Frog design, and The Reboot. In a USAID funded project, IDEO.org worked on designing new tools for mapping open defecation sites by combining a digital mobile platform with offline community driven activities in Kumasi, Ghana. Frog design serves as the lead design and innovation partner for UNICEF's Innovation Group, whose major initiatives include work on a mobile health program to improve maternal and infant health and welfare in Malawi and Zambia by leveraging mobile technologies to increase mothers' visits to clinics. The Reboot has worked in collaboration 
with the World Bank, and the Government of Nigeria on creating a mobile SMS-based citizen feedback tool to monitor public service quality and government accountability.

These interdisciplinary approaches to solving complex challenges have emerged from design's evolution beyond merely being a tool used for the development of innovative consumer products, towards being seen as a process capable of eliciting radical change (Bjögvinsson, Ehn, \& Hillgren, 2012), whether it is with products, services, systems, or environments.

\section{Design and development approaches are becoming more participatory in nature.}

Participatory processes in design and development are methods of engaging local knowledge and talent, which is traditionally difficult for outsiders to interpret and learn. These processes are increasingly being used to empower local participants and make the best use of culturally specific knowledge that is tacit to those who are often the beneficiaries of development work. Increased participation also aims to minimize the cultural bias and top-down approaches external 'experts' often bring to development work.

\section{ICT enables large-scale digital participation in design.}

The advancement and diffusion of ICT enables the digital participation of many who were previously unreachable and voiceless in development work. The tools for participation in development are increasingly in the hands of beneficiaries and stakeholders, enabling an evolution from being passive recipients to contributors in development work. Design now has the ability to leverage the diverse knowledge of vast groups of networked people in participatory processes, and forming these groups has become easier in terms of money, time, effort and attention (Shirky, 2009).

Digital participation in design can result in collective intelligence that outperforms expert knowledge.

The benefit of engaging locals in participatory design projects is not only likely to result in a project with a greater chance of success, but ultimately holds the promise of attaining a higher-order collective intelligence greater than that of individual expertise. By employing ICT in participatory design to engage a large number of diverse participants, it becomes possible to envision how the theory of collective intelligence can be harnessed for significant impact in human development. 


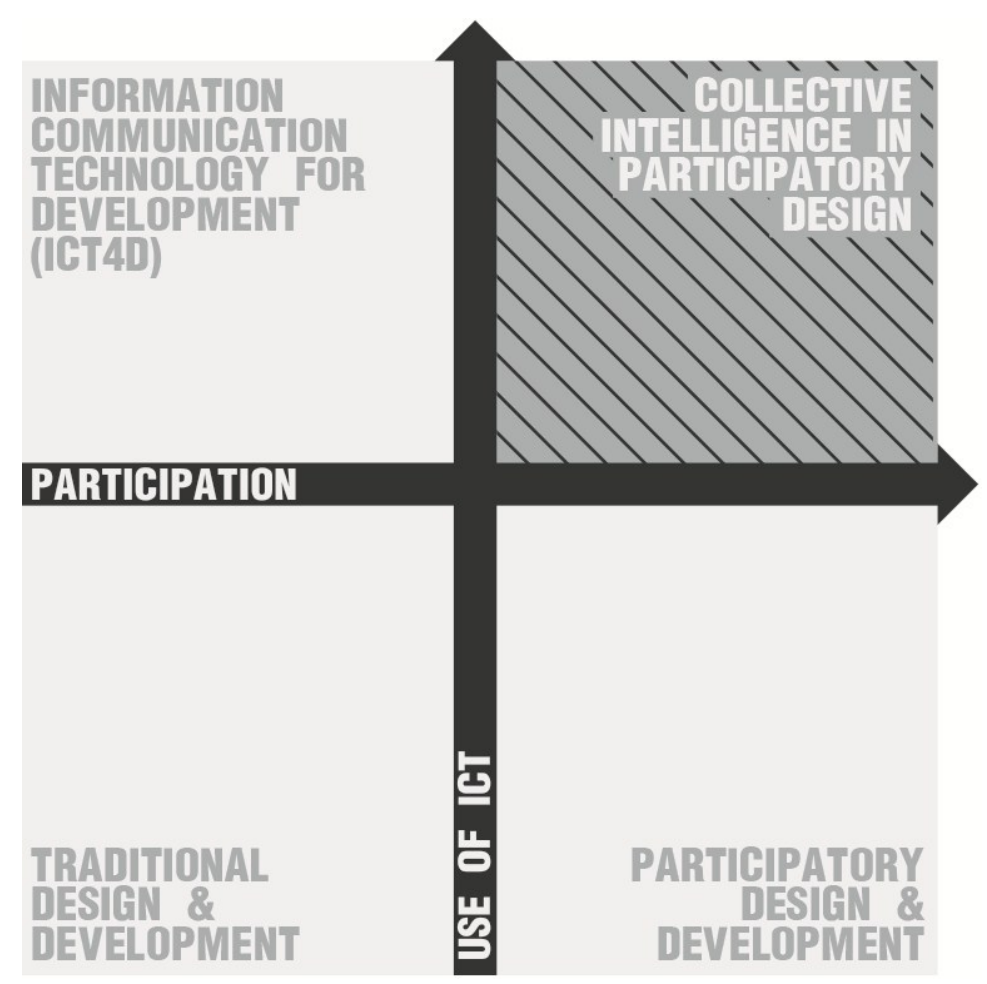

Figure 1 Rationale for research: participation and use of ICT

\subsection{Scope of the Research}

The research deals with the intersection of three increasingly overlapping fields: participatory design, collective intelligence and ICT for development (ICT4D). It focuses primarily on exploring the necessary conditions for the overlap and application of these three fields towards human development challenges, and places an emphasis on the frontend design research component of design processes. The fields of research are interpreted through the contextual lens of interdisciplinary design research. 


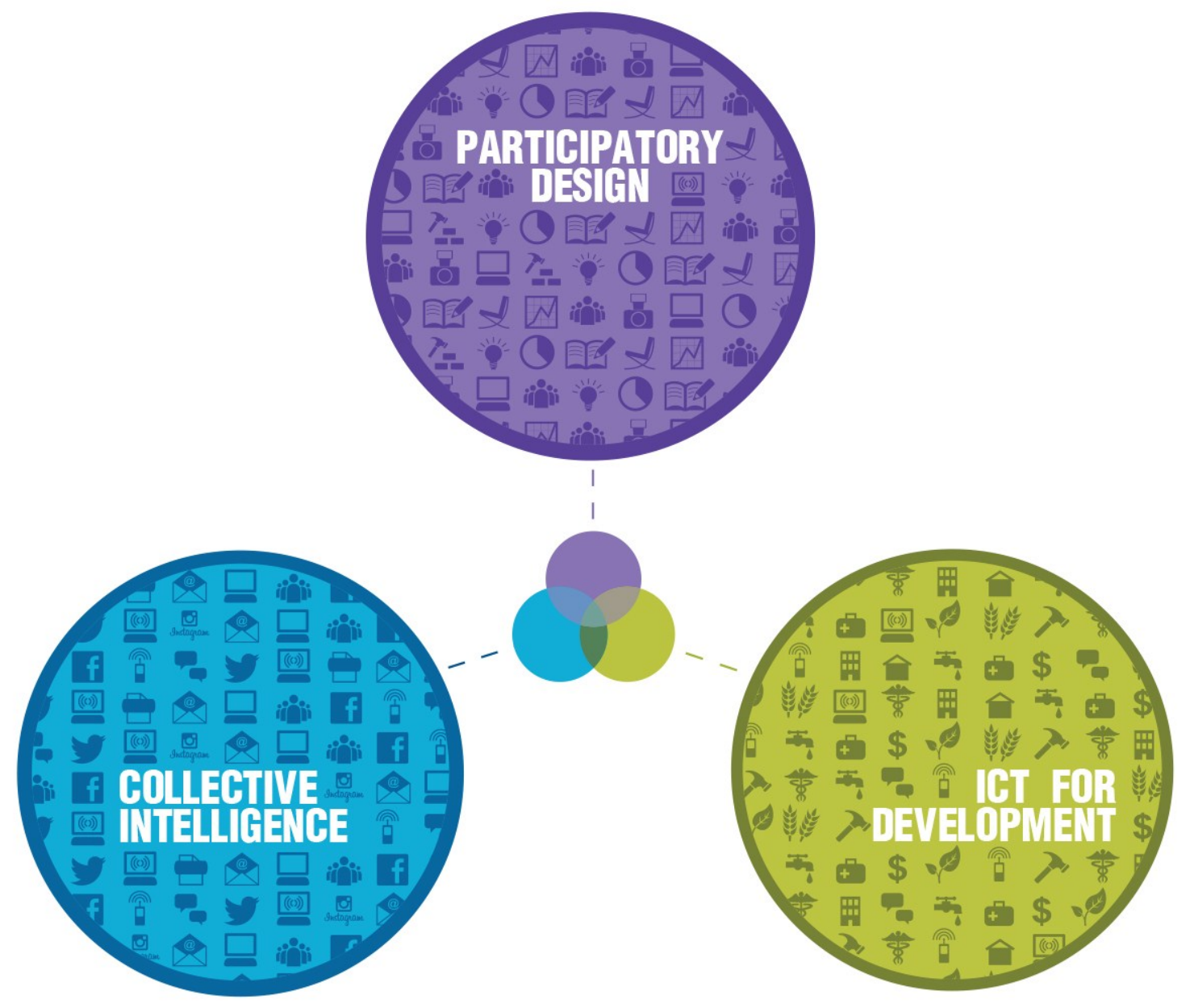

Figure 2. Intersecting fields of research

\subsection{Purpose of Study}

The purpose of the study is to form a greater understanding of the growing overlap between the fields of research in order to aggregate theory and practice in a set of guidelines. In doing so, the research will create the conditions to advance beyond existing theory and promise, towards applicable outcomes that seek to leverage the collective intelligence of locals in participatory design for human development. The study is broken down into two phases. 


\section{PHASE 1: Advancing theory towards application}

While the identified fields of research hold great promise, it is difficult to identify evidence of their tangible value and applications. As it stands, the prospect of achieving collective intelligence under the right conditions within participatory design is apparent, however it is still not clearly understood how human resource on the network may be employed and successfully applied in design (Fathianathan, Panchal \& Nee, 2009). In a field that has long-valued the 'lone visionary' and the 'creative spark', how will design adapt to embrace a collaborative and mediated process in which the contributions of many nonexperts leads to a solution?

This study seeks to aggregate theory and practice in a set of comprehensive guidelines for the application of ICT within participatory design research. It aims to combine theoretical literature with experience and perspectives from practising experts to create the necessary structure and guidance for the researcher and future practitioners in application scenarios.

\section{PHASE 2: Assessing an application for the guidelines}

The study will proceed to assess a potential application for the developed guidelines in a suitable environment that will be identified and explored. The results of this identification aim to provide evidence of the type of conditions capable of progressing theory and literature towards more actionable applications in an effort to move beyond the promise and idealism the fields embody.

\subsection{Research Questions}

The primary research question for the study is:

\section{Q1: How can ICT be used as an effective design research tool capable of leveraging a} community's collective intelligence in participatory design?

The question invites an exploratory approach towards research will which span the three identified fields in order to create a better understanding of how to employ ICT within a design process that relies on participation. The exploration of the following sub-questions will enable the researcher to address the primary research question: 
SQ1: What is the role of individual and design firm expertise within a participatory design process that leverages ICT?

SQ2: What are the ideal methods and tools to most actively engage participants within community-driven participatory design?

SQ3: How might community participation in design through the use of ICT minimize external bias in human development initiatives?

\subsection{Significance and Contributions to Field}

This research represents an attempt at establishing the requirements to achieve collective intelligence within participatory design geared towards addressing human development. It builds on growing interdisciplinary relationships between design and human development by providing necessary structure that unifies best practice from increasingly intersecting fields. The research will contribute towards informing those within the fields of design and human development looking to apply contemporary approaches that leverage ICT within their participatory processes, yet lack the experience or theoretical background to do so. By developing a set of actionable guidelines, these findings will provide the necessary structure and support that may have otherwise been missing in order to encourage others to employ these approaches as they seek to address development challenges. By progressing beyond theory towards providing tangible applications and project examples, the research hopes to serve as inspiration for future practitioners in these fields going forward. Finally, due to the interdisciplinary nature of the research, it will provide further justification for the growing relationships between the fields of design and development to continue to develop and apply approaches capable of achieving meaningful impact towards development challenges.

The remainder of the document will present a literature review, and then the research processes undertaken in two phases. Phase 1 will discuss the development of the guidelines, and Phase 2 discusses the assessment of an application for the guidelines. 


\subsection{LITERATURE REVIEW}

The primary themes reviewed in the literature review are: Participatory Design and Development, Collective Intelligence, and ICT for Development (ICT4D). It will explore the background of participatory approaches in design and development, as well as theory on collective intelligence to strengthen social design initiatives and ICT4D work. By exploring participatory methodologies in both design and development, it will seek to understand the potential of networked participants engaging in development by harnessing ICT. It will also shed light on the resulting impact on designer's expertise, as well as the designer's role within a new participatory landscape.

\subsection{A Changing Design Landscape}

Design is currently in the midst of expanding its interdisciplinary breadth as it becomes tasked with playing a larger role in occupying "the space between the world that is, and the world that could be" (Margolin, 2007b, p.4).

\section{Why Design Matters for Development}

While the world's issues become increasingly more complex, designers are in a position to become part of the solution, as it is within design's genetic code to improve the quality of the world (Manzini, 2007). Designers, above all other professions take into account the everyday relationships of human beings with their artefacts, and as a result, they possess the tools that are needed to help shape the future with these objects, services, and systems (Manzini, 2007). In what has been described as using "build-and-fix" instincts, the field of design is beginning to evolve beyond being a tool used for the development of functional and innovative consumer products, and is instead being seen as a process capable of eliciting radical change (Bjögvinsson, et al., 2012). In this changing design landscape, the role of the designer must shift from that of an operator who develops for a final user, towards one who acts within a more complex network where the client may be an institution, a local authority, or a community (Manzini, 2007). This evolution beyond design serving users or consumers towards design being a valuable tool and process with which to engage organizations and agencies has set the course for an increasingly innovative and human-centred approach in development initiatives.

While design's impact within development is unfolding, it is becoming recognized as a valuable resource with which to address large-scale societal challenges. However, 
traditional design processes have difficulty addressing the scale or complexity of these challenges (Sanders \& Stappers, 2008). In order for design to make progressive steps towards addressing complex and 'wicked problems', it must focus on leveraging the knowledge and abilities that exist within society, and applying its expertise towards creating the conditions for large-scale participation in its processes.

Participatory approaches to design and development are recognized for their ability to better engage local communities by designing with beneficiaries (as opposed to for), while involving different non-designers and non-experts in various co-design activities throughout the design process (Sanders, Brandt \& Binder, 2010). They serve to engage the beneficiaries of a design project as opposed to superficial attempts at remote research that are often plagued by a lack of true cultural and contextual understanding (Papanek, 1985). While the call for greater participation in design and design research is not new, the profession is in a position to evolve the popular 'ethnographic' model it has traditionally relied on and move towards approaches driven by new concepts and technologies (Brown, 2009). Thanks to these new concepts and technologies, design is beginning to open up and the traditional boundaries between designer and user are beginning to dissolve as roles and responsibilities are beginning to change (Hagen \& Robertson, 2009).

The notion of collective intelligence - that a group of diverse, independent and reasonably informed people might outperform even the best individual estimate or decision (Bonabeau, 2009) - represents a concept with powerful potential in participatory design initiatives. It is enabled by the Internet, which provides a perfect technological platform that is capable of aggregating millions of independent ideas (Brabham, 2008). By potentially engaging vast amounts of people, collective intelligence can enable a significant expansion in the breadth of participatory design practice and leverage the intelligence of many.

While it is appreciated that participatory design and collective intelligence stand to dramatically alter the way society approaches large, pressing challenges (Sanders \& Stappers, 2008), there still remains much to understand on the topics and their implications on design in development initiatives. As groups of networked people become increasingly intelligent and exhibit the 'wisdom of the crowds' as described by James Surowiecki (2005), how can that collective intelligence be leveraged in order to unleash the full power of design thinking (Brown, 2009)? 


\subsection{Participatory Approaches in Design and Development}

In design and development, there is a strong appreciation for using participatory approaches that engage a local community in order to better cope with increasingly complex challenges. In design, an evolution occurred from treating the "user" as a passive consumer and subject of study towards treating individuals as "co-designers" in a project (Sanders \& Stappers, 2008). In development, there is growing appreciation for the role of participatory rural appraisals (PRA) that empower and engage a local community, and in the field of ICT4D, technology is seen as the necessary tool that will connect and enable locals to become active participants in development initiatives. In all contexts, while the overarching goal of these participatory approaches is to solve a current challenge by leveraging local participants; it is also to build local human capacity and focus on empowerment so that in the future projects can be carried out without the dependence on and interjection of foreign designers and experts (Hussain, Sanders \& Steinert, 2012). While participatory approaches have accomplished successes and offer great potential moving forward, it is worthwhile to develop an understanding for why this is a relatively new approach given the seemingly obvious benefits.

\subsubsection{A Flawed 'Expert'}

Design - like much of society - tends to operate in an 'expert' mindset. This mindset is also very common in business, and is representative of existing power structures that are built on hierarchy and control (Sanders \& Stappers, 2008). The notion of relinquishing influence to outsiders runs counter to long established basic intuitions about intelligence and business (Surowiecki, 2005). The business world (which design is intimately tied to) is caught up in the idea that a few well-trained experts can make the difference between excellence and mediocrity, yet in many contexts it has been found that this value of expertise tends to be overrated (Surowiecki, 2005). The idea that a large group of diverse individuals are in many instances more intelligent than experts and can come up with better forecasts and intelligent decisions is very threatening to an established method of doing business (Surowiecki, 2005).

In the development community, the same condition exists where it has taken time to embrace the richness of locals' knowledge, creative and analytical abilities (Chambers, 1994). Similarly to the world of design and business, the delay in embracing a participatory approach had much to do with overcoming the arrogance, naivety, overconfidence or lack of knowledge of individual external experts. These external experts and officials all over the 
world had long believed that their knowledge was somehow superior to that of locals in appraising, and analyzing conditions (Chambers, 1994). These experts also tended to look down on the influence and knowledge of local "poor people". This demeanor, behaviour and attitude, was ultimately found to be self-validating and locals accepted outsiders' roles as experts and their knowledge as being inferior. Locals who were treated as being incapable began behaving that way and reflected the beliefs of the powerful outside experts. They hid their unique capabilities, at times even from themselves (Chambers, 1994). Not only were outsiders in ignorance of the abilities of locals, but they were also not aware of how to enable them to actually express, share, and extend the knowledge they had towards development challenges they were tasked in addressing. The perception of locals being ignorant and unable was not just an illusion, but emerged as an artefact from the behaviour and attitude of arrogant and ignorant outsiders' interaction with them (Chambers, 1994).

British economist Schumacher (1973) recognized the value of empowering ordinary people forty years ago, with his recognition that "ordinary people are often able to take a wider view, and a more 'humanistic' view, than is normally being taken by experts" (Schumacher, 1973, p.169). This perspective is particularly relevant within design, as leading firms such as IDEO pride themselves on being attuned to human needs with their 'human-centred' approaches. Schumacher's (1973) call for "production by the masses instead of mass production" was one of the earlier perspectives on knowledge needing to emerge from the people who are the subjects of development and technological interventions aimed at improving their quality of life. Nigel Cross (2007) further builds on the value that ordinary non-designers can offer the design process. He recognized that designing is something that all people do, and that the ability to design is part of human intelligence, which is a natural ability widespread among the population (Cross, 2007). For participation to have meaningful impact, it must place local realities at the heart of development interventions. In doing so, it must transform agents of development from directive 'experts' to 'facilitators' while acting as the 'enablers' of local knowledge, capabilities, and creativities (Hickey \& Mohan, 2004).

\subsubsection{Participatory Development}

Within development practice, information was traditionally communicated from a knowledgeable elite - that was usually based in richer Western and Northern countries - to 
less-well informed poor people in the expectation that this information will have positive development impacts (Kleine \& Unwin, 2009).

In the 1980's and 1990's these perspectives began to give way to new approaches that current participatory development finds its origins in: Rapid Rural Appraisal (RRA) and Participatory Rural Appraisal (PRA) (Chambers, 1994). Participation has a longer and more varied genealogy in development thinking and practice than is usually acknowledged, and many forms and goals of participation exist in development. However, much of the focus on the mainstreaming of participation over the 1990s, both laudatory and critical, has tended to single out the spread of PRA (which was born from RRA) and treat it as the definitive form of participation (Hickey \& Mohan, 2004).

\section{Rapid Rural Appraisal (RRA)}

The focus of a Rapid Rural Appraisal is for an outsider to extract information from a community in the most efficient ways to then take it away and analyze it (Chambers, 1981). It is an extractive approach that often consists of survey questionnaires and attempts by outsiders to gain information and insight from locals and local conditions with a particular emphasis on cost-effectiveness and efficiency (Chambers, 1994). RRA approaches recognized the value of tapping into local indigenous knowledge as a source of information, which set the course for a renewed perspective on development research to equip outsiders with the necessary information to analyze and make decisions (Chambers, 1994). Within development, the principles of RRA found traction, since for decision-makers it is critical to have information that is not only relevant, timely, and accurate, but usable as well (Chambers, 1981).

While the motivation for RRA was driven by a focus on efficient and informed engagement, it became apparent that its extractive approach left a need for richer, more meaningful information. The need for empowering a local community as part of the research process motivated a move away from extractive survey questionnaires familiar to RRA towards new approaches in a more participatory manner, and the birth of the many 'ethnographic' approaches popular today.

\section{Participatory Rural Appraisal (PRA)}

In PRA, the emphasis is on enabling local people to share, enhance and ultimately analyze their domestic knowledge of life and conditions, resulting in the ability to plan and 
then act to address their own problems (Chambers, 1994). Where RRA is extractive and is used to equip outsiders with knowledge efficiently, PRA is a participatory and empowering approach intended to enable locals to conduct their own analysis, plan and take action. According to Chambers (1994) it is "an approach and methods for learning about rural life and conditions from, with and by rural people" (p.953), with outsiders acting as conveners, catalysts and facilitators in the process. This participatory approach reflects a shift from the role of the professional developer as expert-investigator to that of a facilitator of community processes (Juarez \& Brown, 1997). In terms of development success, approaches that are participatory and engage a local community have proven to be quite successful, because by engaging active participants who will ultimately be affected by the project outcome, not only will the result embody local sensitivities, but the process and outcomes are more likely to be accepted and sustained (Hussain, Sanders \& Steinert, 2012).

RRA and PRA represent the growing recognition within development of the need to engage locals in a development project's processes.

\subsubsection{Participatory Design}

Viewpoints began to emerge in the early 1970's about the role of design in underdeveloped and emergent countries, which laid the groundwork for a more participatory, engaged approach to design in development work. Much like Schumacher's (1973) early perspectives on ordinary people having a more 'humanistic' view than experts, Victor Papanek (1985) critiqued 'instant experts' who conducted research in a 'fly-over' manner resulting in their attempts at solutions leading to twenty or thirty new problems (p85). Within design, these early critiques were a significant step towards appreciating the value of local knowledge and talent. After all, these are individuals who live and experience the problems daily, and in many cases have an enormous amount of design and technological expertise (Papanek, 1985).

When dealing with complex social challenges, design began to evolve from the 'usercentered' approach that proved to be most useful in the design and development of consumer products (Sanders \& Stappers, 2008), towards participatory approaches. The traditional 'expert perspective' where trained researchers interviewed or observed largely passive users only to relay their opinions and experiences has difficulty addressing the scale 
or the complexity of the challenges we now face (Sanders \& Stappers, 2008) and yielded to a more participatory approach to design.

Participatory Design is a design approach in which users and other stakeholders work with designers in the design process (Sanders et al., 2010). The process that was first touched on by Papanek (1985) calls for the person who is ultimately the beneficiary of the design process be given the role of 'expert of his/her experience' and as a result plays a significant role in knowledge development, idea generation, and concept development (Sanders \& Stappers, 2008). The core driving idea is that those who are affected by a decision or event should ultimately have an opportunity to influence it (Hussain, et al., 2012), and this notion is particularly relevant to design initiatives that have far-reaching and meaningful social implications. It is an approach that affirms the importance of participants' tacit knowledge in the design process.

The popular participatory viewpoints explored in development and design, have been acknowledged to hold the potential to dramatically change the way design approaches complex problems facing society (Sanders \& Stappers, 2008). The evolution within the design and development fields over the past several decades have evolved beyond the question of whether participation should be part of the process, and instead has shifted to who should participate, what methods should be used, what knowledge will be produced, and how that knowledge will be integrated into the design or development process (Juarez \& Brown, 2009).

By leveraging knowledge that exists within society, and relying less on individual expertise, the designer's role itself changes as well. Within this participatory landscape, it is no longer sufficient to act as an anthropologist who is attempting to understand people and culture in order to impose his interpretation of a successful intervention for development (Brown, 2009). As Tim Brown (2009), founder of IDEO says:

"...we need to invent a new and radical form of collaboration that blurs the boundaries between creators and consumers. It's not about 'us versus them' or even 'us on behalf of them'. For the design thinker, it has to be 'us with them'." (p.58)

For this 'us with them' mindset to genuinely contribute towards tackling complex development problems, the first critical step for designers is to humbly acknowledge the 
deficiencies and gaps in their own 'expert' knowledge. It will always be extremely challenging for outside designers to understand the critical tacit knowledge of a culture, user identity, behavior and activity of the community they are designing with (Petersen \& Hussain, 2012) due to their innate cultural biases.

The second step is to recognize that while the necessary knowledge likely exists, it is with the application of networked social technologies towards participatory design that the promise for the "radical form of collaboration" that Brown (2009) refers to exists. Already, the emergent collective intelligence from within these participatory endeavors has been found to be partly responsible for favorable outcomes in participatory design initiatives (Fisher, Giaccardi, Eden, Sugimoto \& Ye, 2005 as cited in Sanoff, 2006).

\subsection{Collective Intelligence}

While participatory initiatives in design and development are being hailed as the ways in which a community generates rich, meaningful, and empowered knowledge, it is the effective harnessing of collective intelligence that stands to dramatically strengthen these participatory initiatives in unprecedented ways. A collective approach to the design process that employs participatory methodologies, involves both designers, and non-design specialists while engaging the broader community to participate in design thinking (Maher, Paulini \& Murty, 2010) is the process by which design can seek to achieve meaningful development impact moving forward.

\subsubsection{Terminology}

Within the literature and theory on collective intelligence, a variety of terms exist that deserve clarification. The common terms of collective intelligence, crowdsourcing, and 'wisdom of the crowds' share many overlaps, yet they each represent varying aspects of a familiar theme and are not interchangeable.

\section{'Wisdom of the crowds'}

The simplest of the three terms thematically is the notion of the 'wisdom of the crowds', a term coined by James Surowiecki (2005), who described it as:

"under the right conditions, groups are remarkably intelligent, and are often smarter than the smartest people in them. With most things, the average is 
mediocrity. With decision making, it's often excellence. You could say it's as if we've been programmed to be collectively smart" (p.11).

It is Surowiecki's (2005) book, The Wisdom of the Crowds that is credited with reigniting the notion of crowd intelligence. His particular emphasis on rather simple decision making and aggregation of judgment sets the conceptual stage for more advanced explorations and interpretations of collective intelligence.

\section{Crowdsourcing}

The term itself was originally coined by Jeff Howe (2006) in a Wired Magazine article, and emphasized "the act of a company taking a function once performed by employees and outsourcing it to an undefined network of people in the form of an open call". The first academic definition was credited to Brabham (2008) who defined it as:

“an online, distributed problem-solving and production model." (p.75)

While crowdsourcing and 'wisdom of the crowds' do overlap, it is only partial, and the terms are not interchangeable. Both phenomena rely on the "crowd", however crowdsourcing relies on an open call to action, and does not necessarily rely on a crowd's wisdom or opinions, rather its skills (Saxton, et al., 2012). For clarification, it is helpful to understand crowdsourcing as the behavior of a group of people online contributing towards solving a challenge, whereas the 'wisdom of crowds' is the resultant intelligence that emerges from a group of individuals with sufficient diversity, independence, and decentralization.

\section{Collective Intelligence}

Highest on the echelon of group participation and intelligence - and also with the greatest promise for design - is the theory of collective intelligence. The term has often been associated with Pierre Lévy (2013), and due to terminology confusions he has most recently described it quite simply as:

"the combination of two concepts: cognition ("intelligence") and society or community ("collective"). Collective intelligence therefore refers to the cognitive capacities of a society, a community or a collection of individuals." (p.100). 
While Lévy's explanation sounds quite similar to the 'wisdom of the crowds', distinctions can be seen when considering the effect of the Internet, which due to its rise has enabled the emergence of crowd intelligence and new forms of collective intelligence (Malone, et al., 2009). When considering crowdsourcing, it can be the process (but not ultimately required) by which collective intelligence is aggregated.

The connections between collective intelligence and favourable participatory design outcomes have been established (Fischer et al., in Sanoff, 2006) to go along with research findings that suggest within participatory design, positive outcomes are attributed to solutions being informed by users' tacit knowledge (Spinuzzi, 2005).

\subsection{Conditions for Collective Intelligence}

The concept of collective intelligence operates in the spirit of participatory design and development. It empowers individuals to harness their collective wisdom to address the problems and challenges they experience daily, while external designers and agencies use their expertise to act as facilitators and catalysts in the process. The promise that "a group of diverse, independent and reasonably informed people might outperform even the best individual estimate or decision" (Bonabeau, 2009, p.51), is one of great significance to participatory design. The acknowledgement that individual intelligence is not enough to address pressing social challenges (Atlee \& Zubizarreta, 2003), establishes the need for design to learn to harness far more collective intelligence.

The key, and challenge in harnessing this collective intelligence is in creating the right conditions for communities to collectively reflect on their problems and possibilities in order to create solutions. Collective intelligence has been seen by some as a "holy grail of social change and social creativity" (Atlee \& Por, 2012) yet before collective intelligence can dramatically change the way society addresses complex issues, it is critical to better understand how to support it, increase it, and facilitate it in order to co-create a better world (Atlee \& Por, 2012).

\subsubsection{Role of the Designer}

If design is to tackle significant challenges in social development it must first acknowledge and overcome the deficiencies and characteristics of designers themselves. Designers frequently exhibit tendencies - such as a noted fixation effect - that inherently counteract the benefits arising from participatory initiatives. This fixation effect could 
hinder design by preventing the designer from considering all relevant knowledge and experience that should contribute to a problem (Cross, 2007). Also, designers often readily re-use existing designs rather than explore the problem in great depth and can become attached to early solutions and concepts (Cross, 2007). When dealing with significant challenges where leveraging local knowledge is of the utmost importance for project success, these are traits that must be overcome by the greater understanding of collective, rather than individual intelligence.

For design experts, these approaches mean a repositioning of effort towards creating the conditions for employing the intelligence of others, and recognizing where one's expertise is relevant. It does not mean that well-informed and practised designers are of no use, however, it does mean that their advice and predictions should be pooled with others to get the most of them (Surowiecki, 2005). A designer's expertise is still highly relevant due to their considerable specialization, but as part of an aggregated approach where they mediate teams and provide the expert knowledge that other stakeholders don't have (Sanders \& Stappers, 2008).

The challenge for designers becomes how to mediate these new processes, and how to best employ technological advances to diversify and distribute components of their work to an engaged and intelligent crowd, notably in the ideation and evaluation stages, where collective intelligence systems have demonstrated successful value in design (Murty, Paulini, \& Maher, 2010). While the notion of 'chasing the expert' mentioned by Surowiecki (2005) is eroding in favour of more participatory and collaborative approaches, the skills and knowledge of designers won't disappear as they become part of these processes. Instead, their expertise and highly developed skills are even more relevant at larger levels of scope and complexity, and as a result will remain important as design and participation evolves (Sanders \& Stappers, 2008).

\section{$\underline{\text { 2.4.2 Motivation }}$}

Of vital importance to any collective intelligence system is reliance on motivated and active participants (Murty, et al., 2010). Brabham (2013) reiterates this need, as he says that "all individuals engaged in a crowdsourcing application, are in some way motivated to participate... Understanding how and why individuals participate in crowdsourcing 
applications is necessary to design effective problem-solving applications going forward." (p.121).

The MIT Center for Collective Intelligence identified three sources of motivation within effective collective intelligence systems: the promise of financial gain (money), the enjoyment of an activity that contributes to a larger cause (love), and recognition by peers (glory) (Malone, Laubacher \& Dellarocas, 2009). Brabham (2013) also identified sources of motivation for crowds to participate, and among them socializing, sharing, having fun, and contributing to a large project of common interest are of greatest significance in a development context (Brabham, 2013).

While multiple sources of motivation exist, the most effective motivation tends to stem from the intrinsic sources to participate for deeper personal reasons than simple financial rewards or social advantage among peers (Murty, et al., 2010). These intrinsic sources are more advantageous than extrinsic motivators for their durability and association with creativity (Murty, et al., 2010).

\subsection{Mechanics of Collective Intelligence}

The key to implementing collective intelligence effectively lies in understanding what type of collective intelligence is possible, desirable, affordable, and under what conditions it can be implemented (Bonabeau, 2009). It is under the right circumstances that groups can become more intelligent than the smartest people within them, and need not be dominated by the exceptionally intelligent in order to be smart. The crux of collective intelligence is that group members do not themselves need to be especially well-informed or rational, since it relies on the aggregation of imperfect judgments (Surowiecki, 2005).

The basics for a successful system for employing collective intelligence within design towards development needs to understand how to leverage ICT, and then organize the design tasks so that people are actually motivated to participate (Maher, Paulini \& Murty, 2010). Various perspectives have emerged on the necessary conditions under which large groups of people can contribute towards complex challenges, and this section will discuss the most prominent amongst them. 
Diversity, Independence, and Decentralization

As James Surowiecki (2005) discovered, the necessary conditions for the crowd to be wise are: diversity, independence, and a certain kind of decentralization. Members of the crowd need to be of a diverse enough representation that they bring their different perspectives and experiences to the forefront. It is in the aggregation of diverse - yet not necessarily expert - knowledge that is critical. Furthermore, participants in the group need sufficient independence of thought to not fall subject to established mob deficiencies such as 'groupthink', which seeks conformity and harmony within a group even the cost of making the right decisions. However, while participants need sufficient independence of thought and decision making, it is necessary for a group of participants to have a shared vision strong enough to find the group together, geared towards collective action (Shirky, 2009). Of Surowiecki's (2005) conditions, the one that is ultimately of greatest significance to design is the need for decentralization, where power does not stem from one central location. Instead, many decisions are made by individuals with their own local and specific knowledge rather than an external omniscient planner (or designer) (Surowiecki, 2005).

This decentralization is critical for leveraging the tacit knowledge within a community, which is the knowledge that is difficult to convey to others because of its specificity to a place, job, or experience (Surowiecki, 2005). It is this type of knowledge that is incredibly difficult for an outsider to interpret and employ in development work given the challenge in conveying it, yet is critically important because the closer a person is to a problem the more likely they are to have a good solution to it (Surowiecki, 2005).

Surowiecki's (2005) conditions, while accepted as being vital, have proven to be difficult to meet. It's accepted that diversity of participants is critical, yet reaching a truly diverse group means finding multiple ways to reach people, as potential participants can be connected in very different ways (or not even connected at all) (Seltzer \& Mahmoudi, 2012). If these conditions are to be met however, it is the Internet that is able to exchange the diversity of opinions that are independent of each other in a decentralized way (Brabham, 2008). It is this certain kind of thinking that the web stimulates, one in which humans see themselves as actors, creators and innovators in the information flow, rather than just witnesses (Brabham, 2008) or passive consumers of information like other communication mediums (tv, radio). 


\section{The Building Blocks of Collective Intelligence}

The MIT's dedicated Center for Collective Intelligence has attempted to identify the necessary components of a collective intelligence system, by gathering nearly 250 examples of web-enabled collective intelligence systems in order to begin to understand the conditions for their use. From the work, a set of building blocks emerged with the following related questions being of significance when developing a system:

- Who is performing the task, and why are they doing it?

- What is being accomplished by the system, and how is it being done? (Malone, et al., 2009)

These building blocks of who, why, what, and how were identified as the genes of collective intelligence systems, and the fundamental aspects to understand within a system (Malone, et al., 2009).

\section{'Passive' and 'active' systems}

While collective intelligence systems rely on technological facilitation in order to achieve the higher-level intelligence achievable by the group actions of many, it is useful to note that are two categories: 'passive' and 'active' systems (Lykorentzou, Vergados \& Loumos, 2009).

In passive systems, individuals act as they normally would without the system's presence; they are unaware that there is a system. These types of systems can be used in many cases where groups are already exhibiting a collective-mind or swarm-resembling behavior. In these systems, while individuals are behaving individually, it is obvious that they are sharing some common goals. While there is a lack of awareness and intentionality in passive systems, by using technology, they can be modeled into a passive collective intelligence system that advances community and individual goals (Lykorentzou, et al., 2009). Given this explanation of a passive system, an example that could be modeled into a collective intelligence system is the organic use of hashtags on twitter to group themes or messages. A number of individuals are expressing correlated thoughts through the selfidentification of that statement with a certain thematic hashtag.

In active systems, crowd behavior doesn't pre-exist (like in passive systems) but it is created and coordinated through specific intentions and requests (Lykorentzou, et al., 2009). Active systems can be broken down into additional categories: 
- Collaborative systems where individuals collaborate with each other to reach community and individual targets. The highest profile example of a collaborative system is the online encyclopedia Wikipedia, where user behavior did not exist prior to system creation, and decentralized users collaborate and build on the contributions of each other. Within design, IDEO's crowdsourced design platform named openIDEO.com has proven to be a popular online community of collaborators working on design projects.

- Competitive systems that trigger competition among participants in order to achieve the best solution. The website TopCoder is an example of a competitive system whereby programmers compete in computer programming contests. TopCoder's online community consists of nearly 500,000 members, and the site has described this group as the world's largest competitive community for software development and digital creation.

- Hybrid systems that combine collaborative and competitive types of systems such as competition among groups of collaborators (Lykorentzou, et al., 2009, p.136).

\subsubsection{The Technology}

While participatory design and collective intelligence aren't new concepts, the conditions that currently exist, thanks to technological advancements, have finally made the intersection of these approaches viable. These technologies are enabling new forms of collective action, and the creation of collaborative groups that are larger and more distributed than at any other time in history. Due to technological and social factors, forming these groups has become a lot easier, and the costs incurred by creating or joining a group of others have collapsed in terms of money, time, effort and attention (Shirky, 2009). The scope of meaningful work that can now be done by non-institutional groups is a profound challenge to the status quo within development and design (Shirky, 2009), and is an affront on the tried and tested (yet not necessarily successful) ways of the past.

ICT - and specifically social technologies - is what enables the communication and collaboration necessary for collective intelligence within participatory design (Murty, Paulini, \& Maher, 2010). The ability to create, produce and apply technological artefacts and processes towards practical societal challenges is for many a sign of progress and development (UNDP, 2001). ICT and social technologies represent the opportunity to harness the intelligence of a large group of people, connected in very different ways, and on 
different scales than has ever been possible before. This perfect technological platform (the Internet) is capable of aggregating millions of independent ideas (Brabham, 2008), and as a result offers a potential to magnify the design cognition of ordinary people in ways that are analogous to a functioning brain, which draws upon many different neurons (Murty, et al., 2010). In part due to these communication technologies, the opportunity exists to encourage participation from individuals that may or may not be designers on a very large scale, in the hopes that their results and performance are able to go beyond the capability of a carefully crafted design team (Maher, et al., 2010).

\section{The 'Digital Divide'}

While connectivity is the key, dependence on Internet technology can result in a significantly skewed demographic of participants, and have the potential to widen existing gaps by blocking access to those already without access (Jo, Tacchi \& Watkins, 2007). When reliance on Internet access exists, collaborative processes depending on the contribution of many are susceptible to falling into the trap of the 'digital divide' (Brabham, 2008) whereby those without access are not able to engage. Studies have shown that typical web users are likely to be white, middle- or upper-class, English speakers with higher education and highspeed Internet connections (Brabham, 2008). Ultimately this can result in a dramatic lack of diversity of opinion and identity in the crowd, which runs counter to what was determined by Surowiecki (2005) as being critical to the effective implementation of collective intelligence (Brabham, 2008). In order for the marginalized to actually be represented in these initiatives and systems, a constant eye must be kept on who is missing from the crowd as barriers to access in participation do not only include the access to computers, web, or high-speed connections (Brabham, 2008).

Other potentially complex social factors can inhibit the marginalized from participating in the very systems that are developed for their input and knowledge. Often in developing countries, access to technology is restricted to those of a certain social class and status, whether that's defined by wealth, age, or gender. While ICT represents hope for engaging previously unreachable and marginalized people, processes that leverage them must keep an eye out for those that are still absent from the conversation.

In order for collective intelligence to ignite participatory initiatives to play a significant role in helping address the dramatic social challenges that exist, the reliance on internet technology represents a significant barrier to access, and can ultimately result in the 
exclusion of the very people it can help (Brabham, 2008). For collective intelligence to be appropriately employed - particularly in a development context - it must be enabled by more pervasive technologies and platforms than the Internet.

The types of technologies that must be employed need to be more 'intermediate' in nature, and fit more smoothly into the relatively unsophisticated environments in which they are to be used (Schumacher, 1973); technologies that are much more adaptable to local needs, and are already a part of participants' lifestyles. These communication tools must be flexible enough to match social capabilities (Shirky, 2009) and enable 'social media' or 'social computing'.

\section{Social Technologies}

The rise of the Internet has brought about the emergence of highly pervasive social technologies that have brought the capacity for communication and engagement that better mimics society's communication norms and patterns as a platform for supporting crowdsourcing and incarnations of collective intelligence (Paulini, Maher, and Murty, 2011). Social technologies refer to "the combination of mobile and online tools and systems that enable and seek out participation and contribution by users" (Hagen \& Robertson, 2009, p.2). Within this landscape, mobile phones, SMS, MMS, Twitter, Facebook, Flickr, and many other examples exist - all technologies that enable greater participation in technologymediated contexts (Hagen \& Robertson, 2012).

These technologies and network developments are critical to providing the opportunities to extend beyond the traditional design team and to open up the opportunities to share with a large number of people (Maher, et al., 2010). The technologies enable greater social participation, and within design, social technologies have become a tool for design, the subject of design, and represent the new context within which design is conducted (Maher, et al., 2010). They represent the lowering, and in some cases erosion of barriers to participation in innovation processes due to their scale and availability (Maher, et al., 2010).

For designers, social technologies are rewriting traditional design models and methods (Hagen \& Robertson, 2009). Barriers to public participation are eroding due to the accessibility and ease of use of these technologies, and as a result they are disrupting and in some cases circumventing traditional processes and practitioners (Hagen \& Robertson, 
2009). The ability to share, and act collectively outside of traditional organizations on a large scale is due to the application of these technologies, and of particular relevancy in the context of development is the mobile phone.

\subsection{ICT4D and Mobile Phones}

The deployment of technology and ICT within development work is driven by the belief that ICT has the capacity to contribute towards the improvement of various aspects of life (Avgerou, 2010). While the Internet, and social technologies are lowering the barriers to participation in design and development, it is mobile phones (particularly in the developing world) that hold the greatest potential for expanding the reach of engagement and collaboration. According to the International Telecommunication Union (ITU), there are an estimated 3.3 billion mobile phone subscribers (a number that has surely increased since 2009) and 1.3 billion Internet users (Samii, 2009). In developing countries, mobile telephony is the predominant mode of communication, and has helped reduce the gaping digital divide that once existed (Samii, 2009). Recent estimates have shown that $30 \%$ of people in Africa are mobile subscribers, compared to 6.5\% who are Internet users (Samii, 2009). Seeing as most of the countries in the developing world hardly embraced the physical telephone landline (if at all) and leap-frogged directly into mobile technology (Aker \& Mbiti, 2010), the mobile phone could be seen as the first modern telecommunications infrastructure on the continent in Africa (Samii, 2009), and is the predominant mode of communication in the developing world (Aker \& Mbiti, 2009). In the field, it has been observed that accessibility to mobile phones is allowing marginalized groups to take a more active part in the economic and social spheres of their communities (Samii, 2009), a requirement for the participatory initiatives already spoken of.

Aside from the mobile phone's popularity within marginalized and poor communities who are often at the heart of development projects, there are other reasons why the mobile phone is considered particularly important for development. Beyond allowing for basic connectivity and mobility, the mobile phone is an accessible technology that allows for transfer of data. It is a communication tool that requires only basic literacy, and is therefore accessible to a large segment of the population (Aker \& Mbiti, 2010). For these reasons, it is a technology that is of particular relevance to development, and can be used as a mechanism to ensure greater participation of the lower strata of the population in the development process (Aker \& Mbiti, 2010). When looking back at Schumacher's (1973) call 
for intermediate technologies that fit smoothly into unsophisticated environments and adapt to local needs, the mobile phone is the prime example. It is a technology that is used by a broader segment of the population than computers (Aker \& Mbiti, 2010) and is increasingly sought after and used by those who are at the focus of development work. Now that the tools are in the hands of those who are looked to become active participants in development work, a shift in perception is occurring where instead of being victims, these participants are becoming producers and innovators in a digital age (Heeks, 2008).

Within ICT4D discourse, the familiar refrain emerges of the need to leverage locals with the view of social embeddedness. This approach sees the purpose of ICT innovation as arising from local challenges, and the course of development and intervention being shaped by the way local actors make sense of the technology and accommodate it in their lives (Avgerou, 2010). The value that locals provide is recognized as being critical in all stages of the development process in ICT4D projects.

\subsubsection{Digital Ethnography}

Of particular relevancy in the context of design, ICT such as the mobile phone has the ability to expand the scope of design research, which has traditionally relied on qualitative in-person interaction and ethnographic research.

While stemming from anthropology, classical ethnography is "a way of producing detailed, in-depth observations of people's behavior, beliefs and preferences by observing and interacting with them in a natural environment." (Ireland, 2003, p26). It is a demanding approach that requires the researcher to conduct extended observations while immersed in the day-to-day lives of people as they go about their normal lives. These ethnographic studies are ideal in exploratory early stages when knowledge is needed about people. While it is helpful in generating this knowledge, it is an approach that takes a lot of time, and has difficulty in rapid paced development programs (Ireland, 2003).

Digital ethnography that employs ICT is a modern day digital equivalent of traditional ethnographic forms. While traditional ethnography is conducted by the researcher physically immersing themselves within a place, or culture, digital ethnographers employ ICT and social technologies to extend traditional ethnographic approaches like participant observation to the digital world. As ethnography extends itself into digital realms, its epistemological remit remains the same. It is fundamentally still about telling social stories 
(Murthy, 2008) and understanding people. This approach to ethnography is particularly valuable due to its ability to document the fluidity and flexibility of contemporary and increasingly digital culture and communities (Masten \& Plowman, 2003). It is important to note however that digital ethnography isn't simply transplanting traditional text-based techniques that aren't inherently digital (like surveys or questionnaires) to the Internet. Instead, it concentrates on how data gathering can be extended to the Internet and ICT in new and creative ways (Masten \& Plowman, 2003).

The use of these digital tools can speed the process of ethnography, without necessarily compromising the quality of work (Ireland, 2003). These digital approaches to ethnography can minimize researcher bias, extend geographic capabilities, time, and resource restraints of researchers, while also allowing for remote and simultaneous research (Masten \& Plowman, 2003). By using digital ethnography within passive collective intelligence systems as described in section 2.5 , a researcher is able to observe the real-time behaviour of people using social technologies. Twitter in particular offers rich grounds for digital ethnography, due to the public accessibility of tweets, and the availability of thirdparty applications capable of analyzing sentiment and geographic location of tweets.

\subsection{Collective Intelligence in Participatory Design}

While there have been few comparative studies on whether or not non-experts can actually outperform experts - aside from the relatively straightforward judgment and approximation examples put forward by Surowiecki (2005) - it has in fact been found by some that when it comes to generating ideas for new products, users can generate as feasible, and as novel ideas as experts (Poetz \& Schreier, 2012). In a study geared around generating ideas for new product development that pitted professional engineers, marketers, and/or designers against potential customers or users in a crowdsourcing process, the users were found to perform very well with needs and solution-based information (Poetz \& Schreier, 2012).

Furthermore, many initiatives that have begun to make sense of how a crowd can contribute to a diversified design process have called on a very large and highly distributed international crowd (such as OpenIDEO). Of particular relevance to this research is the question of whether or not it is possible to achieve collective intelligence by engaging participants in a smaller group, in a much more specific community with a more targeted 
problem. This type of group has been referred to as a "mob", which is defined as a small and fleeting group of individuals who briefly unite for a short-lived cause or project when a community leader calls them to action (Bojin, Shaw \& Toner, 2011). While processes that include smaller groups are susceptible to certain unwanted conditions such as groupthink, voter barnstorming, and vote manipulation, given the appropriate attention and mediation, leveraging the collective intelligence of even a small group is still possible (Bojin, et al., 2011).

\subsection{Conclusion}

This literature review explored the growing significance of participatory practices in design and development, while demonstrating the potential collective intelligence holds for significantly strengthening these approaches towards significant and complex social challenges. Within the field of design for social development, more participatory approaches are being embraced that emphasize a shift from a "user-centred" design approach towards a participatory approach. This participatory approach to design and development draws inspiration, knowledge, innovation, and abilities from locals who are experts on their environment and conditions. While it is accepted that locals are often best suited to addressing their own problems, challenges exist in how to structure and encourage these participatory design initiatives. This perspective demands a redefined role for designers within development work where they are tasked with leveraging their expertise towards acting as catalysts and enablers of a process, while their knowledge is aggregated with other non-experts.

While collective intelligence holds great potential for tapping into the shared wisdom of participants, it is still an emerging field that remains to be entirely understood in terms of its potential and appropriate applications. The concept is very dependent on ICT, which can create barriers for acceptance and uptake. While the proliferation of mobile phones in the developing world seeks to alleviate some of these barriers for implementation, one must consider the richness of information that can actually be communicated using different mediums, and how to best employ 'intermediary technologies' and social technologies to achieve these goals.

It is by recognizing the changing landscape of design, and leveraging the capacity of networked technologies towards the aggregation of our intelligence that we will be able to 
begin to address the highly complex development challenges that design is now faced with, for conventional design approaches are only suitable for conventional design problems. 


\section{PHASE 1 PD-ICT GUIDELINES}




\subsection{METHODS: PHASE 1 PD-ICT GUIDELINES}

The literature review illustrated the intersection of three overlapping fields: collective intelligence, participatory design, and ICT4D. It described how design processes are increasingly being used in development work for new human-centred innovative approaches to solving development challenges. With design no longer being a discipline geared solely towards the creation of artefacts, and its processes becoming increasingly participatory in nature it is primed to contribute to human development initiatives and continue to build interdisciplinary connections in the development community. For design, the promise of large groups of cooperating individuals producing higher-order intelligence (Lykorentzou, et al., 2009) - the kind that escapes even the greatest experts - has the potential to expand the scope and impact of participatory design projects addressing human development challenges. However, while the potential of collective intelligence in participatory design is apparent, a need exists for a unified theory that reflects the growing overlap of the fields of research and creates the conditions to enable tangible applications of theory.

Phase 1 of the research sought to combine the experiences and perspectives of leading practitioners with academic theory to create a comprehensive set of guidelines. These guidelines sought to provide the necessary structure and support for practitioners seeking to employ ICT in participatory design research in the hopes of leveraging a community's collective intelligence. The development of these guidelines provides the necessary first step before progressing to an application in human development in Phase 2.

The research conducted to generate the guidelines was partially informed by existing theory, but primarily by qualitative research relying on primary data from interviews. Interviews were conducted with expert practitioners from the three pre-defined fields of research, and one additional field:

- Participatory Design (PD)

- Collective Intelligence (CI)

- ICT for Development (ICT4D)

- Design Ethnography (DE)

\subsection{Approach}


The research approach taken was exploratory, and the methodology for research was inspired by grounded theory, developed by Glaser and Strauss (1967). An exploratory approach was useful due to the lack of a clear problem definition, and no approach was taken to develop a hypothesis before embarking on research. While the researcher was informed by existing literature prior to commencing primary research, and comes from a background in design, the content and structure of the guidelines were primarily developed using data emerging from the qualitative interviews. The "code $\rightarrow$ concept $\rightarrow$ category $\rightarrow$ theory" approach (Glaser \& Strauss, 1967) was employed when conducting and processing primary data from interviews.

\subsection{Participants}

Participants were identified and chosen who had professional experience practising in the four fields: PD, ICT4D, CI, and DE. They were chosen based on their visible relevancy to the research, influence and practical experience. Due to the emerging nature of these fields, there is a lack of highly experienced experts practising within them; therefore the criteria for participant selection relied primarily on the impact and visibility of their real-world experience. As a result, the contribution to academia and number of years practising was not deemed to be of critical importance to the determination of research participants.

These participant's organizations are all based in the United States, and while they have varying levels of focus in their work, they share the common value of participatory engagement.

\begin{tabular}{|c|c|c|c|c|}
\hline PARTIBIPANT & ORGANIZATION & ROLE & EXPERTISE & INTERVIEW FOCUS \\
\hline Panthea Lee & REß30OT & Principal & PD, ICT4D, DE & SQ2, SQ3 \\
\hline Jeremy Canfield & REß300T & Service Designer & PD, ICT4D, DE & SQ2, SQ3 \\
\hline Noel Wilson & Catapultoesign & Lead Designer & PD, DE & SQ1, SQ2, SQ3 \\
\hline George Aye & $\begin{array}{l}\text { GREATER } \\
\text { GOAD } \\
\text { STU>IO }\end{array}$ & Founder & $\mathrm{PD}, \mathrm{DE}, \mathrm{CI}$ & SQ1, SQ2, SQ3 \\
\hline $\begin{array}{l}\text { Annemarie } \\
\text { Spitz }\end{array}$ & 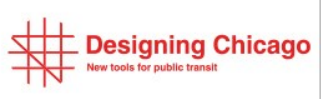 & Project Manager & $\mathrm{PD}, \mathrm{DE}, \mathrm{CI}$ & SQ1, SQ2, SQ3 \\
\hline
\end{tabular}

Table 1. Interview participants' expertise and interview focus 
(See Appendix A for organization descriptions and participant biographies)

Participant recruitment was conducted via e-mail with a standard letter of invitation for participation found in Appendix A, and interviews were scheduled at an appropriate time for participants ranging from January $8^{\text {th }} 2013$ to April $3^{\text {rd }} 2013$.

\subsection{Data Collection and Recording}

Interviews were conducted over Skype from Ottawa, Canada and were digitally recorded for transcription purposes. While the participants' organizations are based in the United States, two participants themselves were located internationally at the time of interview with Panthea Lee in Nigeria, and Noel Wilson in Australia.

\section{Interviewing Procedure}

The interview process itself was semi-structured using pre-determined open-ended questions, which were few in number (five at most) and intended to elicit the views and opinions from participants based on their experience. These open-ended questions served to stimulate participant discussion (e.g., How would you describe the type of design research that you conduct?), and they varied for each interview depending on the interview focus. Further questions probed more specifically into their experiences and perspectives (e.g., What do you consider the role of your design expertise is in a participatory design project?), and were often ad-hoc to dive deeper into particular topics as opportunities emerged.

While the initial questions were open-ended to allow for participant interpretation and emphasis on topics of particular knowledge or preference, they were performed with the goal of extracting the necessary knowledge for the formulation of guidelines, which span all participants' experiences.

Interviews were conducted at a mutually agreed time, and ranged from 20 to 100 minutes.

\subsection{Processing and Analyzing}

Interview data was recorded, and manually transcribed verbatim - although it omitted grammatical errors, and hesitations. Interviews generated approximately 250 minutes of 
audio recording, and 10,500 words of transcribed data. All transcribed interviews were sent to research participants for their approval before being used in analysis, allowing participants to clarify or choose that certain information be omitted.

Analysis followed a three-stage process to establish codes, concepts and categories.

The following table demonstrates the process undertaken in interview analysis.

\section{CODE}

Identifying common topics and key points in data by highlighting and analyzing relevant sections.

\section{CONCEPT}

Identifying patterns and grouping of codes of similar content to identify concepts.

\section{$\rightarrow \quad$ CATEGORY}

Grouping of similar concepts to guide formulation of theory in guidelines.

\section{Figure 3. Interview analysis process}

The results of this process set the stage for the formulation of guidelines. 


\subsection{RESULTS: PHASE 1 PD-ICT GUIDELINES}

The results presented in this section address the primary research question (Q1) with the development of a set of guidelines for the application of information communication and social technologies as design research tools capable of leveraging a community's collective intelligence in participatory design.

The guidelines represent the aggregation of perspectives and experiences across the fields of research that emerged from processing and analyzing primary data from qualitative interview results as described in Figure 3. The perspectives, experiences, and knowledge of leading practitioners were supplemented when appropriate with existing theory found through the literature review. The resulting guidelines combining the best in practitioner knowledge with academic theory consist of three categories: Project Identification, Participant Engagement, and Process Implementation.

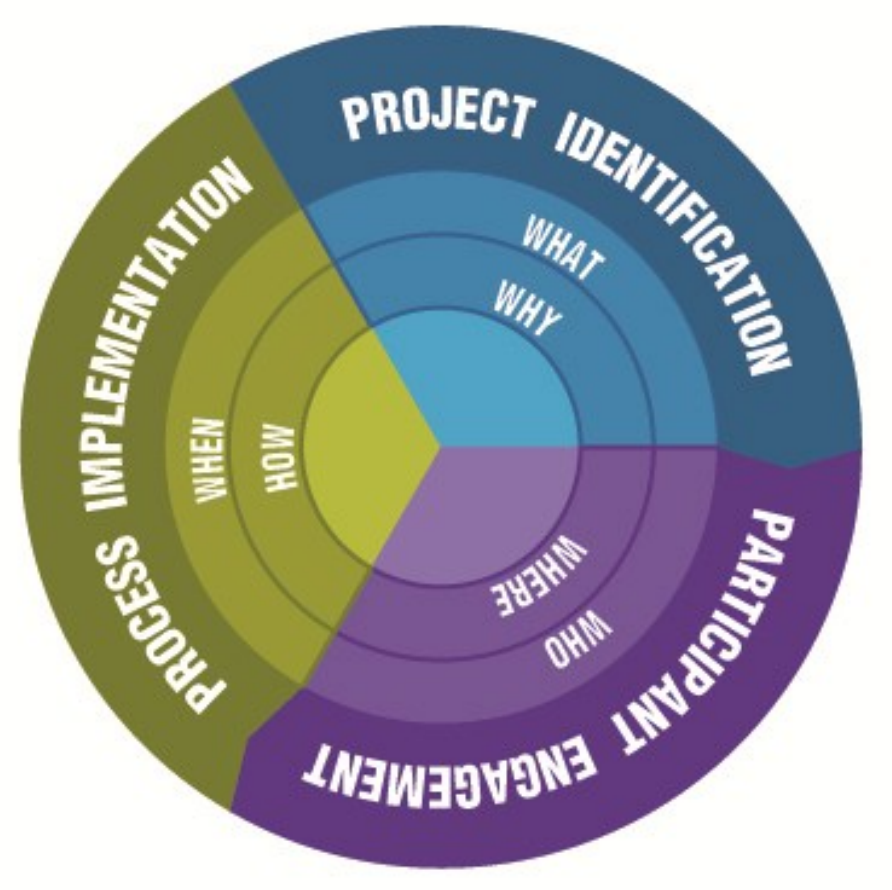

Figure 4. Guideline categories and focus 


\section{- Project Identification}

Creates an understanding of what type of project is suitable for an approach that leverages information communication and social technologies in participatory design, and why the project should employ this approach.

\section{- Participant Engagement}

Once the project focus has been established the 'Participant Engagement' category provides guidance for who should participate, and where participation should occur.

\section{- Process Implementation}

Once the project has been identified, and participants recruited, the Process Implementation category describes how to use participatory processes that leverage information communication and social technologies, and when these approaches should be employed.

Within the guidelines, each of these categories contains their own overarching guiding principles to consider. The descriptions of the following categories also provide samples of the coding process undertaken in qualitative interview analysis that contributed to the formulation of the guidelines.

\subsection{Project Identification}

Not every design or development project is well-suited to a participatory approach, much less one that also employs ICT. As such, the first step of the guidelines is to identify the criteria which make a project and focus suitable for these processes.

\subsubsection{Project Identification Guiding Principles}

For an effective application of ICT in a participatory design project, every project requires:

1) A clear understanding of its purpose and stakeholders.

2) Transparency and honesty in communication.

3) Active communication and participation throughout the length of the project to build and maintain relationships, trust and cooperation with participants.

\subsubsection{Determining Project Focus}

The focus of a project can emerge from two scenarios: 
1) The project focus is pre-determined, and the process of participatory design is determined as being vital to the execution of the project (i.e., designing a mobile transit application for the city of Chicago using the citizens of Chicago).

2) The project focus will emerge from research conducted on a social problem or cause. While the actual focus of the project may not be immediately obvious, the solution and problem are likely to emerge in parallel as Cross (2007) has suggested is native to design. The research is likely to be qualitative in nature and may consist of interviews and ethnography (digital or traditional).

\subsubsection{What Type of Project is Suitable?}

In order for a project to successfully employ a participatory approach that leverages ICT it should aim to address a problem that:

1) Many people care about and are affected by without a sense of exclusivity.

2) Is specific to a community that is large and engaged enough to enable the sustained participation of many participants.

3) Is a non-traditional design problem (i.e., a wicked problem) such as a large-scale public project that requires input and participation from many stakeholders.

\subsubsection{Why Take This Approach?}

Participatory approaches that use ICT are particularly valuable in a project when:

1) Community input is required at the core of a project's processes as a source of otherwise unavailable knowledge.

2) Research needs to be efficient, frugal, and timely due to budgetary or timing constraints.

3) Participation and knowledge is necessary from those that may traditionally be physically or culturally difficult to reach. 


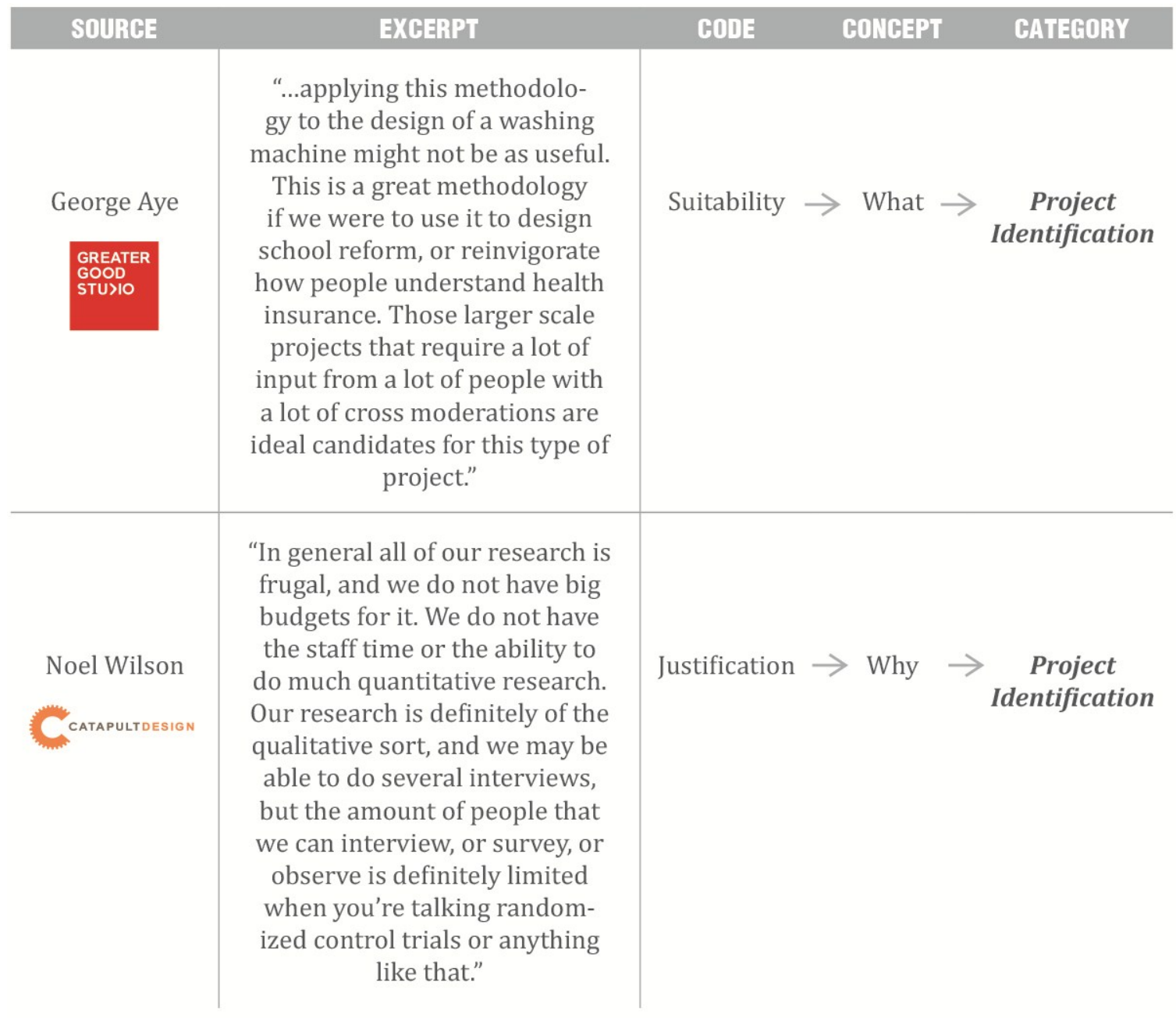

Table 2. Sample interview coding - Project Identification

\subsection{Participant Engagement}

Participatory design projects are dependent on an awareness of how to identify, recruit and motivate participants identified as necessary to a project. Project success depends on the ability to not only engage participants, but ultimately leverage local knowledge and expertise - which is traditionally difficult for an outsider to interpret or understand due to the impact of their external bias.

In the context of participatory projects leveraging ICT aimed at addressing human development challenges, the goal is to maximize the engagement of those who have traditionally been marginalized as participants, whether as a result of geographic or social isolation. The potential impact of access to ICT is a reduction in barriers to participation, thereby increasing potential beneficiaries' ability to participate. A project that takes a digitally enabled participatory approach aiming to achieve collective intelligence relies on 
participants who both have access to ICT and have the ability to participate with minimal barriers. The goal of the guidelines is to engage marginalized people to participate through ICT, however it is important to note the variations among potential participants in their current ability to participate and access ICT. The following figure demonstrates the variation among potential participants who are critical to engage in development processes in relation to their ability to participate and access ICT.

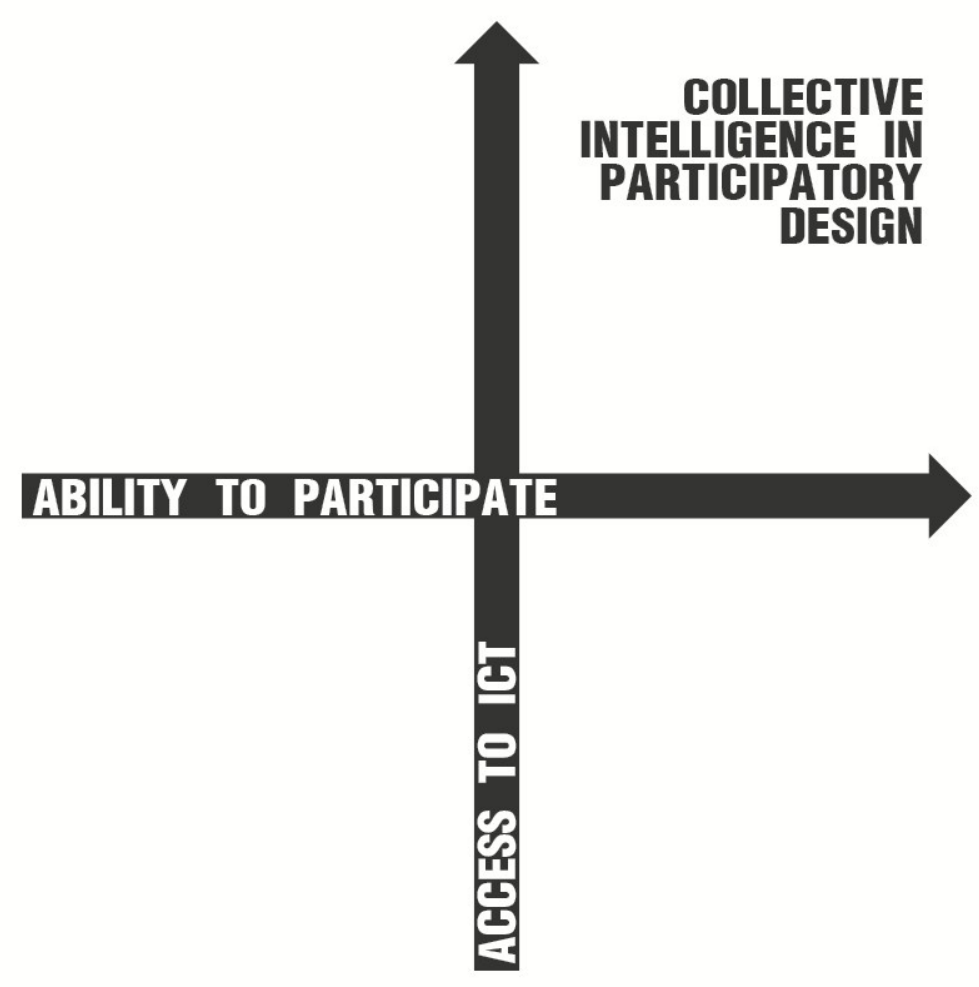

Figure 3. Participant classification

A project's ability to achieve collective intelligence in participatory design towards human development depends on how it is able to progress traditionally marginalized participants towards both having the ability to participate and having access to ICT.

\subsubsection{Participant Engagement Guiding Principles}

Regardless of participant classification, motivating and maintaining participation in a project is challenging, so to increase the likelihood of successful engagement the project must: 
1) Ensure that participants are aware they are contributing to a real project and that their contributions are being heard and acknowledged. It is the aggregation of collective contributions that are valuable, even if their direct individual contributions may or may not be used.

2) Focus on establishing intrinsic sources of motivation for participants such as socializing, sharing, having fun, gaining respect among peers, love, and contributing to a large project of common interest. Giving participants a channel for their frustrations has also proven to be an effective motivator.

3) Lower perceived and real barriers to participation. Focus on eliminating intimidation or shyness so that participants are not filtering or screening their contributions. The impact of an 'expert' can affect participation, as participants may be self-screening what 'counts' as a contribution, where in actuality unfiltered sharing and insights are critical.

4) Equalize relationships between the researcher and participants by instilling a sense of collaboration, eliminating the superiority of resources, and not treating participants as research subjects.

5) Allow for participant anonymity for unbiased contributions. While anonymity is important, if possible or available, collect demographic information in an unobtrusive way. This quantitative data may prove to be highly useful.

\subsubsection{Who Should Participate?}

The goal of participatory projects is to engage those who will ultimately be the beneficiaries of a development project throughout the research and design processes, and instill a sense of attachment and pride to the project outcomes for greater likelihood of adoption and sustainability.

While the goal is to engage as many people as realistically possible it is important to understand who should participate in these processes. The need for diversity, independence, and decentralization of participants as described by Surowiecki (2005) has already been discussed in section 2.5 , but the ability to meet these conditions may be difficult depending on the context of community-specific projects. Therefore, specific particular attention must be paid to ensure participation from: 
1) A variety of stakeholders that are engaged throughout the duration of the project. Complex problems generally have a large amount of different stakeholders beyond the obvious beneficiaries of the project.

2) Marginalized people who traditionally lack a voice and have been disregarded in consultation or outreach. The goal is to engage those that are not accustomed to being heard, and use technologies to reach the previously unreachable (whether geographically or societally).

3) Local trusted and respected community leaders. These local leaders are critical for project credibility and to inspire participation of others in the community. They know how to best engage participants in the intricacies of local custom and their knowledge of the local context will prove useful for messaging, engagement, analysis, and synthesis.

4) Those who are in close geographic proximity to the problem. Those who live and experience the problem daily must be engaged as a source of knowledge and experience.

5) Pre-existing networks, agencies and partners. This is the most effective way to establish a presence and engage participants in-person. 'Buy-in' from these existing networks and relationships can increase time and resource efficiencies, while also assisting in participant selection and engagement by motivating and exciting others.

\subsubsection{Where Can They Participate?}

Depending on the project focus, participants' ability to participate, and access to ICT, participation will occur across different spaces. While the focus of these guidelines is to leverage digital participation towards collective intelligence, in order to ensure appropriate representation and diversity of participants, emphasis must be made on reaching those beyond the upper-right quadrant of having access to ICT and being able to participate. The project must aim at enlisting the participation of as many minds as possible, and to do so it will require a mixed approach for recruitment and engagement.

Effective participant engagement depends on the researcher's ability to engage participants using the methods and techniques that participants are familiar with, and will elicit the greatest balance between breadth and depth of interaction. Regardless of the project scenario, or participant classification, effective engagement requires: 
1) A balance between talking to community leaders, pre-existing networks, and regular participants. In leveraging existing networks and local leaders, there is a possibility for existing entrenched relationships and hierarchies to negatively impact unbiased participation. As such, the researcher needs to be aware of both the benefits and risk of relying on existing relationships within a community.

2) The use of tools that are technologically and socially accessible to participants. These tools should be ones participants are already familiar with and already have integrated in their lives. The more unfamiliar an ICT tool is, the less likely it will be used; this extends to apps, websites, and social networks.

3) Use of active and passive forms of engagement. The more demanding or "active" digital participation is, the fewer participants will contribute. Less demanding participation can lead to greater volumes of participants, but may lack depth and richness information. Information has to be deep enough to be useful, but shallow enough for high volumes of participation.

\begin{tabular}{|c|c|c|c|c|}
\hline SOUREE & EXGERPT & BODE & BONGEPT & GATEGORY \\
\hline $\begin{array}{l}\text { Panthea Lee } \\
\text { REß30OT }\end{array}$ & $\begin{array}{l}\text { "Who are the beneficiaries? } \\
\text { Who are the actors to influ- } \\
\text { ence our ability to achieve the } \\
\text { outcome we want? Who are the } \\
\text { intermediaries around that to } \\
\text { help us understand our users } \\
\text { and service providers along the } \\
\text { chain? It sounds straightfor- } \\
\text { ward but it's not." }\end{array}$ & Stakeholders & $\rightarrow$ Who $\rightarrow$ & $\begin{array}{l}\text { Participant } \\
\text { Engagement }\end{array}$ \\
\hline $\begin{array}{l}\text { Noel Wilson } \\
\text { Catapultoesign }\end{array}$ & $\begin{array}{l}\text { "Us going somewhere and } \\
\text { cold-canvassing is a pretty } \\
\text { time-heavy activity. Going } \\
\text { somewhere and meeting an } \\
\text { organization that's been active } \\
\text { there for forty years and is } \\
\text { generally socially inclined, has } \\
\text { networks within many different } \\
\text { villages that they can actually } \\
\text { guide us towards the right peo- } \\
\text { ple that are willing is critical." }\end{array}$ & $\begin{array}{l}\text { Existing } \\
\text { Networks }\end{array}$ & $\rightarrow$ Where $\rightarrow$ & $\begin{array}{l}\text { Participant } \\
\text { Engagement }\end{array}$ \\
\hline
\end{tabular}

Table 3. Sample interview coding - Participant Engagement

\subsection{Process Implementation}


The actual participatory processes implemented will vary depending on the project, participants, organization, the designer, and other factors. This category creates awareness

around key considerations for the actual processes of applying ICT as design research tools in participatory design for human development projects. It describes potential techniques for how to use processes that leverage ICT in participatory design, and when these processes are appropriate. Seeing as projects, goals and participants vary dramatically this section does not provide a rigid structure for processes, as it is critical that they be tailored depending on the project context.

\subsubsection{Process Implementation Guiding Principles}

While processes must be adaptable to specific project requirements, guiding principles will assist in ensuring the project is best able to effectively leverage the knowledge of participants in a participatory process using ICT. In order to do so, these participatory processes need to:

1) Think of participants as a distributed team member. Participants will not replace designers in a project, but instead should be thought of as a mixed team member that complements processes.

2) Prototype methods of engagement. Prototypes are necessary to see if participants are actually responding in ways that are necessary for the project while testing approaches that generate the most feedback and activity.

3) Ensure participation is as easy as possible. Projects need to respect participants' time, and make the best use of it by engaging them in mostly lowhassle and low-involvement tasks.

\subsubsection{How to Use Processes}

The processes used must be a reflection of processes that designers are familiar working with. They are not meant to be revolutionary, and instead are an extension of familiar approaches that significantly expand the scope and breadth of participation. The possibility for participation on a large scale in design processes enabled by ICT means that:

1) The designer's role shifts from project expert to facilitator. In these processes, the designer uses their experience and acts as a design facilitator who enables design processes by others while acting as an intermediary between stakeholders. 
2) Research is synthesized based on designer's experiences with processes. Synthesis needs to be conducted in a way that the firm or individual is comfortable with relative to the project goals. However, during research synthesis, the designer is responsible for the viability of a project, due to a sense of what is in fact possible based on experience.

3) The problem should be 'reverse-engineered' to understand what information is required from participants. Participants work well with clear communication, so before engagement begins, the project needs a clear understanding of what information is required and at what stages to achieve the required goals.

4) An interplay should be used between in-person and digital participation. A large crowd is good for breadth, but when depth is necessary, use in-person engagement with specifically chosen participants. These participants should be the most active \& useful participants (determined using your own metrics) in order to act as an incentive to maintain participation. In-person engagement works best as workshops, and can be used to filter content and reward participation.

\subsubsection{When to Use Processes}

The processes used in the project must be highly adaptable and strategically leverage participation. Participants are particularly valuable for certain parts of the process, and cannot be asked or expected to completely execute a design. The designer needs to understand the strengths and weaknesses of large groups of participants in a project, as well as where and when their contribution is most important. When using these processes, it is important to note that:

1) Levels of participation vary among participants and active participation is difficult to sustain. The project should engage participants as much as they are willing to be engaged, and must be flexible enough to allow for varying levels of engagement and intensity. Participation will not be consistent, and will likely drop off over the duration of a project. The project should account for this, and an awareness of external factors that may influence your engagement process is necessary.

2) A crowd of participants behaves best when it is tasked with being generative and evaluative. Participants can generate ideas, and evaluate them well, but the project should not expect or depend on them to create meaningful content.

3) Mass participation is more useful for divergent than convergent processes. In divergent processes when looking to generate broad and varied content, leverage 
the crowd of participants. In convergent processes where synthesizing is important, leverage the expertise of a smaller group and the designers.

\begin{tabular}{|c|c|c|}
\hline SOURGE & EXCERPT & GATEGORY \\
\hline $\begin{array}{l}\text { George Aye } \\
\text { GREATER } \\
\text { GOOD } \\
\text { STU>IO }\end{array}$ & $\begin{array}{c}\text { "We still have to make very } \\
\text { strong judgements based on } \\
\text { our experiences as designers } \\
\text { in order to know what's } \\
\text { worthwhile, what's worth } \\
\text { doing." }\end{array}$ & Expert Role $\rightarrow$ How $\rightarrow \begin{array}{c}\text { Process } \\
\text { Implementation }\end{array}$ \\
\hline $\begin{array}{l}\text { George Aye } \\
\text { GREATER } \\
\text { GOOD } \\
\text { STU>IO }\end{array}$ & $\begin{array}{l}\text { "...the role of the designer does } \\
\text { not need to be the expert in } \\
\text { everything, but being able to } \\
\text { bring in that expertise from } \\
\text { outside and use a lot of the } \\
\text { same thought processes and } \\
\text { potentially methods that } \\
\text { 'traditional' design would do." }\end{array}$ & Expert Role $\rightarrow$ How $\rightarrow \begin{array}{c}\text { Process } \\
\text { Implementation }\end{array}$ \\
\hline $\begin{array}{l}\text { Annemarie Spitz } \\
\text { \# Designing Chicago }\end{array}$ & $\begin{array}{l}\text { "We need to consider } \\
\text { throughout the project, how } \\
\text { long can we engage with } \\
\text { people, how long can we keep } \\
\text { them interested, how long can } \\
\text { we hold their attention and } \\
\text { how much time can we ask of } \\
\text { them realistically?" }\end{array}$ & $\begin{array}{l}\text { Engage- } \rightarrow \text { When } \rightarrow \begin{array}{c}\text { Process } \\
\text { ment }\end{array} \\
\text { Levels }\end{array}$ \\
\hline
\end{tabular}

Table 4. Sample interview coding - Process Implementation 


\subsection{PD-ICT Guidelines Summary}

The following tables summarize the PD-ICT guidelines developed in Phase 1 research.

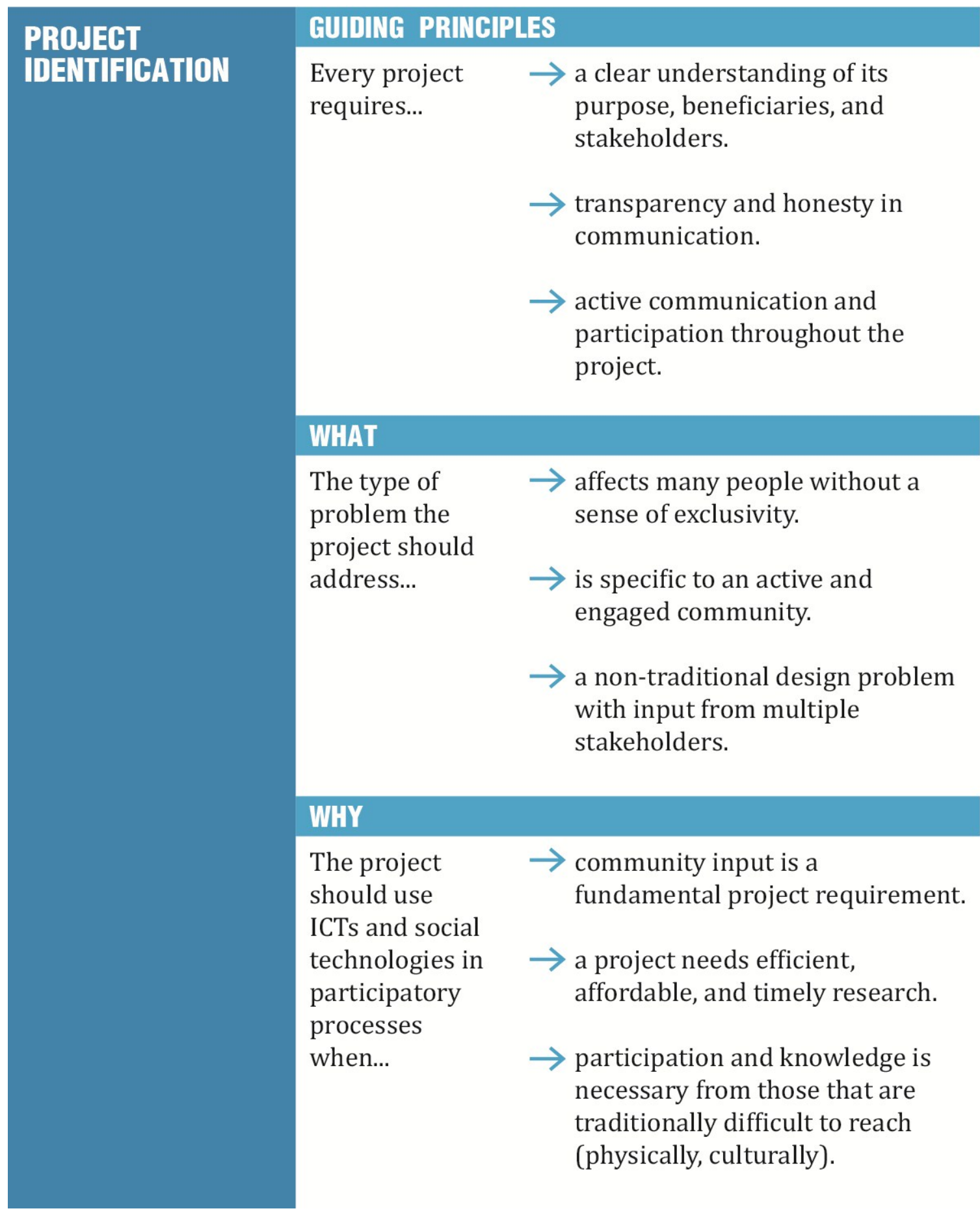

Table 5. Project Identification category summary 


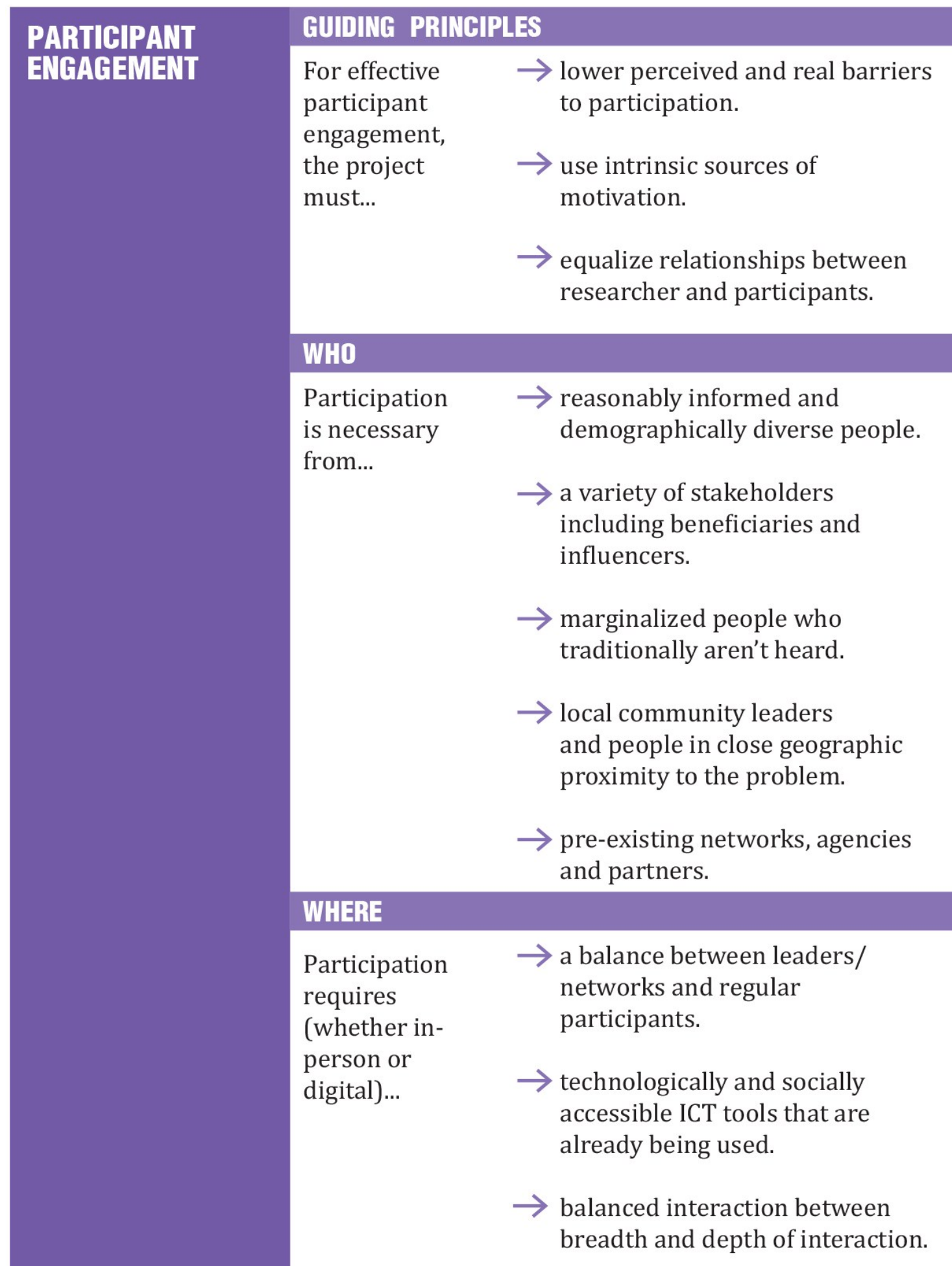

Table 6. Participant Engagement category summary 


\section{PROGESS \\ IMPLEMENTATION

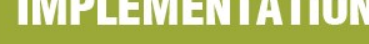$$
\text { . }
$$

\section{GUIDING PRINCEIPLES}

\section{HOW \\ Processes \\ change when using ICT and social technologies by... \\ $\rightarrow$ shifting the designer's role from expert to facilitator. \\ $\rightarrow$ synthesizing research based on designer's experience. \\ $\rightarrow$ 'reverse-engineering' the problem to determine information required.}

think of participants as a distributed team member that enhances design processes.

$\rightarrow$ prototype methods of engagement before interacting with participants.

ensure participation is as easy and painless as possible.

\section{WHEN}

Using these participatory processes, note that... $\rightarrow$ levels of participation vary among participants and tend to drop off during a project.

$\rightarrow$ participants are good for generative and evaluative tasks, not generating rich meaningful content.

$\rightarrow$ mass participation is more useful for diverging rather than converging processes.

$\rightarrow$ in-person participation will generally yield greater depth than digital, so don't hesitate to employ it when necessary.

Table 7. Process Implementation category summary 


\subsection{DISCUSSION: PHASE 1 PD-ICT GUIDELINES}

Phase 1 of research resulted in the development of a set of PD-ICT guidelines presented in section 4.0. They are communicated in three categories (Project Identification, Participant Engagement, Process Implementation), and ultimately consist of 35 points, 11 of which are guiding principles. The development of these guidelines - whose theory mainly emerged from primary data gained from qualitative interviews with practitioners- is the central method with which the researcher sought to address the three sub-questions (SQ1,2,3), which collectively seek to answer the primary research question (Q1). The following sections will discuss the results of the researcher's attempts to answer the research questions.

\subsection{Role of the Literature Review}

The role of the literature review in section 2.0 was to inform the researcher by identifying research opportunities, setting the necessary context, providing enough substantial knowledge and preliminary reading with which to conduct Phase 1 research. The emphasis before conducting primary research (interviews) was on being informed enough for the research to have focus, while not being consciously directed by earlier theories and concepts. This fine line between having enough knowledge and awareness of the research topics without being too heavily influenced or skewed by existing theory was kept in mind throughout the reading and interpretation of literature. This approach enabled the researcher to justify the proposed research, identify if similar work had been conducted before, and motivated the need for this research to be conducted while keeping an open mind towards new emergent findings. 


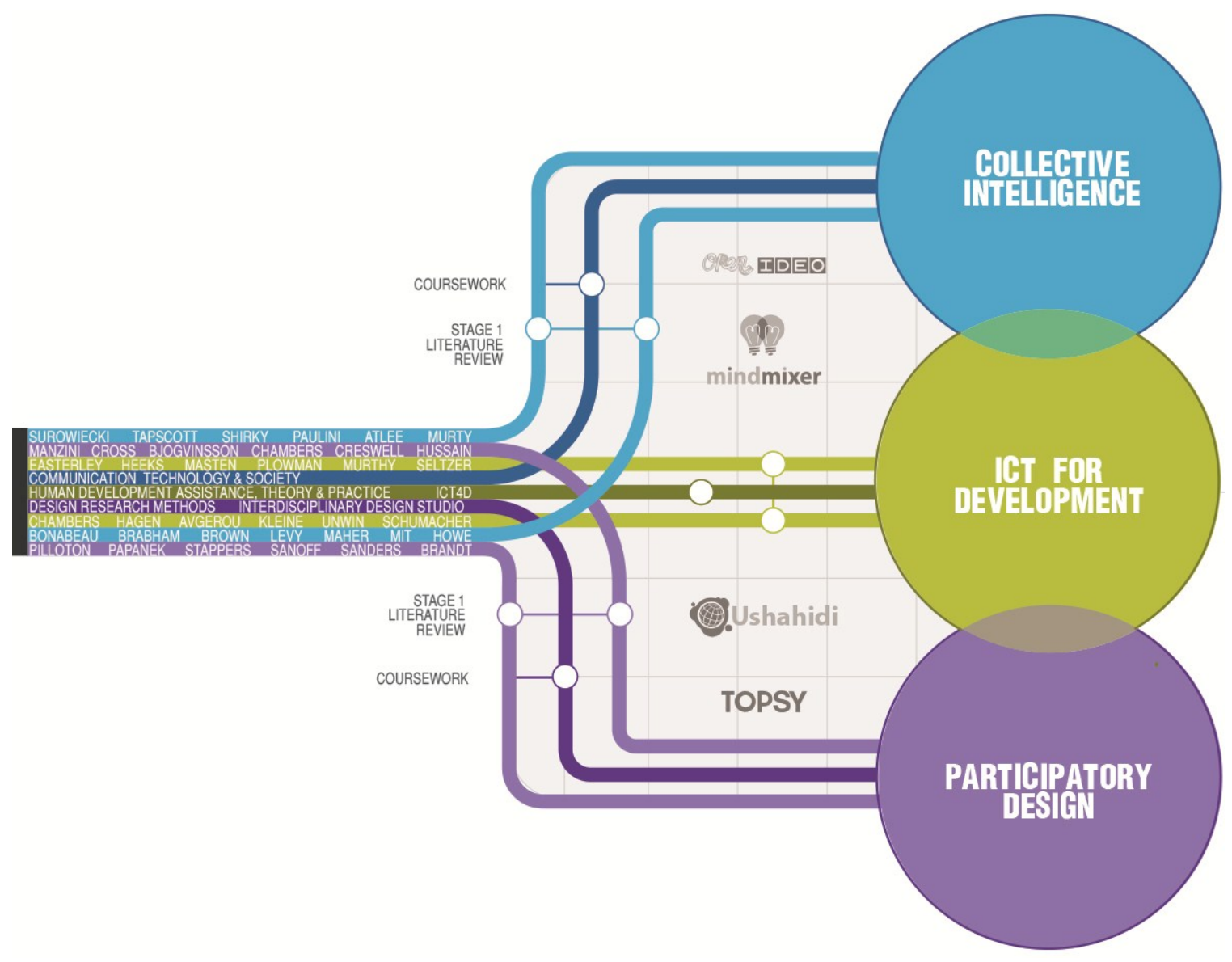

Figure 5. Early research process

It is helpful to consider the literature review to have been conducted in two stages. The first stage served to set the context and provide sufficient knowledge to the researcher in order to gather primary data, and the second sought to reinforce the primary data with existing theory and literature once guideline development was underway. 


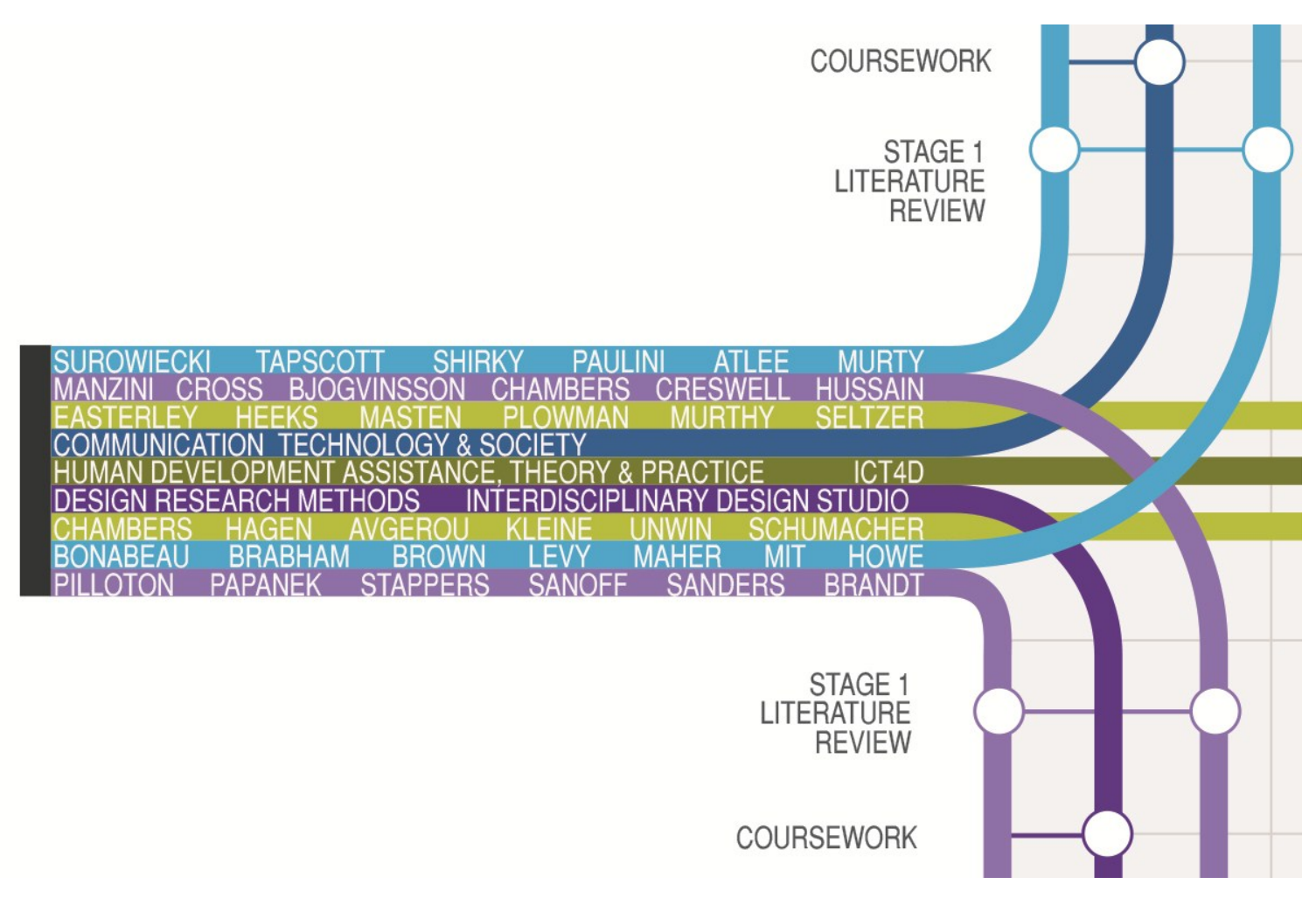

Figure 6. Primary literature sources and coursework

\section{Literature Review: Stage 1}

The review of literature identified a lack of existing research, theory, or examples that unified the intersecting fields of participatory design, collective intelligence, and ICT4D. Due to the conceptual nature of much of the literature, which in many instances lacked concrete examples or prior applications, the researcher had difficulty in identifying a specific hypothesis. It was upon conducting this initial literature review and observing the theoretical and conceptual nature of the literature that the need for an emergent unified theory (guidelines) became apparent. While within the reviewed literature an overlap was apparent between the fields, an opportunity existed to formalize the theory and approaches from across the fields in a set of guidelines. The plan for these guidelines was to assist in interpreting the conceptual theory towards potentially actionable research applications. At this point the researcher became aware that grounded theory methodology was the most appropriate methodology with which to conduct further research. 


\section{Literature Review: Stage 2}

Given the lack of hypothesis to emerge from the initial review of literature, rather than using a deductive approach to inquiry that aims to prove or disprove a hypothesis, inductive enquiry was primarily relied on as a means of generating new theory and understanding in the development of the guidelines.

This inductive approach involved an interplay between building theory based on analysis of data (interviews), and supplementing emergent themes from the data with additional targeted literature. The goal was to not be heavily influenced in early stages by existing theory (which in many cases lacked precision or applicability), and instead rely on the primary data to identify the structure and approach of the PD-ICT guidelines. This approach resulted in further, more targeted literature being later sought, once guideline development had emerged from interviews - at a point where existing theory would not derail the research.

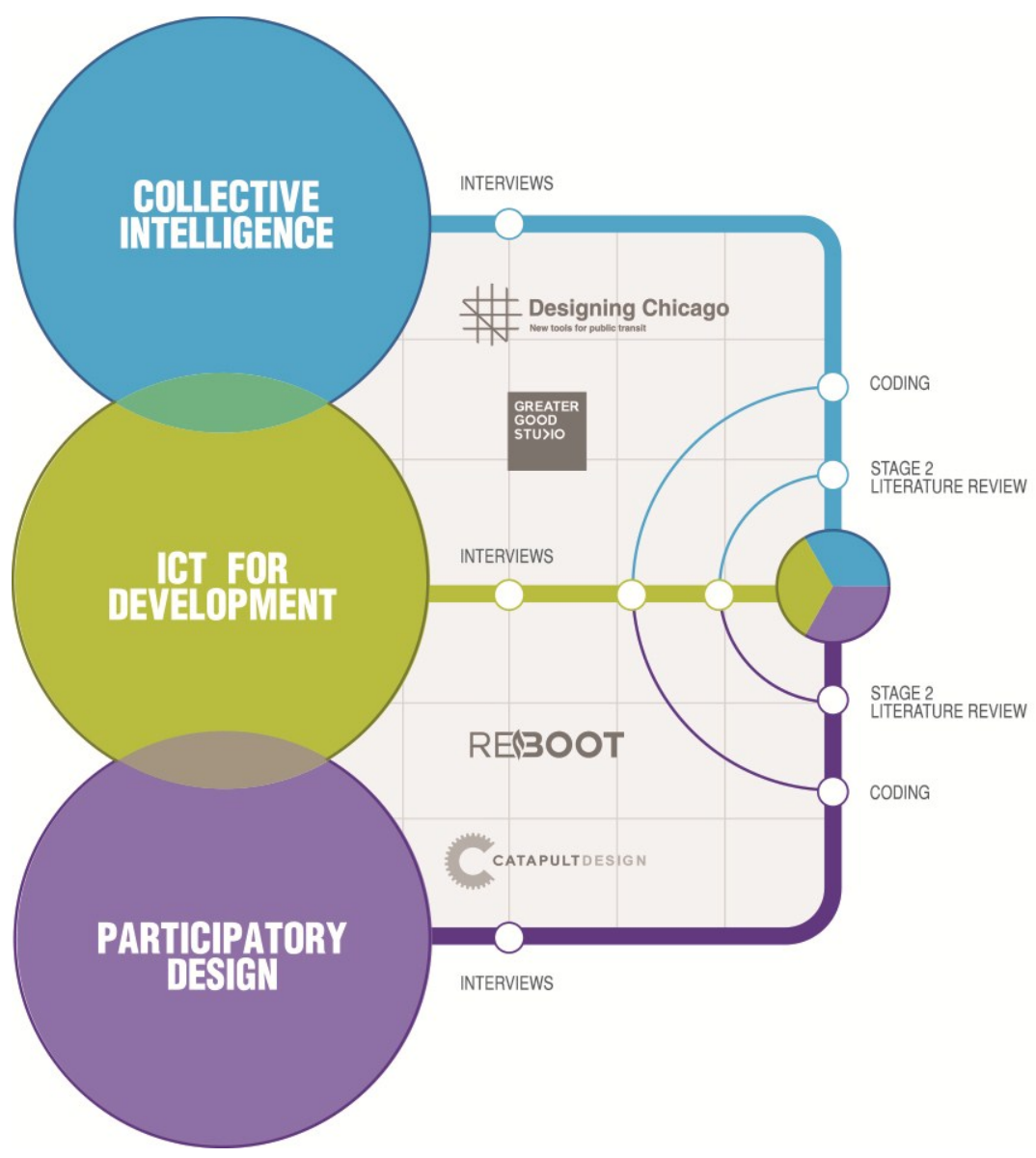

Figure 7. Process of interviews, coding and stage 2 literature review 


\subsection{Comparison of Data to Literature}

The majority of content for the guidelines emerged from primary data gained in interviews. This was attributed to the fact that the interview subjects were practitioners who have awareness of, and experience in, multiple fields, as well as the interdisciplinary connections between them (as seen in Table 1 from section 3.2). The identified literature was generally specific to one of the fields of research (i.e., participatory design), whereas the guidelines represent the emergence of theory spanning the fields, rather than the simple combination of theory from each of the fields. Therefore, direct attribution to guideline theory from literature is difficult to find.

While the explicit use of theory from the literature review is rare to find within the guidelines, upon review of the literature, there are similarities between existing theory and the structure of the guidelines. Of particular significance is how the formation and categories developed within the guidelines mimic the genes of collective intelligence that the MIT Center for Collective Intelligence had identified in their research discussed in section 2.5. The building blocks discussed by Malone, et al., (2009) that MIT had developed (who, what, why and how) as being the genes of a collective intelligence system emerged within the PD-ICT guidelines as well. The guidelines however also included where, and when components that speak more to the participatory design influence within the guidelines and are reflective of the guidelines representing emerging theory from the intersection of the fields, whereas MIT's work dealt primarily with collective intelligence exclusively.

Upon further review of literature, it is valuable to note the fundamental underlying themes that emerge in both the literature review and the emergent guidelines. These themes can be considered of significant importance due to their recurring nature across literature and data as well as their ability to address the three sub-questions (SQ1, 2, 3). These themes have been identified in the following sections as they relate to the categories of the PD-ICT guidelines.

\subsubsection{Project Identification}

Non-traditional design problems require non-traditional participatory approaches.

This overarching theme speaks to the general need for design to embrace contemporary and non-traditional approaches as the breadth of its involvement in social development evolves. Non-traditional design problems refer to complex social challenges 
with multiple stakeholders and no obvious correct answer or solution. These types of problems are often referred to as 'wicked problems'. The idea that design must evolve beyond traditional processes and involve the intelligence of many more people emerged within the literature where Sanders \& Stappers (2008) state how traditional design processes will have difficulty addressing the complexity of challenges that design will increasingly become involved in. The growing recognition for design to embrace more participatory processes when facing challenges such as social development was echoed by George Aye within the interview data when stating that "traditional design approaches are well-suited for traditional design problems". For these non-traditional problems, the idea of increasing the likelihood of a positive resolution of a problem by "having more eyes on the problem" can be achieved by greater participation in design. The conditions to allow for greater participation in design are now enabled by the use of ICT and social technologies in order to leverage the intelligence of far more people beyond the experts.

\section{Local knowledge will always be difficult for outsiders to get. (SQ3)}

The acceptance that external researchers and designers will always be biased is the necessary foundation before seeking attempts at trying to minimize the impact of this researcher bias. A frequent recurring theme within literature and interview results was the need to tap into local knowledge from people who live and experience problems daily. This perspective was reiterated by Chambers (1981), Papanek (1985), Peterson \& Hussain (2012), and many others as a fundamental requirement for project success. Practitioners such as Panthea Lee further explained the requirement for locals to play a fundamental part in the project's processes in interview as she further elaborated on just how difficult it is for outsiders to ever conduct research free of bias and be treated as a local. Her thoughts on just how critical local partners are for project success reiterated the improbability of achieving meaningful outcomes without ceding some control and influence to locals in a participatory process. While many sources of literature encourage ethnographic approaches towards embedding in a community, the general consensus is that regardless of the amount of time spent within a community, there are far too many barriers to conduct unbiased research. While this sentiment was equally shared among practitioners and sources of literature, practitioners must often make do with the existing bias, and be as aware of its effect on research as possible.

\subsubsection{Participant Engagement}


Participation must occur with technologies people are currently using in their lives. (SQ2)

The awareness of accessibility, sensitivity, and empathy is fundamental to enabling participants to actually engage in design processes. This theme of accessibility emerged as early as Schumacher's (1973) discussion on the need for 'intermediate technologies' that are adaptable to local needs and are a part of participants' lifestyles. While his interpretation of intermediate technologies did not specifically refer to the use of ICT in participatory projects, this sensitivity towards only using technologies which locals are already familiar with in development work has translated all the way through to interview results with Jeremy Canfield and his experiences with The Reboot. He emphasizes the fundamental need to exclusively use tools that are accessible to participants and are already engrained in their lifestyles if the project hopes to achieve the type of participation that will make this type of process valuable.

The motivation to participate needs to stem from intrinsic rather than extrinsic sources. (SQ2)

Community engagement depends on a motivated group of participants. Malone, et al., (2009) from MIT's Center for Collective Intelligence discuss how in effective collective intelligence systems, participant motivation occurs because of love, money, or glory. Others such as Murty, et al., (2010) have elaborated that the most effective sources of motivation stem from the need to participate for deeper personal reasons than financial reward. Interview data on the topic of motivation reinforced the need for intrinsic motivators as being critical for participation success. These sources of motivation can be as simple as having a method of voicing frustration, or actually having one's opinions respected, and are of primary importance to ensuring active and engaged participation in a project.

Participation must involve a variety of diverse stakeholders. (SQ2 \& SQ3)

The need for a variety of stakeholders to be involved in a project serves to minimize external bias by tapping into diverse local knowledge, and also stimulate participation by engaging with local community leaders. The need for a diversity of participants that is discussed in Surowiecki's (2005) tenets of collective intelligence was also reflected in the interview data in the context of involving a diverse variety of stakeholders and beneficiaries who can impact and will benefit from the project. While a different interpretation of a similar theme, the underlying sentiment is that participants who offer a diversity of opinion and experience need to be sought out. Surowiecki (2005) also places emphasis on other necessary factors such as the need for participants to be able to make decisions 
independently of each other, and be able to participate in a decentralized manner. Given the community-specific nature of the research and application of guidelines, these conditions did not emerge within the data, and were not considered as critical to participatory design as they are to achieving the higher-order collective intelligence that Surowiecki (2005) speaks of.

\subsubsection{Process Implementation}

The role of expert needs to change towards that of a facilitator. (SQ1)

The participation of large numbers of people through ICT and social technologies in processes that were traditionally left to the 'experts' in development and design means that the role of the expert needs to change. The idea of the expert using their expertise towards facilitating and catalyzing the participation of many into their processes is a recurring theme within literature and data. Development experts such as Chambers (1994) have called on outside experts to act as catalysts and facilitators in participatory processes. Annemarie Spitz of the Greater Good Studio, who in interview data cited the need to use design experience and expertise to mediate and facilitate the design process when dealing with large numbers of participants, mirrors this perspective. The realization that designers do not need to be the expert on everything, and should focus on creating and facilitating the conditions for others to participate is of primary significance. However, it is important to note that design expertise is still incredibly valuable and will continue to be so as more nondesigners engage in design. It is the shift and redistribution of this expertise towards participatory rather than individual processes that is the role of the design facilitator and catalyst.

Crowds should not be depended on for complex tasks. (SQ2)

A recurring theme within literature is a debate about what types of tasks crowds are good at performing. The arguments include whether crowds are better at generating ideas versus choosing between alternatives, and just how complex of a task a crowd is actually able to outperform experts on. Some studies such as those by Poetz \& Schreier (2012) have found that crowds can generate as feasible and novel (and often more novel) ideas as experts. Other perspectives such as those by Lanier (2011) propose that crowds are only good for problems involving optimization where the answer can be easily evaluated and questions aren't self-defined. Much of Surowiecki's (2005) examples of crowd intelligence cite excellent performance in prediction markets and guess-work. These differing 
perspectives complicate the notion of whether or not a crowd cannot be relied upon for real creativity or innovation. While the perspectives vary, the overall theme across primary research and literature is that a crowd of participants should primarily be relied upon for simple generative and evaluative tasks, and not highly complex matters that are the responsibility of experts. George Aye has described these tasks as those that are "a good use of their time" and one should not expect or demand too much from a crowd of participants.

\subsection{Preparing for Application}

Phase 1 research resulted in the development of a set of guidelines aimed at preparing the researcher and other practitioners to conduct a participatory design project using ICT aimed at leveraging a community's collective intelligence. The guidelines represent the amalgamation of leading theory and practice in participatory design, collective intelligence, and ICT4D, and provide the necessary structure and guidance to advance towards application in a real scenario. They are a valuable tool for those looking to expand the breadth and intelligence of their participatory design initiatives aimed at addressing human development challenges. Phase 2 will discuss the identification for an application of a portion of the guidelines in the context of an actual human development challenge. 


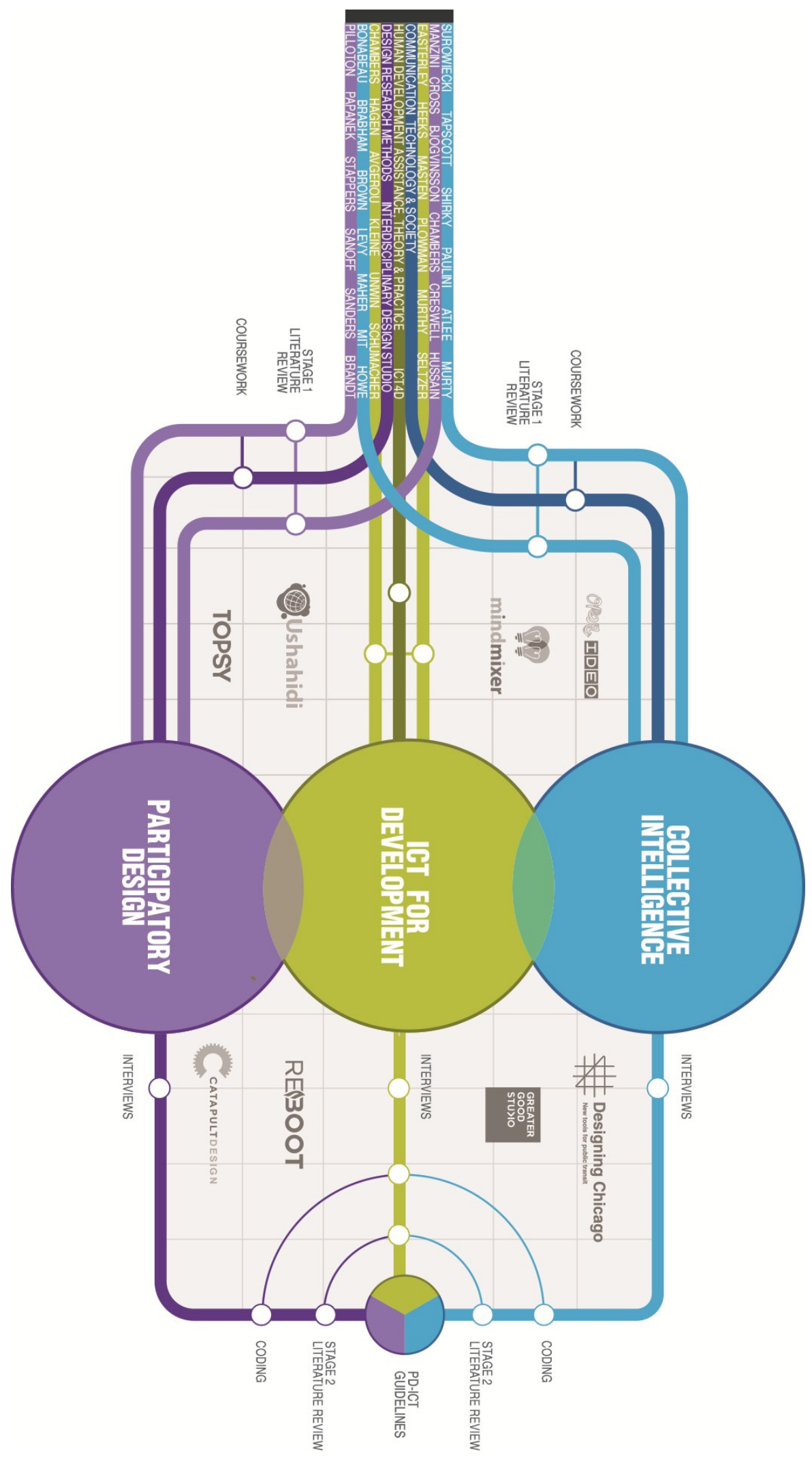

Figure 8. Phase 1 research process 


\section{PHASE 2 \\ APPLICATION IDENTIFICATION}




\subsection{METHODS: PHASE 2 APPLICATION IDENTIFICATION}

Phase 2 consisted of identifying an area of application for the PD-ICT guidelines developed in Phase 1. The goal was to explore and understand an environment in which the guidelines could be employed by referencing the Project Identification category. In doing so, the context was set for the application of the guidelines in their entirety in future research, within an environment and suited to a focus area that aligns with their purpose. Phase 2 research was primarily qualitative in nature consisting of interviews and ethnography, but also employed quantitative social media analytics analysis.

\subsection{Approach}

Given the research approach embodied principles of grounded theory, the process of identifying an opportunity and applying the guidelines was not an act of truth-searching, or proving an idea. Instead it sought to make conceptual sense of what was transpiring and gaining familiarity with a phenomenon.

In the context of the research processes undertaken to inform the Project Identification category, data can emerge from anywhere in the environment - not just formal interviews or questionnaires - due to the geographic proximity of the unfolding events that were being researched. As a result, the unpredictability and spontaneity of these events demanded a primarily qualitative and ethnographic approach, although when necessary, quantitative research was conducted using social media analytics software. The research methods employed included interviews as well as ethnographic observations (in-person and digital).

For the purpose of this research, in-person ethnographic research was conducted through the theoretical lens of design. Like traditional ethnography, this 'design ethnography' relies largely on qualitative methods and values the designer's ability to make cognitive leaps and assumptions that are necessary for faster-paced design work compared to traditional anthropological ethnographic studies.

Digital ethnography as described in section 2.6.1 was employed as an approach to extend design ethnography approaches like participant observation into the digital world. The strong social media activity surrounding the area of research presented the opportunity to leverage ICT in digital ethnography as another tool for Project Identification. 
Combined, these research approaches sought to enable the overcoming of innate cultural differences in a flexible, responsive, and efficient manner capable of responding to a quickly evolving landscape. The breadth of digital ethnography, and its ability to lower barriers to participation while enabling the contributions of many respondents was critical, as well as the depth of design ethnography conducted in more traditional in-person settings.

\subsection{Researcher's Role}

By conducting ethnographic qualitative work, the researcher was susceptible to bias, and interpretations that are shaped by particular worldviews. It is important to note that the researcher comes from an industrial design background, and is a citizen of the city in which the research was conducted. As a result, daily life was influenced and impacted by the events under research, and was partial to influence by media, and conversations with fellow citizens.

\subsection{Participants}

Research participants were observed digitally, in-person, and engaged in interviews. Participants who were self-identified Aboriginal people, consisting of First Nations, Inuit, and Métis were identified as being of particular relevance, the criteria of which is discussed in section 7.0 Results. In this context, culture is not just demographic, but is something that is learned through membership in a group or community, and influences the attitudes, beliefs, behaviours and values of group members (Steers, Sanchez-Runde \& Nardon, 2010). Since Ottawa (and Canada) is a pluralistic culture, where a variety of cultures live within one society, it was not possible to exclusively target Aboriginal people and while they did represent the majority of participants, other cultural groups were also present in-person, and online.

\subsubsection{Ethnographic Research}

The researcher's physical location in Ottawa allowed for ethnographic research to be conducted in person, and online for the unfolding events surrounding the 'Idle No More' movement, which is further described in section 7.1. Ethnographic research was conducted surrounding three specific high-profile events, which were chosen for their breadth in participation volume, content, and timing as it was deemed necessary to conduct research at least over the span of two months. Due to the organic nature of the 'Idle No More' 
movement, the events themselves were organized fairly quickly, and in a fluid manner that responded to the emerging nature of the movement itself. The chosen dates for ethnographic research provided the necessary varying levels of breadth and depth of participant engagement over a sufficiently long period of time for a comprehensive look on the actions surrounding the movement. The following table demonstrates the chosen events the researcher attended.

\begin{tabular}{|c|c|c|c|c|}
\hline EVENT & DATE & LOGATION & ESTIMATED ATTENDANGE & $\begin{array}{l}\text { PARTICIPANT } \\
\text { DEMOGRAPHICS }\end{array}$ \\
\hline $\begin{array}{l}\text { Global Day of } \\
\text { Action }\end{array}$ & $\begin{array}{l}\text { January } \\
11^{\text {th }} \\
2013\end{array}$ & $\begin{array}{c}\text { Parliament Hill - } \\
\text { Ottawa }\end{array}$ & 1000 & $\begin{array}{c}\text { Broad } \\
\text { representation } \\
\text { across age groups } \\
\text { (children to } 70+\text { ) } \\
\text { and genders. } \\
\text { Primarily } \\
\text { Aboriginal. }\end{array}$ \\
\hline $\begin{array}{l}\text { Idle No More } \\
\text { Youth Forum } \\
\text { (Ottawa- } \\
\text { Gatineau) }\end{array}$ & $\begin{array}{l}\text { January } \\
25^{\text {th }} \\
2013\end{array}$ & $\begin{array}{c}\text { Ottawa Convention } \\
\text { Centre - Ottawa }\end{array}$ & 50 & $\begin{array}{c}\text { 13-30 age group } \\
\text { Primarily } \\
\text { Aboriginal. }\end{array}$ \\
\hline $\begin{array}{l}\text { Arrival of the } \\
\text { Nishiyuu } \\
\text { Walkers }\end{array}$ & $\begin{array}{l}\text { March } \\
25^{\text {th }} \\
2013\end{array}$ & $\begin{array}{c}\text { Victoria Island, } \\
\text { Wellington St, } \\
\text { Parliament Hill - } \\
\text { Ottawa }\end{array}$ & $1000-5000$ & $\begin{array}{c}\text { Broad } \\
\text { representation } \\
\text { across age groups } \\
\text { (children to } 70+\text { ) } \\
\text { and genders. } \\
\text { Primarily } \\
\text { Aboriginal. }\end{array}$ \\
\hline
\end{tabular}

Table 8. Idle No More events attended for ethnographic research

In-Person Ethnography

Due to the nature of the research topic, the great majority of participants at the three events appeared to be of Aboriginal heritage. All participants were there on their own accord due to their affiliation with the movement and its surrounding events. Participants were freely and voluntarily participating, and the researcher was simply observing and engaging in the same environment as participants.

\section{Digital Ethnography}

Digital ethnography was conducted using tweets sent on Twitter +/- 1 day of the inperson ethnography events listed in Table 8. Digital ethnography was conducted in a 'passive' manner, where participants were not knowingly contributing to research. Tweets 
are publically available, and are for the purpose of this research, were not directly attributed to a person, or Twitter username.

Digital ethnography was limited to those individuals engaging on Twitter. Observation was conducted on the publically available tweets of participants who used the established \#idlenomore hashtag. By searching for tweets with the hashtag \#idlenomore, the researcher was able to observe tens of thousands of digital messages thematically relating to the chosen research topic.

The following table demonstrates the volume of available tweets organized under the \#idlenomore hashtag corresponding to the dates of the in-person ethnographic research including one day before, and one day after.

\begin{tabular}{c|c|c|c|c}
\multicolumn{2}{c}{$\begin{array}{c}\text { EVENT } \\
\text { VOLUME }\end{array}$} & $\begin{array}{c}\text { AGTUAL DATE } \\
\text { TWEET VOLUME }\end{array}$ & $\begin{array}{c}\text { +1 DAY TWEET } \\
\text { VOLUME }\end{array}$ & TOTAL TWEETS \\
$\begin{array}{c}\text { Global Day of } \\
\text { Action (January } \\
\text { 11, 2013) }\end{array}$ & 25,958 & 55,334 & 27,402 & 108,694 \\
\hline $\begin{array}{c}\text { Idle No More } \\
\text { Youth Forum } \\
\text { January 25, } \\
\text { 2013) }\end{array}$ & 10,304 & 8,444 & 6,686 & 25,434 \\
\hline $\begin{array}{c}\text { Arrival of } \\
\text { Nishiyuu Walkers } \\
\text { (March 25, 2013) }\end{array}$ & 2,108 & 6,808 & 3,557 & 12,473 \\
\end{tabular}

Table 9. Twitter volume using \#idlenomore hashtag (Topsy, 2013)

The following figure demonstrates the volume of tweets under the \#idlenomore hashtag occurring on and around the chosen dates for physical and digital ethnography (Data sourced from Topsy Pro Analytics Software). It provides context for the impact of the chosen dates relative to overall Twitter activity under the \#idlenomore hashtag from January $1^{\text {st }} 2013$ - March 30th 2013. 


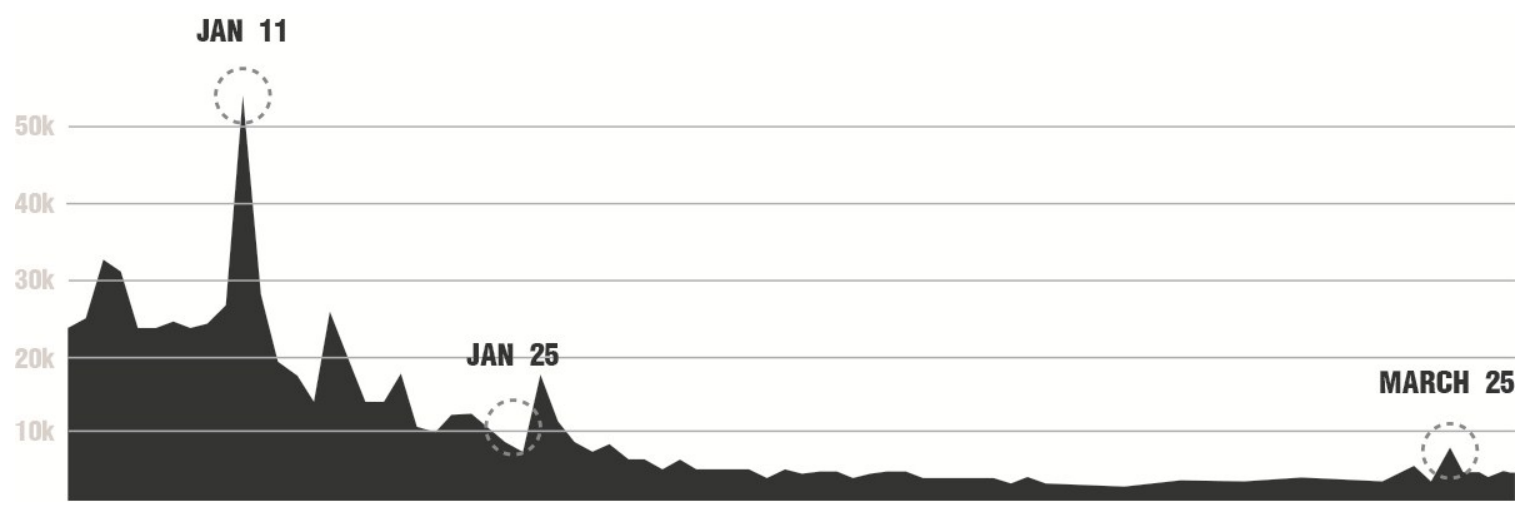

Figure 9. Tweet volume of \#idlenomore hashtag adapted from Topsy. (Topsy, 2013)

The digital ethnography approach to research reflects the 'passive systems' described by Lykorentzou et al. (2009) that could ultimately be modeled into a collective intelligence system. In this 'passive system' individuals act as they normally would without a system's presence. Participants lack awareness and intentionality in their actions towards contributing to a system, or research.

\section{$\underline{6.3 .2 \text { Interviews }}$}

Interviews were conducted with chosen participants. Participant suitability was determined from Phase 1 guidelines. Participants were recruited by e-mail, and interviews were conducted in-person in neutral locations (coffee shops) in Ottawa. Participants were chosen based on their ability to bring diverse, educated, and respected opinions to the topic. They included Jo McCutcheon (a professor, historian and researcher on Indigenous history), and Gabrielle Fayant (Ottawa-based youth coordinator for National Aboriginal Organization, and Idle No More community leader).

\subsection{Data Collection and Recording}

Data collection in Phase 2 ranged from traditional field notes and photos taken during ethnographic research, to interviews, and the collection of thousands of tweets. Data collection was conducted both in 'passive' and 'active' systems, where depending on the context, participants were either knowingly and willingly contributing to research, or acting as research subjects while they went about their lives in the physical and digital world.

\subsubsection{Ethnographic Research}

In-Person 
Ethnographic data collected during the events listed in Table 9 consisted of field notes, observations, photographs, and videos. Field notes were recorded in a notebook, and sought to capture the tone, and stories from events. Photos and videos were primarily taken with the researcher's smartphone during the events. Of particular relevance was an attention to the underlying sentiments and attitudes of participants, as well as the themes of conversation. An effort was made to capture the breadth of stories and sentiments being conveyed, as well as the emotive qualities of the participants.

Digital

Digital ethnographic data collection and recording was reliant on software applications that have a partnership with Twitter, known as Topsy. Topsy is the only full-scale index of the public social web. The San Francisco based company describes its product as: "Topsy provides deep, comprehensive analyses of hundreds of billions of Tweets and web pages gathered from millions of unique websites, blogs and social media services. Topsy's platform leverages these social conversations to index, analyze and rank content and trends. With instant access to conversations from moments ago or years ago, Topsy enables users to discover, quantify, predict and make decisions using the world's most powerful social analytics products." (Topsy, 2013).

It has worked in collaboration with Twitter on high-profile projects such as the 'Twitter Political Index' that was deployed during the 2012 US Federal Election to act as a daily measurement of Twitter users' feelings towards the candidates expressed in millions of tweets each week.

The feature known as 'Pro Analytics' was employed by the researcher to collect tweets for the aforementioned dates listed in Table 10, in which the researcher also conducted inperson ethnographic research. Using Topsy, the researcher was able to collect all tweets containing the \#idlenomore hashtag on the specified dates of research, and analyze them using Topsy's proprietary analytics software. The 250 most relevant tweets (as determined by Topsy's relevance rankings) were then exported to a Microsoft Excel spreadsheet to enable processing and analyzing.

\section{$\underline{6.4 .2}$ Interviews}

Interviews were open-ended, conducted in-person and in public environments due to the spontaneity of participant identification and availability. Attempts were made to 
digitally record interviews, which were then transcribed verbatim and supplemented with additional researcher notes. Subjects were chosen for the potential insights they can contribute and for their perspectives on the topic. Open-ended questions such as "What does Idle No More mean to you?" were used in order to stimulate conversation.

\subsection{Processing and Analyzing}

The research methods undertaken by the researcher were intentionally chosen to provide a diversity of perspective and approach. While the emphasis of processing and analyzing was done digitally, the in-person ethnography and interviews served to add context and colour to events and conversation occurring simultaneously in the digital space for a well-rounded observation.

\subsubsection{Ethnographic Research}

\section{In-Person}

Qualitative observational data was used to provide the researcher with greater context and situational awareness around an initially unfamiliar topic and research theme. The data was analyzed for meaning, recurring themes, and underlying messages that emerged from the breadth of stories, opinions, and sentiments present at the public events.

\section{Digital}

Using the hashtag \#idlenomore as a filter, the 250 most influential tweets were extracted from Topsy's Pro Analytics - as determined by Topsy - for each of the chosen date ranges. The resulting 750 tweets were placed into an Excel spreadsheet, and uploaded into qualitative research software QRS NVivo 10. A word frequency analysis was conducted, and tweets were manually coded using the emerging themes from in-person ethnography and interviews. It is important to note that not all tweets were suitable for coding due to their content not containing any significant sentiment (ie. news-story links). These tweets were left blank and not included in the overall analysis.

\section{$\underline{6.5 .2 \text { Interviews }}$}

Interview processing and analysis was conducted by analyzing both interview transcripts and notes. Analysis followed a similar process of identifying codes, concepts, and categories. The purpose of the interviews was to layer the depth of information that emerges from face-to-face interaction with the breadth that is possible in digital ethnography. 


\subsection{RESULTS: PHASE 2 APPLICATION IDENTIFICATION}

The goal of Phase 2 was to identify a suitable area for the application of the PD-ICT Guidelines. The results of Phase 2 are observational and interpretative, and depended on ethnographic observation (digital and in-person) as well as qualitative interviewing.

The following section describes the process of identifying an application using the Project Identification section of guidelines (4.1). It includes the exploration of a focus area through qualitative interviews as well as digital and physical ethnography.

\subsection{Project Identification: Idle No More}

The first step in identifying where to apply the PD-ICT guidelines was to determine an appropriate project focus area. Not all projects require, or are suitable for the application of ICT and social technologies in participatory processes. The developed guidelines can be applied to a project focus that is either pre-determined where it is known beforehand what should be researched and developed. Alternatively, in this case, the project focus was not apparent or pre-determined; however, a social movement was identified as an appropriate area of research from within which a project focus could emerge.

\section{Idle No More}

'Idle No More' was a highly active, publicized, yet loosely knit political movement that emerged from Canada's Aboriginal communities, which gained significant public attention beginning in December of 2012. Some participants described it as a social rights movement that affects all original inhabitants of a pre-colonized land who are now marginalized (Indigenous people). The movement's initial trigger stemmed from backlash against the Canadian Conservative Government passing Bill C-45 (Parliament of Canada, 2013) and its perceived potential to erode Indigenous rights and circumvent traditional treaty agreements. The bill's most contentious issues touch on the controversial Indian Act, the Environmental Assessment Act, and the Navigation Protection Act (formerly Navigable Waters Protection Act). These changes resulted in Canadian Aboriginal people fearing for their land claims, rights, and the sustainability of future generations among a multitude of other concerns.

What started as a number of demonstrations, road blocks, protests, a high profile polarizing hunger strike, and heavy use of social media directed at Bill C-45, quickly took on 
many new and different meanings. While thousands of people became engaged in the movement across the country, there was no common uniting theme or problem identification. 'Idle No More' became an umbrella social movement with many stakeholders involved from government all the way to minute communities in remote areas of the country and quickly became a complex embodiment of a broad array of voices and issues.

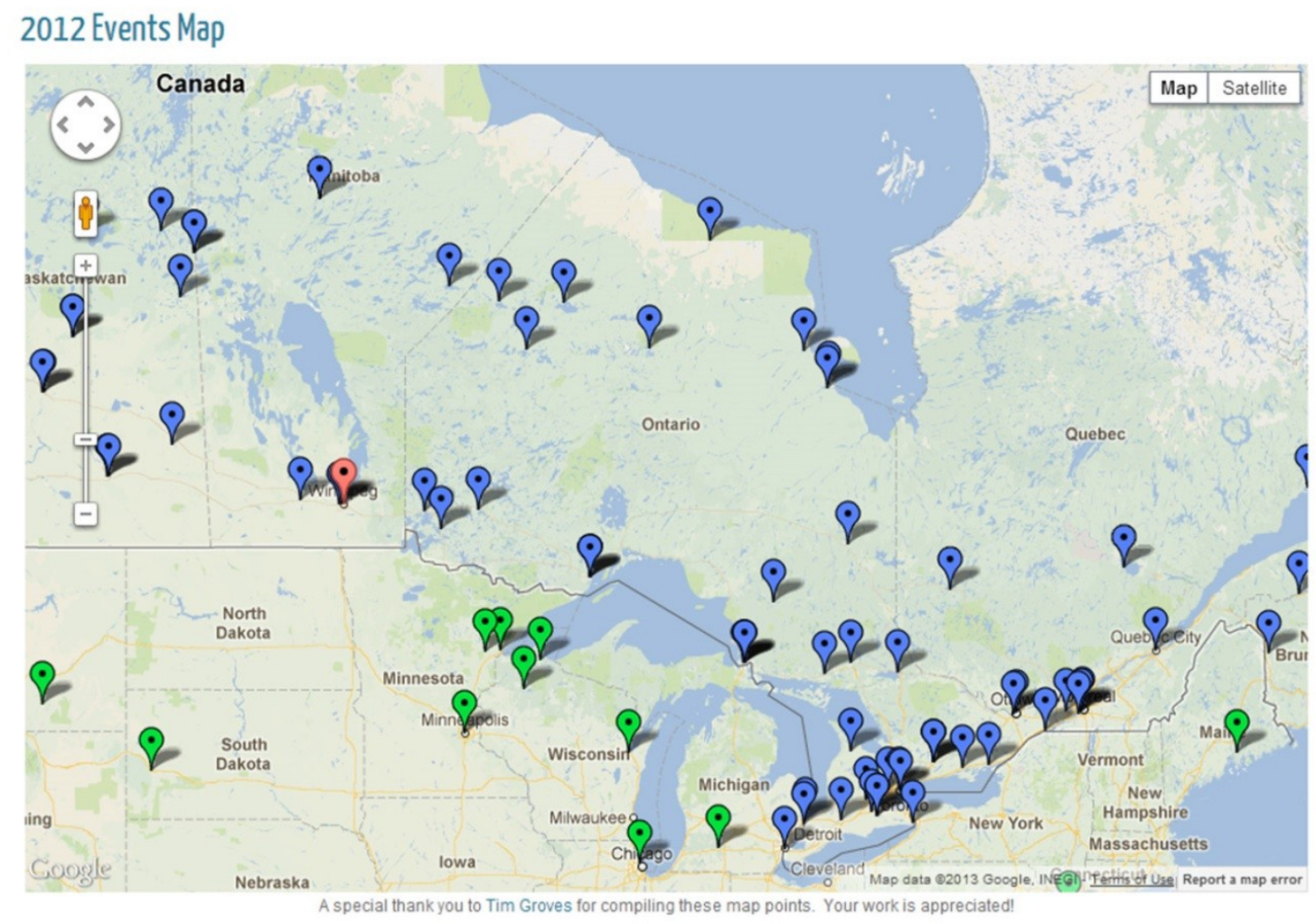

Figure 10. Idle No More 2012 events map sample (Idle No More, 2013)

Due to 'Idle No More's' complex nature, incomplete information, changing requirements, and difficulty in identifying a problem, it draws parallels to a 'wicked problem'. Meaningful design projects are inherently wicked problems (Cross, 2007), which are ill-defined, and ill-structured by nature, meaning that due to 'Idle No More's' fluid and complex challenge, it is well-suited for an exploration into a potential design intervention.

While 'Idle No More' is a complex societal challenge, its key differentiator for the application of Phase 1's guidelines is its reliance on social technologies and ICT. Events were organized through Facebook, and the Twitter hashtag \#idlenomore took on great significance as the main social technology identifier for information, stories, and sentiments surrounding the movement. 


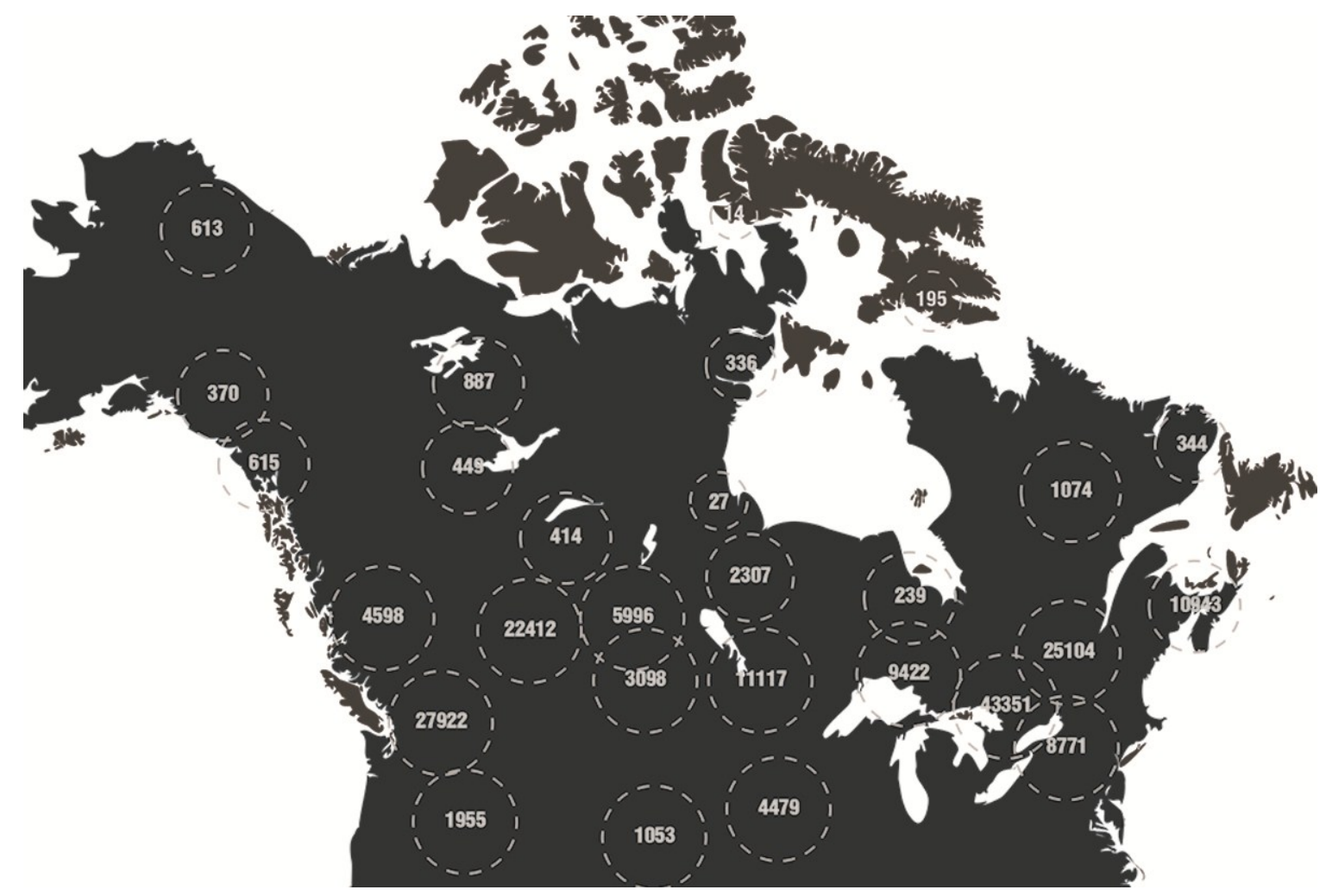

Figure 11. \#Idlenomore tweet cluster density map as of May 6, 2013 (Makook.ca, 2013)

According to Aboriginal Affairs and Northern Development Canada (AANDC)

documents, 'Idle No More' was described as something unlike the government had ever seen:

"Organized and promoted through social media, Idle No More has been able to do something that other movements in the past have not been able to do or manage to sustain. It has people leaving their homes to participate. It (Idle No More) is quite different from what we've seen before in terms of activity and rhetoric." (Press \& Woods, 2013) 

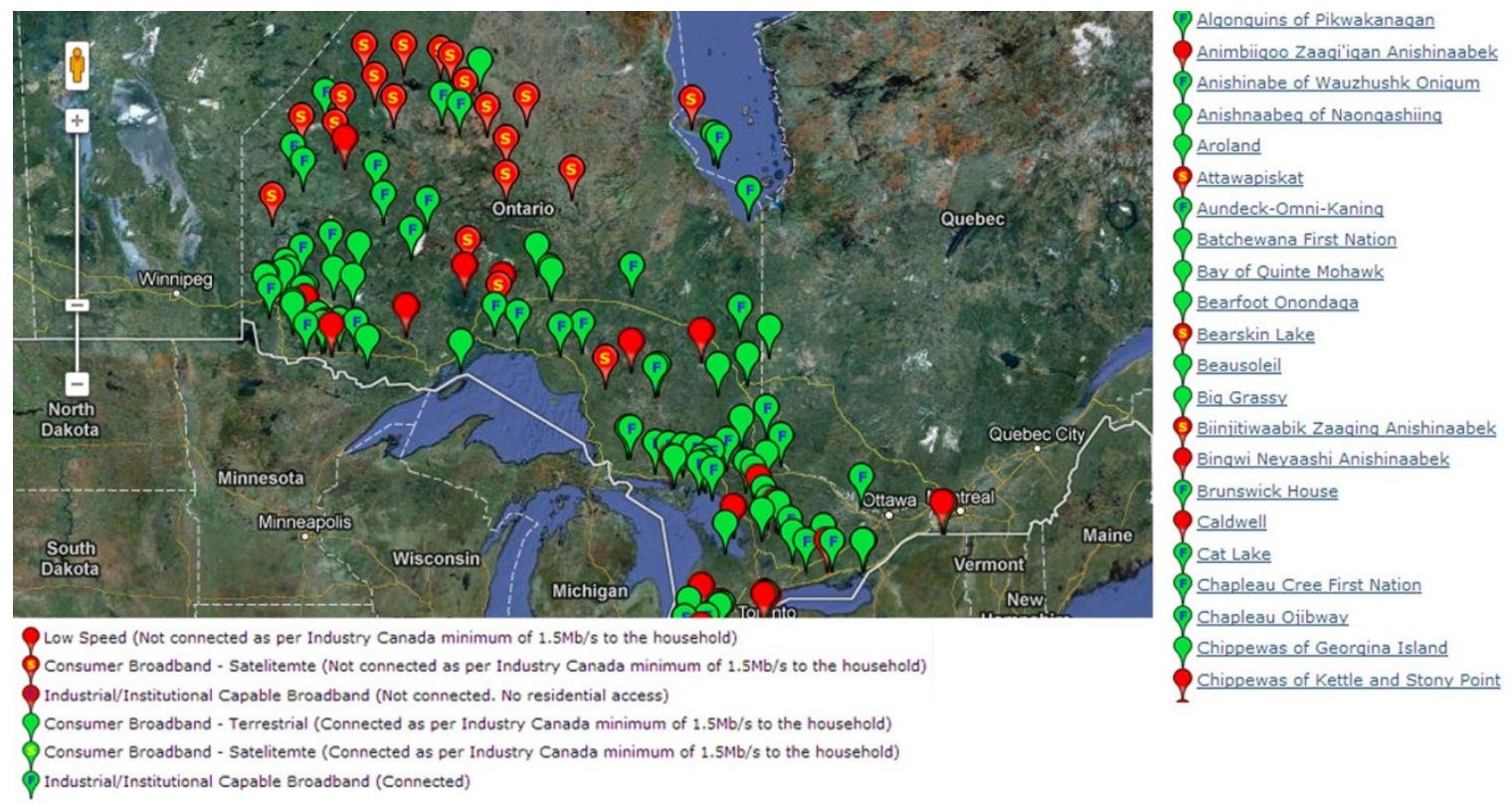

Figure 12. Aboriginal connectivity profiles of Ontario as of March 1, 2013 (AANDC, 2013)

The 'Idle No More' movement was identified as a social movement that could benefit from the leveraging of ICT and social technologies in a concerted effort towards using participatory design as a human development tool. In order for design to potentially play a role in the human challenges that are fundamental to 'Idle No More' it first required the identification of possible practical design interventions and a project focus from within the complex movement.

\subsubsection{Project Focus Area}

Initial research focused on determining the key themes, issues, and messages of 'Idle No More' movement in order for a suitable project focus to emerge from research. This was accomplished by conducting ethnographic research (digital and in-person), and qualitative interviews as described in sections 6.4.1 and 6.4.2.

\section{In-Person Ethnography}

In-person ethnography was conducted on three specific dates as stated in Table 9 from 6.3.1. The researcher took field notes, photographs, and videos during these in-person observations, which were then analyzed and synthesized. The purpose of the in-person ethnography was to inform the researcher of the underlying messages emerging from 'Idle No More' activities as well as the sentiment of participants in order identify the key themes 
of the social movement. A video was created documenting in-person ethnography and is available at http://www.vimeo.com/66206056.

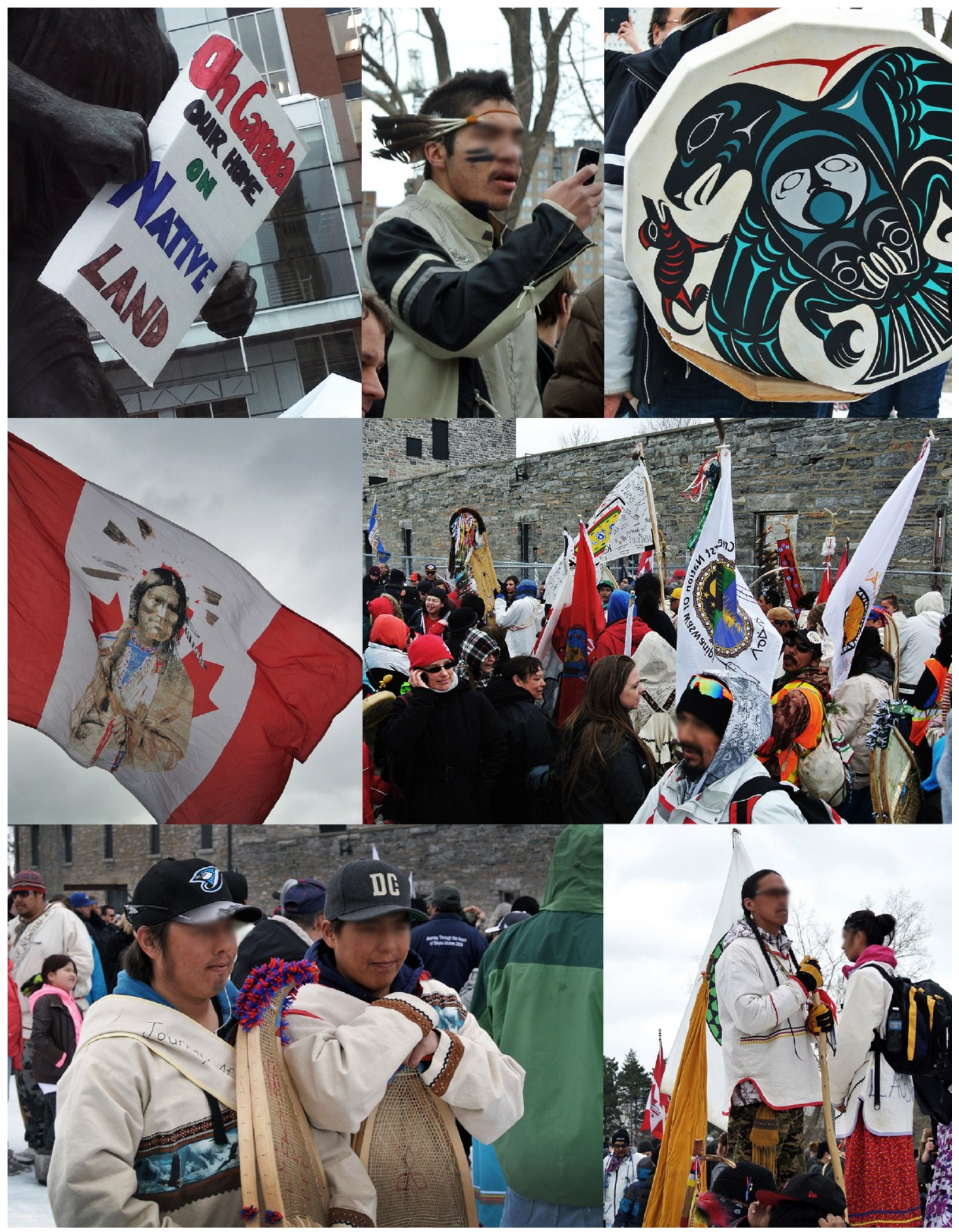

Figure 13. Sample of in-person ethnography 
The primary themes to emerge from in-person ethnography are summarized in the table below.

Conversations about the importance of teaching youth the traditional cultural ways and preserving cultural identity. Nations representing their own cultures through dress, flags, songs.

Cultural

Identity

Many different nations represented at all events, expressing personal and collective beliefs. Different parts of the country representing collective interests of Indigenous people. It is not just an Indigenous issue, and there is no sense of exclusivity.

A call to stand up for beliefs. Presence of traditional artifacts, dancing, music, ceremony. Using traditional languages.

"Personalize to decolonize" phrase encourages sharing stories and putting a face to the movement. Giving a voice to people and communicating the issues.

Cultural Unity

Frequent discussion of the role social media has played in this. Evidence of heavy smart phone use and live-tweeting of events.

Use of ICT

A call for Indigenous people to understand the issues and create dialogue.

Education

Land=God \& Home. Fighting for clarification of terminology and detrivializing ideas that non-Indigenous may not understand.

An overall sentiment of mistrust and frustration. A near paranoia at being circumvented and taken advantage of.

Cultural Pride

Story-Telling

Table 10. Primary themes from in-person ethnography

Interviews

Informal interviews were conducted in order to stimulate conversation about the underlying themes of 'Idle No More'. The open-ended interviews yielded some familiar themes to in-person ethnography. The following table summarizes the key interpreted statements and corresponding themes to emerge from informal interviews. 
Idle No More means very different things to different people.

Cultural Unity

Communities have different problems and they interpret it differently.

It's very organic and affects all - not just Indigenous people.

There is a lack of trust in nation-to-nation dialogue due to treaty violations, so there is a need for greater transparency and accountability.

A need exists for educating Indigenous people about how they are being affected, and to do so in simpler terms without "hidden messages".

There is a greater sense of cultural pride and identity among Indigenous youth who are beginning to embrace traditional roots.

Cultural stories are a strong source of pride and knowledge. Stories may be difficult to talk about, but they are critical for identity.

Stories can die with elders. In many cases these are stories critical for identity, and traditional knowledge.

Mistrust \& Accountability

\section{Education}

Cultural Pride (youth)

Story-Telling Story-Telling \& Cultural Identity

Youth want meaningful change to finally happen. They are interested and engaged in grassroots movements due to frustration at bureaucracy and politics.

Indigenous people are frustrated with not being heard, or respected. They strive for cultural and social equality, and don't want to be seen as mythical figures.

A sense of community is necessary for developing bonds and pride to Community not feel as though you're the only one going through this.

Education, and no longer being digitally (now have access to ICT) or physically (many now live in urban centres) isolated is empowering people.

ICT and social technologies allow for greater accountability and sharing. It makes participation in dialogue and organizing easier.

Inspiration and education often comes from community and cultural Community

Frustration (youth)

Frustration \& Respect

Empowerment

Use of ICT leaders, not traditional figures like chiefs or elders.

Table 11. Primary themes from interviews

\section{Digital Ethnography}


Digital ethnography rounded out the mixed methods approach to research and supplemented in-person ethnography and interviews with a breadth of voices and data. It relied on collecting and analyzing tweets using the \#idlenomore hashtag.

IdleNoMore News @idleNomoreNews

Cree walkers speak at Parliament Hill after Idle No More trek

bit.ly/YbBpsq \#IdleNoMore

Expand

Cree walkers speak at Parliament Hill after Idle No More trek

A group of young people from the James Bay Cree community of Whapmagoostui, Que., has arrived at Parliament Hill in Ottawa, ending a 1,600-kilometre trek meant to bring attention to aboriginal issues.

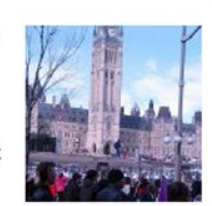

\# CBC Top Stories @CBCNews·Follow

Leadnow A l'Action @leadnowca

25 Mar

Epic journey inspired by \#IdleNoMore arrived to heroes welcome in \#Ottawa today. Big respect to \#Nishiyuu Walkers: cbc.ca/news/canada/ot...

Followed by HUB Ottawa and 2 others

Expand

\section{godammitkitty@godammitkitty}

A few wks ago 7 friends began 1600 mile walk to Ottawa in support

of \#IdleNoMore SHARE this to thank them! \#Nishiyuu

pic. twitter.com/kSk8X2qLXW

回 Expand

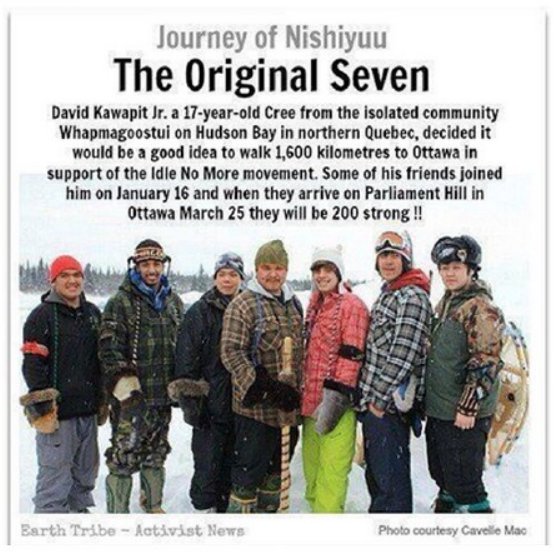
Mar

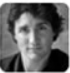
Justin Trudeau, MP @JustinTrudeau communities. Let's equal that with real engagement. \#idlenomore \#Nishiyuu
Retweeted by Nishiyuu
Expand
Matthew Pearson @mpearson78
Ryder Cote, 12, joined the Nishiyuu Walkers in Kitigan Zibi.
\#idlenomore yfrog.com/occdwcbj
Followed by Joanne Steventon and 5 others
Expand

\section{CBC Top Stories@CBCNews} Northern Quebec in January. Watch LIVE: cbc.sh/29PtZdl \#Nishiyuu Expand
Wouckeus Indigenous Waves @indigenousWaves 25 Mar
Today we are reminded how strong we are, how capable our youth are, \& how hopeful our future is \#Nishiyuu \#inspiration \#heroes \#IdleNoMore
Followed by Dee Jay NDN and 5 others
Expand

Dan Sawyer @Mental_Radio_ 25 Mar

People take the street to welcome \#NishiyuuWalkers to Victoria Island \#Nishiyuu \#CdnPoli \#idlenomore pic.twitter.com/BfPHtt5x8U Followed by Graham Lanktree and 5 others 回 Expand

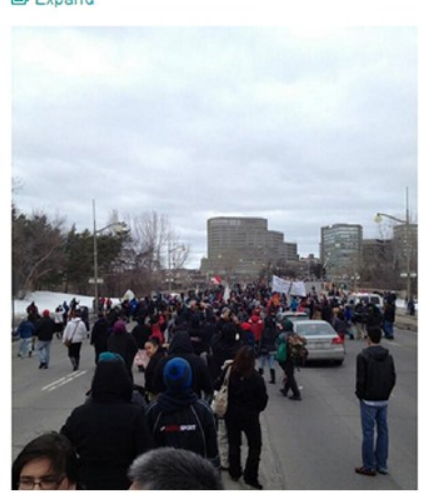

Figure 14. Sample of \#idlenomore tweets (all Twitter data presented in Appendix E)

The following table represents a sample of the coding process undertaken in the analysis of \#idlenomore tweets. 


\begin{tabular}{|c|c|c|c|c|}
\hline 4 & A & B & $\mathrm{C}$ & D \\
\hline 1 & Influence & \# Tweets & Tweet Content & Theme \\
\hline 2 & 1 & 1000 & $\begin{array}{l}\text { Was just offered Queen Elizabeth II Diamond Jubilee Medal from GG. I } \\
\text { respectfully decline in solidarity with hunger strikers +\#IdleNoMore }\end{array}$ & Community \\
\hline 3 & 2 & 395 & $\begin{array}{l}\text { Amazing how obsessed the media is with telling a story of division } \\
\text { around\#idlenomore. Journalism with an agenda can be so harmful. \#cbc }\end{array}$ & Cultural Unity \\
\hline 4 & 3 & 494 & $\begin{array}{l}\text { IdleNoMore is } 4 \text { everyone. It is not just an 'Indian } \\
\text { thing'!!!\#11 http://t.co/1Col3s8B }\end{array}$ & Cultural Unity \\
\hline 5 & 4 & 370 & $\begin{array}{l}\text { Following @NaomiAKlein 's lead and respectfully declining my recently } \\
\text { offered Queen Elizabeth II Diamond Jubilee Medal from GG!\#ldlenomore }\end{array}$ & Community \\
\hline 6 & 5 & 598 & $\begin{array}{l}\text { Youth are engaged. Older generations are standing strong. Canadians of all } \\
\text { backgrounds are offering support. Change is here\#tidlenomore }\end{array}$ & Cultural Unity \\
\hline 7 & 6 & 820 & $\begin{array}{l}\text { The t-shirt says, "Canada- Our Home On Native Land".. I couldn't agree } \\
\text { more.\#idlenomorehttp://t.co/cBryCC18 }\end{array}$ & Cultural Unity \\
\hline
\end{tabular}

Figure 15. Sample of tweet processing in Excel

The following table demonstrates the emergent themes from ethnographic research.

\begin{tabular}{|c|c|c|c|c|c|}
\hline EVENT & $\begin{array}{l}\text { DATE } \\
\text { (LNGLUDING } \\
\text { +/- } 1 \text { DAY) }\end{array}$ & LOCATION & $\begin{array}{l}\text { ESTIMATED } \\
\text { ATTENDANGE }\end{array}$ & $\begin{array}{l}\text { PARTICIPANT } \\
\text { DEMOGRAPHICS }\end{array}$ & $\begin{array}{l}\text { TWITTER } \\
\text { \#IDLENOMORE } \\
\text { THEME POPULARITY }\end{array}$ \\
\hline $\begin{array}{l}\text { Global Day } \\
\text { of Action }\end{array}$ & $\begin{array}{l}\text { January } \\
11 \text { th, } \\
2013\end{array}$ & $\begin{array}{l}\text { Parliament } \\
\text { Hill - } \\
\text { Ottawa }\end{array}$ & 1000 & $\begin{array}{l}\text { Broad representation } \\
\text { across age groups } \\
\text { (children to } 70+\text { ) and } \\
\text { genders. Primarily } \\
\text { Aboriginal. }\end{array}$ & $\begin{array}{l}\text { 1) Cultural Unity } \\
\text { 2) Cultural Pride } \\
\text { 3) Respect } \\
\text { 4) Empowerment } \\
\text { 5) } \text { Frustration }\end{array}$ \\
\hline $\begin{array}{l}\text { Idle No } \\
\text { More } \\
\text { Youth } \\
\text { Forum } \\
\text { (Ottawa- } \\
\text { Gatineau) }\end{array}$ & $\begin{array}{l}\text { January } \\
25 \text { th, } \\
2013\end{array}$ & $\begin{array}{l}\text { Ottawa } \\
\text { Convention } \\
\text { Centre - } \\
\text { Ottawa }\end{array}$ & 50 & $\begin{array}{l}\text { 13-30 age group (as } \\
\text { invited by event } \\
\text { organizers). Primarily } \\
\text { Aboriginal. }\end{array}$ & $\begin{array}{l}\text { 1) Respect } \\
\text { 2) Cultural Unity } \\
\text { 3) Empowerment } \\
\text { 4) Accountability } \\
\text { 5) Education }\end{array}$ \\
\hline $\begin{array}{l}\text { Arrival of } \\
\text { the } \\
\text { Nishiyuu } \\
\text { Walkers }\end{array}$ & $\begin{array}{l}\text { March } \\
25 \text { th, } \\
2013\end{array}$ & $\begin{array}{l}\text { Victoria } \\
\text { Island, } \\
\text { Wellington } \\
\text { St, } \\
\text { Parliament } \\
\text { Hill - } \\
\text { Ottawa }\end{array}$ & $1000-5000$ & $\begin{array}{l}\text { Broad representation } \\
\text { across age groups } \\
\text { (children to } 70+\text { ) and } \\
\text { genders. Primarily } \\
\text { Aboriginal. }\end{array}$ & $\begin{array}{l}\text { 1) Respect } \\
\text { 2) Cultural Pride } \\
\text { 3) Cultural Unity } \\
\text { 4) Empowerment } \\
\text { 5) } \text { Frustration }\end{array}$ \\
\hline
\end{tabular}

Table 12. Idle No More popular themes on dates of ethnographic research

While the Project Identification research processes undertaken did not identify a specific design intervention or artifact that could 'solve' the problem, this is attributed to the complex nature of the movement with so many factors and voices - in short, a 'wicked problem'. What instead became apparent is that from a design perspective, an opportunity exists to further reinforce and invigorate the progress seen organically occurring through 
an act of collective action mobilization leveraging the three most prominent themes of the movement: Cultural Unity, Cultural Pride, and Respect. The possible project to emerge from such a perspective is discussed in the following Discussion section. 


\subsection{DISCUSSION: PHASE 2 APPLICATION IDENTIFICATION}

The results of Phase 2 discussed the exploration of a focus area for the application of a component of the guidelines in an actual social movement - 'Idle No More'. Due to the timeline and scope of the project, emphasis was placed on referencing the first Project Identification category as described in section 4.1.

\subsection{Project Focus Area Identification}

The research sought to explore the environment from which a project focus could emerge from within an observable social movement with development undertones.

\section{WHAT \\ EVIDENGE}

The type of problem $\rightarrow$ affects many people the project should address...

without a sense of exclusivity. is specific to a large and engaged enough community. a non-traditional design problem requiring input from multiple stakeholders.
Indigenous nations from across the country participated in the movement regardless of specific affiliation or geographic location.

Canada's Aboriginal community (those identifying with at least one of North American Indian, Métis or Inuit) is over $1,000,000$ people, is significantly younger than the general population, and represents nearly $4 \%$ of the population. $60 \%$ of this population lives off-reserve, and $76 \%$ of those living offreserve live in urban areas ${ }^{1}$.

The movement involves stakeholders ranging from the federal government, to chiefs and citizens scattered across the country. Problems and causes vary significantly.
The project should use ICT and social technologies in participatory processes when... community input is a fundamental project requirement.
This is a complex social movement stemming from within a society that is different from that of the researcher. The researcher would need to rely on the experiences, knowledge, and input of those within Indigenous communities. 


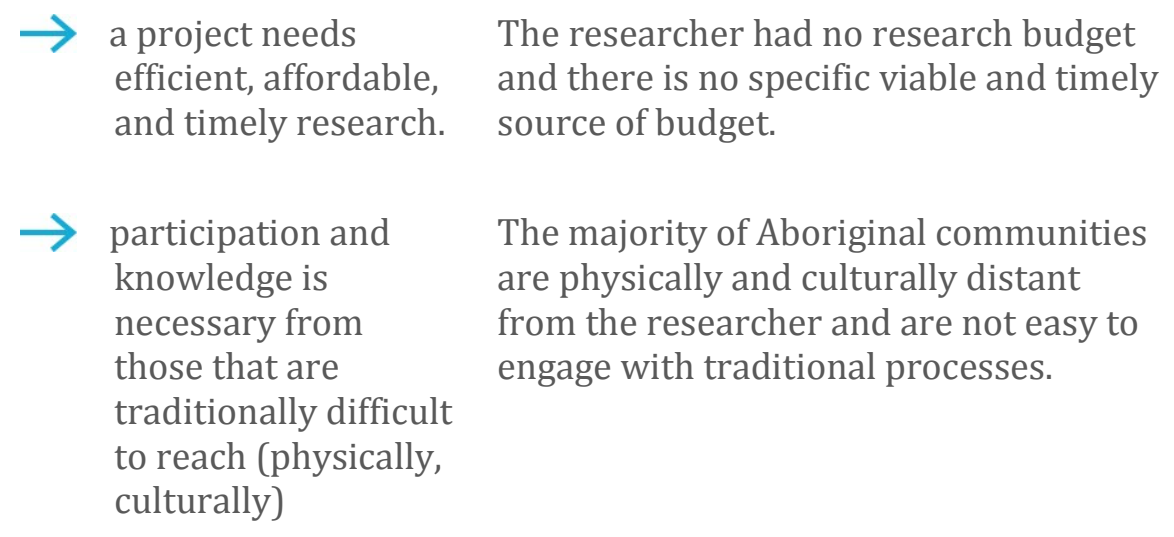

Table 13 Project research area identification using PD-ICT guidelines

Identifying the main themes of the movement through a design lens by means of the Project Identification category represented a necessary first step before any specific attempts at development begin. In this context, the guidelines have played a necessary role in grounding any potential project's focus area before more specific design and development interventions are proposed or implemented. They also provided evidence and set the context for the 'Idle No More' movement being an appropriate area for design and development to leverage ICT and social technologies.

The researcher's ability to identify the themes of the movement depended on the application of a set of research techniques spanning breadth vs. depth, and in-person vs. digital.

\section{Interviews}

Interviews were a necessary form of research, that while the most demanding in terms of arrangement and execution, provided depth and insight that wouldn't have otherwise been achievable using other techniques. While these interviews were casual in nature, and were too few from which to extract any patterns, they provided valuable colour and personal empathy.

\section{In-Person Ethnography}

The researcher was fortunate that he was located in close geographic proximity to opportunities for physical ethnography. The physical nature of the movement with protests, rallies, and forums presented many opportunities to conduct in-person ethnography. This ethnography was a necessary process to ensure a suitable balance between physical and 
digital interaction. This research provided the researcher with a critical human face and voice behind the movement. It represented the most balanced approach between breadth and depth of research.

\section{Digital Ethnography}

Digital Ethnography provided the breadth that physical ethnography and interviews were not able to. By leveraging ICT and social technologies as well as social analytics software, the sole researcher with no budget was able to analyze the movement at a significant level of in-person depth and digital breadth in order to confidently state the primary underlying themes of the movement. Digital presents an intriguing prospect of passive research with which to validate, and inform future design research. While it is not reliable as a sole source of research, when layered with conventional in-person techniques it provides a valuable and previously unavailable scope of research breadth. It is important to note however that for digital ethnography to be a viable tool, it must be conducted on a movement or conversation that has sufficient existing online volume and participation, otherwise its key advantage (breadth and volume of research) will be difficult to meet.

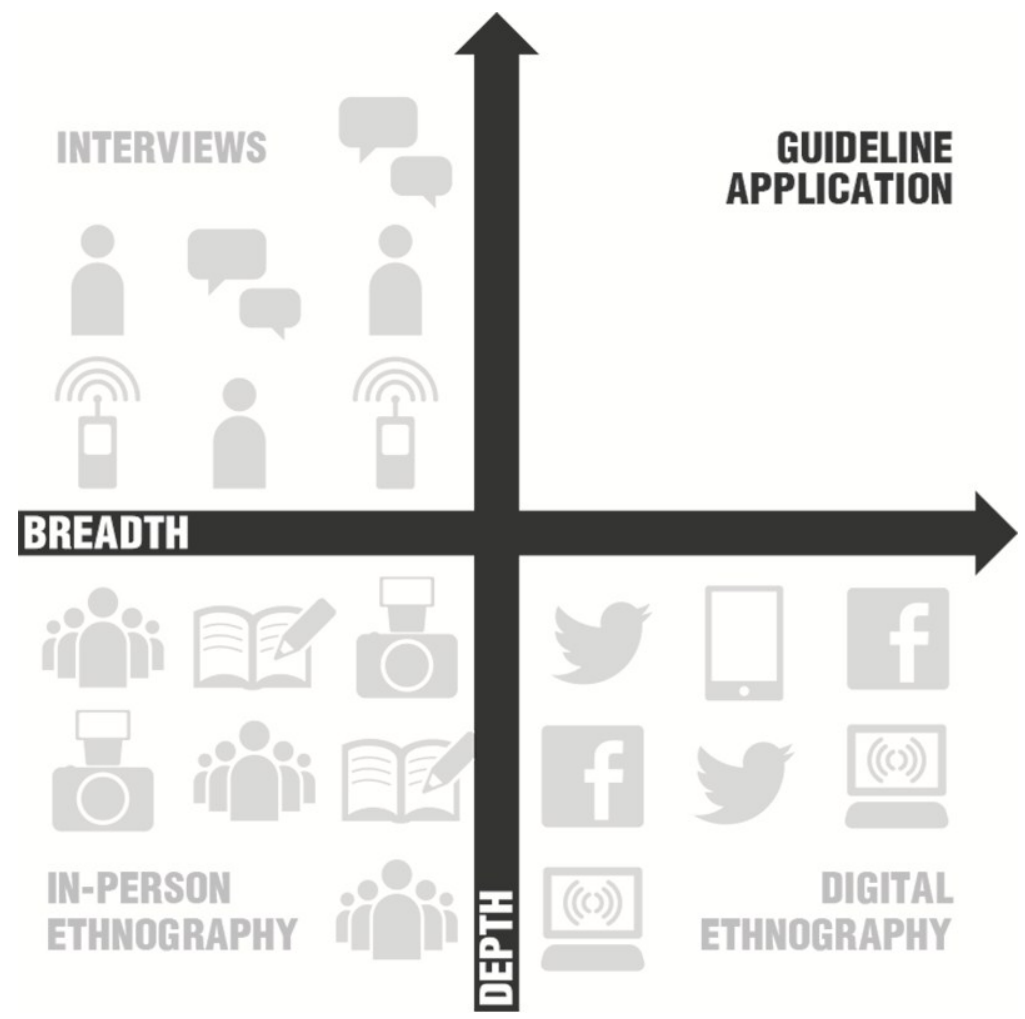

Figure 16 Breadth and depth of research techniques employed 


\subsection{Future Guideline Category Application}

While the events and current activity surrounding 'Idle No More', as well as the process of identifying a project, aren't yet examples of a higher-order collective intelligence, by leveraging ICT and this engaged community of vocal participants in the remaining guideline categories the ultimate project can hope to achieve it.

The findings would indicate that on a broader, nation-wide scope, the role for participatory design initiatives should be geared on the movement itself aimed at collective action mobilization. Design's role in creating a platform for collective action could manifest itself in the design of a system for mobilizing participants and furthering their cause in a more structured and organized manner so that their voices - which have traditionally been marginalized - can be heard in the hopes of achieving impact for their communities.

A potential example of such a project focus might be the development of a web-based service aimed at connecting geographically dispersed Aboriginal communities with a publically accessible repository of accounts, testimonials, and stories from other communities. The creation of a web-based service aimed at encouraging the sharing of stories and accounts can provide a platform to share the cultural pride to a broader population and empower communities to expose perceived violations or issues in their communities on a large scale.

Alternatively, if the future direction of the project focuses on a smaller, narrower, and more specific community-scale level, the process of participatory design could begin to address specific requirements of that community in a process of collective solution generation. 


\subsection{CONCLUSION}

The project sought to explore the growing overlap between three fields: participatory design, ICT4D and collective intelligence. In relation to the primary research question (Q1) identified at the outset of the project, the researcher was able to contribute towards a greater understanding of the applications of ICT and social technologies as design research tools within community-specific participatory design. This was accomplished through the creation of a set of guidelines meant to guide practitioners in the application of ICT and social technologies in within participatory design in the hopes of engaging a community's collective intelligence. The potential for the application of these guidelines was then explored in an ongoing social movement in order to progress the research beyond theory, given that the contributing fields of research were quite rich in promise with few examples of evidence and successful applications.

In relation to the sub-questions, (SQ1, 2 and 3) the following conclusions were drawn from the research reinforced by their appearance in literature, the guidelines, and in application.

SQ1: What is the role of the individual or design firm's expertise within a participatory design process that leverages ICT and social technologies?

Within these processes, the role of the design expert needs to evolve towards that of a facilitator. Where traditional design approaches rely on the designer to research, interpret, synthesize and conceptualize solutions that are often biased by their own world-views and experiences, design for development requires a more participatory approach. While individual design expertise is still highly valuable and not to be overlooked, it must be aggregated with the knowledge of non-designers, and non-experts in order to have the potential to achieve the higher-order collective intelligence that these processes can enable. The designer must enable the conditions for participation, and be aware that participants are not capable of, and should not be tasked with highly complex work that would generally be within the realm of the design expert. Instead, the designer must enlist the participation of others to supplement tasks that are lower in complexity and would benefit from "more eyes" such as information gathering, idea generation, and evaluation. It is up to the designer to guide these processes and mediate the crowd's engagement within already familiar processes. 
SQ2: What are the ideal methods and tools to most actively engage a local community within community-specific participatory design?

Active community engagement in participatory design that employs ICT and social technologies is dependent on three critical factors: enlisting a diversity of stakeholders, understanding appropriate motivators, and using familiar technologies already engrained in people's lives. Having a diversity of stakeholders and community leaders engaged is critical to ensure the necessary diversity of opinions and experiences necessary to project success. Recruitment of these stakeholders and leaders will also generate trust and lend credibility to the project. The greater the understanding and use of intrinsic motivators in a project, the greater the likelihood of active engagement. The project should address a topic that people will be motivated to participate in for reasons greater than simple or superficial rewards. The project cannot rely solely on digital participation, and must have an in-person component as well to build trust, and enable the necessary depth of insights. For the components of the project that do rely on digital participation, it must be with tools and technologies participants are already familiar with, and have access to.

SQ3: How might community participation in design through the use of ICT and social technologies minimize external bias in social design initiatives?

Many failures in design and development work can often be attributed to a researcher or designer's bias when conducting work in a different culture or community. Participatory processes are able to alleviate and minimize the impact of this bias with the promise of leading to solutions that are derived from the local community, rather than interpreted through an outsider's world-view. Design and development must accept that local knowledge will always be difficult for outsiders to get, instead of attempting various often ill-advised techniques at gaining a local perspective. While an awareness of the local conditions and context is important, a participatory approach where the outsider acts as a facilitator and engages large amounts of locals and their local knowledge will enable design and development to conduct projects in more efficient, timely, and better-informed manners.

\subsection{Contributions to the Field}

Advancing conceptual theory towards actionable guidelines 
The chosen fields of research - participatory design, collective intelligence, and ICT4D - each have strong conceptual foundations of great promise to radically alter how complex challenges will be addressed in the future. It is easy to become excited about the potential that these fields hold for a more participatory future where society is able to collectively address the challenges it faces in unprecedented ways. Where these fields have struggled is in providing concrete evidence or examples that these approaches are in fact desirable, as well as plans for actually implementing the theory in practice. The goal of this research was to leverage experience and theory in these fields to advance ideas beyond excitable rhetoric towards creating sufficient knowledge with which practitioners can employ and test the emergent theory of these fields. By creating and applying a set of guidelines that represent leading academic theory and best practice in the field, the research progressed theory towards an actionable state.

\section{Providing structure for future practitioners}

While many within design and development recognize the potential that participatory processes and ICT hold for significantly advancing projects by engaging people and beginning to leverage collective intelligence, few have undertaken these approaches. This is primarily attributable to a lack of clarity, direction, and prior evidence. For those working in development, there is a strong preference for accountability, and minimizing risk due to volatile project funding as well as the often serious implications of squandering projects. These conditions do not lend themselves to experimentation or exploration with new, unproven techniques.

The developed guidelines provide grounds and structure for practitioners to begin to employ these approaches in a less risky scenario. The fact that they have been developed in collaboration with actual practitioners, and reinforced with theory will hopefully prove appealing for those interested in the promise of these fields, yet until now have lacked direction for employing them.

\section{Progressing theory on the role of design and design research in human development}

As evidenced by the 2012 Clinton Global Initiative's Annual Meeting's theme "Designing for Impact", the role design played in conversations at the 2013 World Economic Forum, as well as the emerging partnerships seen between design firms and development agencies, design is increasingly playing a larger role in development. While for some, the connections between design and development are natural and apparent, there remains 
room for much exploration and explanation into the role that design can, and should play in development work. This research served to build more connections for design in development, and advance the conversation on why design should be sought after for its potential impact in reinvigorating development initiatives with progressive approaches. It also equips designers and firms with a set of guidelines that aim to increase credibility, efficiency, and impact of design for development initiatives.

\section{Advancing theory and application of ICT in design research}

Design and design research will not be immune to advancements in the way people interact and communicate. As of the writing of this research, design research processes still rely rather heavily on the traditional research with an emphasis on face-to-face component interaction and observation. This research has progressed the conversation on how design research will evolve in the future to employ more digital tools as a reflection of an increasingly digital society. The explorations into digital ethnography as a viable design research tool, has shed light on how design research will evolve as it becomes attuned to new evolving behaviours and communication norms.

\subsection{Limitations}

\section{Only applied a component of guidelines}

Due to the limitations and timeline of the project, the researcher was only to apply the Project Identification category of guidelines. The guidelines themselves contain many guiding principles and statements, thereby limiting their applicability to a wide range of projects. Due to the scope and richness of the guidelines, it appears as though it may be difficult to ensure the appropriate conditions in a project or scenario are met in order to make use of the full set of guidelines. This may potentially limit the range of applications for the guidelines to a limited type of project or rare scenario.

\section{Difficulty in evaluating effectiveness}

Without applying the full set of guidelines, it is difficult to evaluate their effectiveness and appropriateness. The researcher was not able to comment or discuss whether or not the guidelines themselves are useful without actually applying them in a coherent project, however this does provide rich grounds for future research.

\section{Determining rigidity of adherence to guidelines}


As previously mentioned, the guidelines contain 35 points, 11 of which are guiding principles. Seeing as how they have not been applied in full, it is difficult to comment on how rigidly they must be observed. This will be an important clarification to make in future work as strict and rigid adherence will likely be difficult to achieve, and could attempts at such could have a negative and inhibiting impact on work.

\subsection{Future Research}

Apply all categories of guidelines in a cohesive project

Future research will require the application of all guideline categories in a cohesive project as to test their effectiveness, applicability, and suitability in community-specific participatory design and development projects. Only by testing the guidelines as a cohesive set in a project will it become possible to evaluate them and their potential appropriately.

\section{Research evidence of collective intelligence}

While the guidelines were developed in order to enable the collective intelligence of participants to emerge, the actual application did not provide evidence or an opportunity to evaluate whether or not this was actually occurring. It is in applying the full set of guidelines that the true potential of collective intelligence will conceivably emerge; the impact of which would be significant to propagate the use of the guidelines.

\section{Conduct a comparative study using guidelines versus traditional methods}

Naturally, while the guidelines need to be tested in their entirety, there is also the potential to evaluate them in a comparative study versus traditional methods. These traditional methods of design and development are the ones that the application of these guidelines promises to advance and progress. However, to emerge beyond the aforementioned rhetoric and promise, there needs to be evidence that these approaches are in fact more likely to succeed and lead to more favourable outcomes under the right conditions. It is not only the promise and mechanics of collective intelligence that need to be tested to achieve greater credibility, but design's role in development as well that must stand up to scrutiny and evidence in order to continue on its current path of playing a larger role in the world's development challenges. 


\section{LIST OF REFERENCES}

AANDC. (2013, March). Aboriginal Connectivity Profiles of Ontario - As of March 2013. Retrieved May 5 $5^{\text {th }} 2013$ from http://www.aadncaandc.gc.ca/eng/1352223782819/1353504825398?p=on

Aker, J., \& Mbiti, I. (2010). Mobile Phones and Economic Development in Africa. Journal of Economic Perspectives, 24(3), 207-232.

Atlee, T., \& Por, G. (April 10, 2012). Collective Intelligence as a Field of Multi-disciplinary Study and Practice. 1-4. Retrieved from http://www.community-intelligence.com

Atlee, T., \& Zubizarreta, R. (2003). The Tao of democracy: using co-intelligence to create a world that works for all. Cranston, RI: Writers' Collective.

Avgerou, C. (2010). Discourses on ICT and Development. Information Technologies \& International Development, 6(3), 1-18.

Bjögvinsson, E., Ehn, P., \& Hillgren, P-A. (2012). Design Things and Design Thinking: Contemporary Participatory Design Challenges. Design Issues, 28(3), 101-116.

Bojin, N., Shaw.C., \& Toner, M. (2011). Designing and deploying a 'compact' crowdsourcing infrastructure; A case study. Business Information Review, 28(1), 41-48.

Bonabeau, E. (2009). Decisions 2.0: The Power of Collective Intelligence. MIT Sloan Management Review, 50(2), 44-53.

Brabham, D. (2008). Crowdsourcing as a Model for Problem Solving: An Introduction and Cases. Convergence: The International Journal of Research into New Media Technologies, 14(1), 75-90.

Brown, T. (2009). Change by Design: How Design Thinking Transforms Organizations and Inspires Innovation. New York: Harper Business

Chambers, R. (1981). Rapid Rural Appraisal and Development. Public Administration and Development, 1, 95-106.

Chambers, R. (1994). The Origins and Practice of Participatory Rural Appraisal. World Development, 23(7), 953-969.

Cornwall, A. (2002). Beneficiary, Consumer, Citizen: Perspectives on Participation for Poverty Reduction. Stockholm: Sida

Creswell, J. (2008). Research Design: Qualitative, Quantitative and Mixed Methods Approaches. Los Angeles: SAGE Publications

Cross, N. (2007). Designerly Ways of Knowing. Boston: Birkhauser

Easterly, W. (2006). The white man's burden: why the West's efforts to aid the rest have done so much ill and so little good. New York: Penguin Press 
Fathianathan, M., Panchal, J.H., \& Nee, A.Y.C. (2009). A Platform for Facilitating Mass Collaborative Product Realization. CIRP Annals - Manufacturing Technology, 58(2009), 127-130.

Glaser, B., \& Strauss, A. (1967). The Discovery of Grounded Theory: Strategies for Qualitative Research. New Jersey: Aldine Transaction.

Glaser, B. G. (1992). Emergence vs. forcing: Basics of grounded theory analysis. Mill Valley, CA: Sociology Press.

Glaser, B. G. (1998). Doing grounded theory: Issues and discussions. Mill Valley, CA: Sociology Press.

Hagen, P., \& Robertson, T. (2009). Dissolving Boundaries: Social Technologies and Participation in Design. Ozchi, 1-8.

Hagen, P., \& Robertson, T. (2012). Social Technologies: The Changing Nature of Participation in Design. Design Issues, 28(3), 77-88.

Heeks, R. (2008). ICT4D 2.0: The Next Phase of Applying ICT for International Development. Computer, 41(6), 26-33.

Hickey, S., \& Mohan, G. (2004). Participation: From Tyranny to Transformation? New York: Zed Books.

Howe, J. (2006). The Rise of Crowdsourcing. Wired Magazine, 14(6), Retrieved from http://www.wired.com/wired/archive/14.06/crowds_pr.html

Hussain, S., Sanders, E.B., \& Steinert, M. (2012). Participatory design with marginalized people in developing countries: Challenges and opportunities experienced in a field study in Cambodia. International Journal of Design, 6(2), 91-109.

Idle No More. (2012). 2012 Events Map. Retrieved May 5th, 2013 from http://idlenomore.ca/inm-events/2012-events-map

Ireland, C. (2003). Qualitative Methods: From Boring to Brilliant. In Laurel. B. Editor (Ed.) Design Research: Methods and Perspectives. Cambridge, Massachusetts: MIT

Jo, A., Tacchi. J., \& Watkins, J. (2007). Participatory Research and Creative Engagement with ICT. In Proceedings ACM Sensys 2007 workshop "Sensing on Everyday Mobile Phones in Support of Participatory Research", Retrieved from http://eprints.qut.edu.au

Juarez, J., \& Brown, K. (1997). Extracting or Empowering? A Critique of Participatory Methods for Marginalized Populations. Landscape Journal, 27(2), 190-203.

Kleine, D., \& Unwin, T. (2009). Technological Revolution, Evolution and New Dependencies: what's new about ICT4D? Third World Quarterly, 30(5), 1045-1067.

Lévy, P. (1995). Collective Intelligence: Mankind's Emerging World in Cyberspace. New York: Plenum 
Lévy, P. (2013). The Creative Conversation of Collective Intelligence. Chapter 11 in The Participatory Cultures Handbook, New York: Routledge.

Lykourentzou, I., Vergados, D.J., \& Loumos, V. (2009). Collective Intelligence System Engineering. Proceedings of the International Conference on Management of Emergent Digital EcoSystem, 132-140.

Maher, ML., Paulini, M., \& Murty, P. (2010). Scaling Up: From Individual Design to Collaborative Design to Collective Design. Design Computing and Cognition DCC'10, 581-600.

Malone, T., Laubacher, C., \& Dellarocas, C. (2009). Harnessing Crowds: Mapping the Genome of Collective Intelligence. MIT Center for Collective Intelligence, 2-10.

Manzini, E. (2007). Design, social innovation and sustainable ways of living: Creative communities and diffused social enterprise in the transition towards a sustainable network society. DIS Indaco, Milan.

Margolin, V. (2007a).Design for Development: Towards a History. Design Studies, 28, 111115.

Margolin, V. (2007b). Design, the Future and the Human Spirit. Design Issues, 23(1), 4-15.

Martin, B., \& Hannington, B. (2012). Universal Methods of Design: 100 Ways to Research Complex Problems, Develop Innovative Ideas, and Design Effective Solutions. Beverly, Massachusetts: Rockport Publishers.

Masten, D., \& Plowman, T. (2003). Digital Ethnography: The Next Wave in Understanding the Consumer Experience. Design Management Journal, 14(2), 75-81

Murthy, D. (2008). Digital Ethnography: An Examination of the Use of New Technologies for Social Research. SAGE Publications, 42(5), 837-855

Murty, P., Paulini, M., \& Maher, ML. (2010). Collective Intelligence and Design Thinking. DTRS '10: Design Thinking Research Symposium, 309-315.

Papanek, V. (1985). Design for the Real World; Human Ecology and Social Change. New York: Pantheon Books

Parliament of Canada. (2012, March 29). Bill C-45. Retrieved May 5th 2013 from http://parl.gc.ca/HousePublications/Publication.aspx?DocId=5765988

Paulini, M, Maher, ML and Murty, P. (2011) The role of collective intelligence in design, In Proceedings of the 16th International Conference on Computer Aided Architectural Design Research in Asia, 687-696.

Peterson, S., \& Hussain, S. (2012). Design Insights from User Research and Crowdsourcing. Design Management Review, 23(3), 60-68.

Pilloton, E. (2009). Design revolution: 100 products that empower people. New York: Metropolis Books 
Plowman, T. (2003). Ethnography and Critical Design Practice. In Laurel. B. Editor (Ed.) Design Research: Methods and Perspectives. Cambridge: MIT

Poetz, M., \& Schreier M. (2012). The Value of Crowdsourcing: Can Users Really Compete with Professionals in Generating New Product Ideas? Journal of Product Innovation Management, 29(2), 245-256.

Press, J., \& Woods, M. (2013, April 10). Idle No More movement 'different' from anything the government had ever seen before, documents reveal. Postmedia News. Retrieved May 6th, 2013 from

http://www.ottawacitizen.com/news/national/Idle+More+movement+different+ from+anything+government+ever/8218741/story.html

Samii, R. (2009). Mobile phones: the silver bullet to bridge the digital divide? Chapter 6 in Change at hand: Web 2.0 for development. 44-51.

Sanders. E., Brandt, E., \& Binder, T. (2010). A Framework for Organizing the Tools and Techniques of Participatory Design. ACM, 195-198.

Sanders, E., \& Stappers, P.J. (2008). Co-creation and the new landscapes of design. CoDesign,4(1), 1-16.

Sanoff, H. (2006). Multiple Views of Participatory Design. META JFU, 23(2), 131-143.

Saxton, G., Oh, O., \& Kishore, R. (2013). Rules of Crowdsourcing: models, Issues and Systems of Control. Information Systems Management, 30(1), 2-20.

Schumacher, E.F. (1973). Small is Beautiful; Economics as if People Mattered, Harper \& Row, New York

Seltzer, E., \& Mahmoudi, D. (2012). Citizen Participation, Open Innovation, and Crowdsourcing: Challenges and Opportunities for Planning. Journal of Planning Literature, 28(1), 3-18.

Shirky, C. (2009). Here Comes Everybody: The Power of Organizing Without Organizations. New York: Penguin Books

Spinuzzi, C. (2005). The Methodology of Participatory Design. Technical Communication, 52(2), 163-174.

Surowiecki, J. (2005). The Wisdom of Crowds: why the many are smarter than the new. London: Abacus.

Steers,M., Sanchez-Runde, C.J., \& Nardon, L. (2010). Management Across Cultures: Challenges and Strategies. Cambridge: Cambridge University Press

Topsy. (2013). How We Do It. Retrieved from http://about.topsy.com/technology/overview/

Twitter. (2013) Using Hashtags on Twitter. Retrieved from https://support.twitter.com/entries/49309-what-are-hashtags-symbols 
UNDP. (2001). Human Development Report: Making New Technologies Work for Human Development. New York: Oxford. Retrieved from http://hdr.undp.org/en/reports/global/hdr2001/ 


\section{APPENDIX A}

Hello (recipient's name),

My name is Michael Grigoriev, and I am currently a second year Master of Design student at Carleton University in Ottawa, Canada. My research deals with the fields of participatory design, crowdsourcing, and ethnographic design research. The primary research objective is to create a framework for employing community-specific tacit knowledge within participatory design research by creating guidelines for the suitable applications of crowdsourcing as an ethnographic tool.

I'm currently in a position to conduct my own primary research, which involves the development of guidelines driven by an extensive literature review and with the collaboration of practicing experts through semi-structured interviews.

I would like to invite you to take part in an interview on this topic. The semi-structured telephone interview will take 30-60 minutes of your time and at a time convenient to you.

If you are able or interested to participate any further in this research, please let me know and we can arrange a time that works for your schedule.

Once again, your input would be extremely valuable and your time is greatly appreciated.

This research project has been reviewed and cleared by the Carleton University Research Ethics Board, if you have any questions or concerns you may contact Prof. Andy Adler, Chair \& Prof. Louise Heslop Vice-Chair at 613-520-2517 or at ethics@carleton.ca

Sincerely,

\section{Michael Grigoriev}

B. ID, MDes Candidate (2013)

Carleton University

Supervisor:

Prof. Thomas Garvey

School of Industrial Design

613-520-5674

Thomas garvey@carleton.ca 


\section{APPENDIX B}

Hello, I'm Michael Grigoriev, and I would like to review the purpose of this research project and your rights as a research participant.

I am conducting a research study on the potential applications of crowdsourcing as a design research tool. I am conducting this research as part of my Master of Design studies at Carleton University, in Ottawa, Canada.

I would like to interview you about (relevant subject matter)

The interview will take 30-60 minutes, and will be audio-recorded with your permission. The interview will then be transcribed by me as part of my research notes. All audio recording will be destroyed at the end of the project in May 2013.

There are no risks or harm associated with participating in the interview, and you have the right to not answer questions and end the interview at anytime. You may also withdraw from the study anytime before April 1st, 2013 by contacting me or my supervisor by telephone or email.

I will identify you in the final research thesis. You have the right to ask that any comments or opinions remain unattributed to you in the thesis or any other presentations of the research results. However, given the small sample size for this study this may not fully protect your identity.

Transcripts of the recorded interview will be sent by e-mail for your approval before being used.

The benefits of participating are contributing towards research in order to better understand the applications of ICT within design research, and how to better inform design research in unfamiliar contexts and cultures by leveraging local tacit knowledge. The information you provide during the interview will be used in generating guidelines for further research, and intents will be made to have the findings published.

I would be happy to send a short summary of the study results after analysis and synthesizing research findings.

Do you have any questions or would like any additional details?

Do you agree to participate in this study knowing that you can withdraw at any point by contacting me or my supervisor by telephone or email? 


\section{APPENDIX C}

Organization Descriptions and Participant Biographies

\begin{tabular}{|c|c|c|c|}
\hline PARTICIPANT & BIO & ORGANIZATION & DESGRIPTION \\
\hline Panthea Lee & $\begin{array}{l}\text { Panthea is Reboot's lead designer, } \\
\text { focused on the practical } \\
\text { applications of ethnography and } \\
\text { systems thinking in delivering } \\
\text { effective international } \\
\text { development and governance } \\
\text { programs. She oversees all aspects } \\
\text { of the program management } \\
\text { process, including research, } \\
\text { design, implementation, and } \\
\text { evaluation. }\end{array}$ & \multirow[t]{2}{*}{ REß30OT } & \multirow{2}{*}{$\begin{array}{l}\text { Reboot is a global } \\
\text { social enterprise } \\
\text { working at the } \\
\text { intersection of } \\
\text { design, technology, } \\
\text { public policy, and } \\
\text { service delivery. The } \\
\text { Reboot is engaging } \\
\text { governments and } \\
\text { development } \\
\text { agencies with design } \\
\text { principles aimed at } \\
\text { addressing } \\
\text { significant social and } \\
\text { policy challenges. }\end{array}$} \\
\hline $\begin{array}{l}\text { Jeremy } \\
\text { Canfield }\end{array}$ & $\begin{array}{l}\text { Jeremy is Reboot's resident } \\
\text { technologist and human-computer } \\
\text { interaction genii. He focuses on } \\
\text { translating design research } \\
\text { insights into innovative, intuitive, } \\
\text { and useful user experiences. } \\
\text { Jeremy comes to Reboot from a } \\
\text { career in civic tech where he has } \\
\text { specialized in developing open } \\
\text { government platforms. }\end{array}$ & & \\
\hline Noel Wilson & $\begin{array}{l}\text { Noel is a Lead Designer for } \\
\text { Catapult Design in San Francisco, a } \\
\text { product and process design firm } \\
\text { developing tools to alleviate } \\
\text { poverty within disadvantaged } \\
\text { communities. An Industrial } \\
\text { Designer by training, Noel } \\
\text { previously worked in rapid } \\
\text { prototyping, playground design, } \\
\text { education, and bicycle } \\
\text { empowerment. }\end{array}$ & & $\begin{array}{l}\text { Catapult Design } \\
\text { works on } \\
\text { development } \\
\text { projects spanning the } \\
\text { entire design process } \\
\text { with underserved or } \\
\text { low-income } \\
\text { communities around } \\
\text { the world. }\end{array}$ \\
\hline George Aye & $\begin{array}{l}\text { George co-founded Greater Good } \\
\text { Studio to increase the impact of his } \\
\text { user-centered design practice. He } \\
\text { remains wildly optimistic that we } \\
\text { can solve the most entrenched } \\
\text { problems of our time, together for } \\
\text { the greater good. }\end{array}$ & \multirow{2}{*}{$\frac{+}{\# \text { Designing Chicago }}$} & \multirow{2}{*}{$\begin{array}{l}\text { The Greater Good } \\
\text { Studio spearheaded } \\
\text { the Designing } \\
\text { Chicago Project; a } \\
\text { crowdsourced design } \\
\text { project for building a } \\
\text { better transit apps } \\
\text { that is one of the first } \\
\text { examples of } \\
\text { participatory design } \\
\text { with digital and } \\
\text { physical engagement. }\end{array}$} \\
\hline $\begin{array}{l}\text { Annemarie } \\
\text { Spitz }\end{array}$ & $\begin{array}{l}\text { Annemarie's design work has } \\
\text { focused on understanding complex } \\
\text { human systems and facilitating } \\
\text { small interventions to spark } \\
\text { change toward a more joyful } \\
\text { world. She believes that if you } \\
\text { watch and listen closely, } \\
\text { opportunities can be found in } \\
\text { every challenge. }\end{array}$ & & \\
\hline
\end{tabular}




\section{APPENDIX D}

\section{Research Event Descriptions}

EVENT DATE LOGATON DESCRIPTION

\begin{tabular}{|c|c|c|c|}
\hline & & & $\begin{array}{l}\text { With worldwide support growing for Canada's First } \\
\text { Nations' Idle No More protest movement, protest } \\
\text { organizers around the world organized a Global Day of } \\
\text { Action scheduled for Friday, January 11th. }\end{array}$ \\
\hline $\begin{array}{c}\text { Global Day of } \\
\text { Action }\end{array}$ & $\begin{array}{c}\text { January } \\
11^{\text {th }}, 2013\end{array}$ & $\begin{array}{c}\text { Parliament Hill - } \\
\text { Ottawa }\end{array}$ & $\begin{array}{l}\text { The day coincided with a scheduled meeting between } \\
\text { Canadian Prime Minister Stephen Harper and First Nations } \\
\text { leaders-including Chief Theresa Spence whose hunger } \\
\text { strike, which began roughly one month ago, sparked the } \\
\text { mass movement for indigenous rights. }\end{array}$ \\
\hline
\end{tabular}

The group called upon communities around the world to organize under the motto: "Anything. Everything.

Anywhere. Everywhere." The demonstrations will be designed to show "support for the rising global Indigenous Peoples Movement by taking action in your community."

As Idle No More continues to grow across Canada and the world, the Indigenous (First Nations, Metis \& Inuit) youth voice needs to be louder and stronger than ever before.

For the purpose of this Youth Forum, the proposed age requirements will be 13-30. All nations, creeds and genders will be invited to this important forum to engage in the immediate need to educate the youth on the recent Bills being passed through legislation, the creation and goals of Idle No More, Chief Theresa Spence's Hunger Strike and spiritual awakening, a history of colonization and most importantly youth to youth empowerment and growth.

Collaborating with all youth, non-Indigenous and Indigenous is a key goal for this Forum as well as in future relationship building.

This Forum will be for youth, by youth.

A journey of mythic proportions is being undertaken by six very courageous Cree Youth under 20 yrs old and one very wise Guide. They are walking from Whapmagoostui in Northern Quebec to Parliament Hill in Ottawa. They bring a strong message to prove to other First Nations across

Arrival of the Nishiyuu Walkers
March

$25^{\text {th }}, 2013$
Victoria Island, Wellington St, Parliament Hill Ottawa
Canada that the Cree Nation of Quebec are not sellouts, but keepers of the Language, Culture, Tradition and more importantly; still carry the sacred laws of our ancestors.

This Quest-Journey will establish and unite our historical allies and restore our traditional trade routes with the Algonquin, Mohawk and other First Nations. The time for Unity is now. 


\section{APPENDIX E}

Top 50 Most Influential \#idlenomore Tweets from January 10-12, 2013. (Topsy, 2013)

\begin{tabular}{|c|c|c|c|}
\hline Influence & \# Tweets & Tweet Content & Theme \\
\hline 1 & 1000 & $\begin{array}{l}\text { Was just offered Queen Elizabeth II Diamond Jubilee Medal from } \\
\text { GG. I respectfully decline in solidarity with hunger strikers } \\
\text { +\#IdleNoMore }\end{array}$ & Community \\
\hline 2 & 395 & $\begin{array}{l}\text { Amazing how obsessed the media is with telling a story of division } \\
\text { around\#idlenomore. Journalism with an agenda can be so } \\
\text { harmful. \#cbc }\end{array}$ & Cultural Unity \\
\hline 3 & 494 & $\begin{array}{l}\text { IdleNoMore is } 4 \text { everyone. It is not just an 'Indian } \\
\text { thing'!!!\# } 11 \text { http://t.co/1Col3s8B }\end{array}$ & Cultural Unity \\
\hline 4 & 370 & $\begin{array}{l}\text { Following @NaomiAKlein 's lead and respectfully declining my } \\
\text { recently offered Queen Elizabeth II Diamond Jubilee Medal from } \\
\text { GG!\#Idlenomore }\end{array}$ & Community \\
\hline 5 & 598 & $\begin{array}{l}\text { Youth are engaged. Older generations are standing strong. } \\
\text { Canadians of all backgrounds are offering support. Change is } \\
\text { here\#idlenomore }\end{array}$ & Cultural Unity \\
\hline 6 & 820 & $\begin{array}{l}\text { The t-shirt says, "Canada- Our Home On Native Land".. I couldn't } \\
\text { agree more.\#idlenomorehttp://t.co/cBryCC18 }\end{array}$ & Cultural Unity \\
\hline 7 & 162 & $\begin{array}{l}\text { Talks with First Nations Chiefs, boycott, and\#IdleNoMoreprotests are } \\
\text { now a top story on\#BBC News site -http://t.co/PfZA22Rx \#cdnpoli }\end{array}$ & \\
\hline 8 & 166 & $\begin{array}{l}\text { For Immediate Release@ChiefTheresaOfficial Press Release on Jan } \\
11,2013 \text {, Please Share\#idlenomorehttp://t.co/08cr4dFh }\end{array}$ & \\
\hline 9 & 144 & $\begin{array}{l}\text { The Attawapiskat audit: Distracting us from a legacy of } \\
\text { failurehttp://t.co/eNgo8JS0 \#gpc\#idlenomore\#cdnpoli -hs }\end{array}$ & \\
\hline 10 & 131 & $\begin{array}{l}\text { \#J11 actions are planned for } 190 \text { cities worldwide } \\
\text { tomorrow:http://t.co/KMFO3IFA \#IdleNoMore\#NextChapte }\end{array}$ & Cultural Unity \\
\hline 11 & 67 & $\begin{array}{l}\text { Our friends at Amnesty Canada! RT@amnestynow: Act now! Idle No } \\
\text { More: A crucial call for justice:http://t.co/eGQbfru8 \#IdleNoMore }\end{array}$ & Accountability \\
\hline 12 & 65 & No organization speaks on behalf of Idle No More\#idlenomore & Cultural Unity \\
\hline 13 & 154 & $\begin{array}{l}\text { Very moving grassroots people coming together in Canada to } \\
\text { respect Mother } \\
\text { Earth.\#IdleNoMore\#Anonymous\#OWShttp://t.co/Sd4nEJdM }\end{array}$ & Respect \\
\hline 14 & 101 & $\begin{array}{l}\text { I stand in full and loving solidarity with \#IdleNoMoreand all } \\
\text { words/actions that highlight the dignity of indigenous brothers and } \\
\text { sisters. }\end{array}$ & Cultural Unity \\
\hline 15 & 96 & $\begin{array}{l}\text { Chills up my spine as Chief Fox says "the treaties are still alive within } \\
\text { us"\#idlenomore }\end{array}$ & Accountability \\
\hline 16 & 239 & $\begin{array}{l}\text { Bill C-45 removes } 99 \% \text { of Canada's lakes and rivers from the } \\
\text { protected list:http://t.co/sleVUgfV \#IdleNoMore\#NoKXL }\end{array}$ & Mistrust \\
\hline 17 & 394 & $\begin{array}{l}\text { On BC ferry this AM got a beautiful gift from woman from } \\
\text { KwaKwaKewak Nation (Alert Bay)\#idlenomorehttp://t.co/VCRfMMmD }\end{array}$ & \\
\hline 18 & 105 & $\begin{array}{l}\text { Here's the watershed moment from tonight: Chief Wallace Fox } \\
\text { speech to supportershttp://t.co/j1 } x \text { kl3xL\#idlenomore }\end{array}$ & \\
\hline 19 & 154 & $\begin{array}{l}\text { For Immediate Release@ChiefTheresaOfficial Press Release on Jan } \\
12,2013 \text {, Please Share\#idlenomorehttp://t.co/CYjbh4aj }\end{array}$ & \\
\hline 20 & 33 & $\begin{array}{l}\text { Even during the } 2008 \text { prorogation crisis, media were not forced off } \\
\text { behind the gates of Rideau Hall.\#idlenomore\#cdnpoli }\end{array}$ & \\
\hline 21 & 130 & $\begin{array}{l}\text { Canadians, your government is selling us ALL } \\
\text { out:http://t.co/y2THZohU \#idlenomore }\end{array}$ & Mistrust \\
\hline 22 & 182 & $\begin{array}{l}\text { There's power in seeing a real conversation around native \& First } \\
\text { Nations issues in mainstream media. The\#ldleNoMoreimpact is } \\
\text { undeniable }\end{array}$ & Empowerment \\
\hline 23 & 109 & $\begin{array}{l}\text { Ontario. Manitoba. Dene Nation. Saskatchewan. Atlantic region. All } \\
\text { boycotting meeting with Harper tomorrow.\#ldleNoMore }\end{array}$ & Cultural Unity \\
\hline 24 & 28 & $\begin{array}{l}\text { After Chief Spence's demands that the media publish the } \\
\text { facts,@JenTryon of Global News asks why she won't answer any } \\
\text { questions.\#IdleNoMore }\end{array}$ & \\
\hline 25 & 112 & $\begin{array}{l}\text { John Lennon on First Nations. So } \\
\text { awesome.http://t.co/RhVoXegl \#idlenomore }\end{array}$ & \\
\hline
\end{tabular}




\begin{tabular}{|c|c|c|c|}
\hline 26 & 31 & $\begin{array}{l}\text { Meeting to take place tonight at@ThomasMulcair's residence with } 20 \\
\text { chiefs. Spence will not be present.\#cdnpoli\#idlenomore }\end{array}$ & \\
\hline 27 & 88 & \#idlenomore at the gates of PM's officehttp://t.co/q6QAssgv & \\
\hline 28 & 54 & $\begin{array}{l}\text { Chief Spence's hunger strike will continue, says her spokesperson. } \\
\text { He says they did not "feel the honour" in tonight's } \\
\text { meeting\#idlenomore }\end{array}$ & Mistrust \\
\hline 29 & 32 & $\begin{array}{l}\text { \#IdleNoMore: think \#Occupy, but with deep, deep } \\
\text { roots.http://t.co/RGkQ74OB by }\end{array}$ & Cultural Pride \\
\hline 30 & 54 & $\begin{array}{l}\text { Canada's\#IdleNoMoremarches } \\
\text { on:http://t.co/sH2SOXGb \#Canada\#J11 \#RedFriday }\end{array}$ & Cultural Pride \\
\hline 31 & 72 & $\begin{array}{l}\text { Chiefs announce on January 16th highways and railways will be } \\
\text { blocked by\#IdleNoMoreprotesters.\#Jan } 16 \text { \#Canada }\end{array}$ & Empowerment \\
\hline 32 & 12 & This is how we do in Saskatoon\#idlenomorehttp://t.co/HjqAREmm & \\
\hline 33 & 40 & $\begin{array}{l}\text { There are dozens and dozens standing with Chief Spence in sitting } \\
\text { out meeting. They say other Chiefs can go\#idlenomore }\end{array}$ & Cultural Unity \\
\hline 34 & 66 & $\begin{array}{l}\text { Q: what happens if meeting is a disappointment? Atleo: Look } \\
\text { to\#idlenomore }\end{array}$ & \\
\hline 35 & 19 & $\begin{array}{l}\text { Why First Nations Movement Is Our Best Chance for Clean Land } \\
\text { and Water } \sim \text { Winona LaDukehttp://t.co/L23Rty } 41 \text { \#idlenomore }\end{array}$ & Respect \\
\hline 36 & 23 & $\begin{array}{l}\text { Union flags here too. Canadian Steelworkers, AFL/DIO/CLC local } \\
1005 \text { Hamilton\#idlenomorehttp://t.co/gDXGKh4a }\end{array}$ & Cultural Unity \\
\hline 37 & 112 & $\begin{array}{l}\text { This is what } 3,000 \text { Toronto IdleNoMore supporters walking together } \\
\text { down the street look like.\#idlenomore .http://t.co/keknliOk }\end{array}$ & Cultural Unity \\
\hline 38 & 153 & $\begin{array}{l}\text { Ironic reporters ask about "escalating violence" as a round dance } \\
\text { aka friendship dance breaks out\#idlenomore }\end{array}$ & Cultural Identity \\
\hline 39 & 61 & $\begin{array}{l}\text { \#idlenomore is the most hopeful thing since occupy--and its roots run } \\
\text { deep!http://t.co/HBnOinTE }\end{array}$ & Respect \\
\hline 40 & 42 & $\begin{array}{l}\text { Humbled \& honored that@Freeweatherused our song "Letter To My } \\
\text { Countrymen" in this video for } \\
\text { the\#IdleNoMoreMovementhttp://t.co/y4cCOrtx }\end{array}$ & \\
\hline 41 & 37 & $\begin{array}{l}\text { On BC ferry this AM got a beautiful gift from woman from } \\
\text { KwaKwaKewak Nation \#Lou-Ann } \\
\text { Neel!\#idlenomorehttp://t.co/w01ha4mD" }\end{array}$ & \\
\hline 42 & 47 & $\begin{array}{l}\text { First Nations ironworkers for\#ldleNoMore (via } \\
\text { Facebook)http://t.co/6gyemndn }\end{array}$ & Cultural Unity \\
\hline 43 & 43 & $\begin{array}{l}\text { So very sad watching the\#ldlenomoresituation unfold. Real, pressing } \\
\text { issues have been overtaken by process, acrimony and stakes-raising }\end{array}$ & Frustration \\
\hline 44 & 16 & $\begin{array}{l}\text { National Chief Shawn Atleo wants the meeting to go on; says worked } \\
\text { hard for it; acknowledges neither he nor AFN are perfect.\#idlenomore }\end{array}$ & Cultural Unity \\
\hline 45 & 29 & $\begin{array}{l}\text { Anne Murray: Is Enbridge pipeline a threat to important marine birds } \\
\text { in B.C.?http://t.co/mO4Y2FdZ via@georgiastraight\#idlenomore }\end{array}$ & Respect \\
\hline 46 & 67 & $\begin{array}{l}\text { I humbly offer my explanation. } \\
\text { Peace.\#idlenomorehttp://t.co/hHLgycmV }\end{array}$ & \\
\hline 47 & 17 & \#IdleNoMoreround dance in NYC.http://t.co/KGaaTIT6 & Cultural Pride \\
\hline 48 & 70 & $\begin{array}{l}\text { We need unity. Luckily, the people's movement\#idlenomorecould } \\
\text { provide the impetus for both hands to start working together }\end{array}$ & Cultural Unity \\
\hline 49 & 45 & $\begin{array}{l}\text { I count three women have refused to receive the Queen Elizabeth II } \\
\text { Diamond Jubilee Medal in solidarity with\#IdleNoMore. Women } \\
\text { leading. }\end{array}$ & Cultural Pride \\
\hline 50 & 124 & $\begin{array}{l}\text { i am extremely grateful to my non-native friends who are } \\
\text { taking\#idlenomore very seriously and showing support.\#RESPECT! }\end{array}$ & Cultural Unity \\
\hline
\end{tabular}


Top 50 Most Influential \#idlenomore Tweets from January 24-26, 2013. (Topsy, 2013)

\begin{tabular}{|c|c|c|c|}
\hline Influence & \# Tweets & Tweet Content & Theme \\
\hline 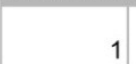 & 165 & $\begin{array}{l}\text { For Immediate Release @ChiefTheresa Official Press Release on Jan 24, 2013, } \\
\text { Please Share \#idlenomore http://t.co/yg073kM0 }\end{array}$ & \\
\hline 2 & 293 & $\begin{array}{l}\text { \#OpThunderbird nearly trending in Canada. Lets end racist, sexist violence } \\
\text { against indigenous women. \#IdleNoMore }\end{array}$ & Respect \\
\hline 3 & 190 & $\begin{array}{l}\text { UBC PhD student Sarah Klein gives powerful testimony v. \#Enbridgeat } \\
\text { Vancouver hearing (read here) http://t.co/0TSTmHH9 \#idlenomore\#BC }\end{array}$ & Education \\
\hline 4 & 137 & $\begin{array}{l}\text { WARNING: if someone sends you a link to Sun News DO NOT OPEN! It is a link } \\
\text { to actual Sun News... \#idlenomore\#UnNewsNetwork }\end{array}$ & \\
\hline 5 & 49 & $\begin{array}{l}\text { @PMHarper's C45 allows Oil leaks in \#Canada water without any penalty WAKE } \\
\text { UP \#idlenomore \#cdnpoli http://t.co/kAKSjJ7Rhttp://t.co/HtcZ5jlg }\end{array}$ & Accountability \\
\hline 6 & 68 & Miigwetch Chief Spence: a letter I wrote http://t.co/aU41KWVq\#idlenomore & \\
\hline 7 & 33 & $\begin{array}{l}\text { Chief Spence in hospital on IV and will miss 11am news } \\
\text { conference. \#breaking \#cdnpoli \#IdleNoMore }\end{array}$ & \\
\hline 8 & 17 & $\begin{array}{l}22 \text { mile long open pit mine "will produce } 900 \text { million tons of } \\
\text { waste"\#wiunion \#nomine \#idlenomore }\end{array}$ & Respect \\
\hline 9 & 62 & $\begin{array}{l}\text { In case you missed this (now deleted) exchange } \\
\text { between@ChiefTheresa and @TheBrazman here is a screen } \\
\text { cap:\#IdleNoMore http://t.co/DmgKbdyh }\end{array}$ & Respect \\
\hline 10 & 15 & Power to her: http://t.co/QDjKPKwe \#idlenomore \#bcpoli \#yyj \#bcndp & \\
\hline 11 & 80 & \#IdleNoMore World Day of Action - January 28, 2013http://t.co/7CAuLLEF \#J28 & Empowerment \\
\hline 12 & 26 & $\begin{array}{l}\text { Tonight \#idlenomore Women's Townhall will focus on women in the movement, } \\
\text { but this is not ceremony and men are welcome!http://t.co/K5rQhY7s }\end{array}$ & \\
\hline 13 & 14 & Please RT \#toronto \#idlenomore day of action Mondayhttp://t.co/tdsIQXtg & \\
\hline 14 & 49 & $\begin{array}{l}\text { 'Protect the Sacred' gathering of Indigenous Nations draft new treaty opposing } \\
\text { pipelines: http://t.co/7WSrdJfP \#NoKXL \#IdleNoMore }\end{array}$ & Cultural Unity \\
\hline 15 & 93 & $\begin{array}{l}\text { When \#idlenomore said we were in this } 4 \text { long haul } 2 \text { protect lands, waters, } \\
\text { sovereignty, and restore sharing in treaty relation, we meant it }\end{array}$ & Respect \\
\hline 16 & 18 & $\begin{array}{l}\text { PM Harper believes \#idlenomore movement creating "negative public reaction," } \\
\text { say confidential notes http://t.co/DouAOIGC }\end{array}$ & Mistrust \\
\hline 17 & 60 & January 28: Global Day of Action \#IdleNoMore \#cdnpolihttp://t.co/5WFHMSY3 & Empowerment \\
\hline 18 & 24 & $\begin{array}{l}\text { Sun News asking for more \#wealthfare (not to be confused with welfare because } \\
\text { rich people arent poor) \#idlenomore }\end{array}$ & \\
\hline 19 & 60 & $\begin{array}{l}\text { We all share the same water so make no mistake Bill c45 affects YOU! Being idle } \\
\text { is not an option anymore, silence is deadly\#idlenomore }\end{array}$ & Respect \\
\hline 20 & 13 & $\begin{array}{l}\text { "The government doesn't know how to deal with love or humour" a good reminder } \\
\text { from someone at the mic \#idlenomore }\end{array}$ & Frustration \\
\hline 21 & 25 & $\begin{array}{l}\text { \#IdleNoMore Rally to coincide w Fed Environment Min Peter Kent's visit } 2 \text { Guelph } \\
\text { Fri Jan. 25th, 11am Cutten Club, } 190 \text { College Ave. E pls RT }\end{array}$ & \\
\hline 22 & 15 & $\begin{array}{l}\text { @ChiefTheresa Spence cheapened the \#idlenomore movement. My latest } \\
\text { in @MacleansMag http://t.co/nZcSpo8L }\end{array}$ & Frustration \\
\hline 23 & 32 & $\begin{array}{l}\text { \#IdleNoMore \#toronto global day of action! MONDAY at 12pm at Nathan Phillips } \\
\text { Sq! Pleads RT! We rock! \#cdnpoli @rabbleca }\end{array}$ & Empowerment \\
\hline 24 & 42 & $\begin{array}{l}\text { For Immediate Release @ChiefTheresa Official Press Release on Jan 24, } 2013 \text {, } \\
\text { Please Share \#idlenomore http://t.co/SaMwlsC5 }\end{array}$ & \\
\hline 25 & 109 & $\begin{array}{l}\text { Thank You@ChiefTheresa for your service \& inspiration\#idlenomore hope you } \\
\text { recover soon! Much Love \& Respect XO darylhttp://t.co/Xr1rOAA6" }\end{array}$ & Respect \\
\hline 26 & 10 & $\begin{array}{l}\text { \#Indigenous rights movement 'as important as ever' } \\
\text { this \#australiaday http://t.co/tk7eovju \#IdleNoMore }\end{array}$ & \\
\hline 27 & 75 & $\begin{array}{l}\text { \#OpThunderbird flaps its mighty wings for another twitter storm. Tonight. } 10 \mathrm{pm} \\
\text { eastern. \#IdleNoMore }\end{array}$ & \\
\hline 28 & 11 & $\begin{array}{l}\text { \#IdleNoMore app will allow users to locate nearby rallies HT@CherissD - } \\
\text { http://t.co/wBF7Mkul }\end{array}$ & \\
\hline 29 & 37 & $\begin{array}{l}\text { For some reason the world thinks Canada has no racism. Don't I } \\
\text { wish!! \#IdleNoMore http://t.co/OTOtcXYj }\end{array}$ & Respect \\
\hline 30 & 78 & $\begin{array}{l}\text { Now it's time to go strong, go hard and grow this movement to achieve the } \\
\text { fundamental change that is needed - Nation to Nation.\#idlenomore }\end{array}$ & Accountability \\
\hline 31 & 23 & $\begin{array}{l}\text { Read the full "confidential" document: http://t.co/DouAOIGC where Harper } \\
\text { discusses \#idlenomore }\end{array}$ & Mistrust \\
\hline 32 & 25 & Protecting water \& land is not just an Indian thing, its a human thing\#idlenomore & Respect \\
\hline
\end{tabular}




\begin{tabular}{|c|c|c|c|}
\hline 33 & 10 & $\begin{array}{l}\text { My story from today's @nationalpost argues Theresa Spence was in way over } \\
\text { her head: http://t.co/iLwNrzf4 \#IdleNoMore \#cdnpoli \#roft }\end{array}$ & \\
\hline 34 & 60 & Venice Beach round dance \#idlenomore. Gorgeous picture!!http://t.co/ARQOpWrJ & Cultural Pride \\
\hline 35 & 22 & What do Whites Want? http://t.co/37SHXzeW by Thomas King\#IdleNoMore & \\
\hline 36 & 38 & $\begin{array}{l}\text { Indigenous Chief Theresa Spence Ends 6-Week Hunger Strike in } \\
\text { Canada http://t.co/D8robc1X \#IdleNoMore }\end{array}$ & \\
\hline 37 & 30 & $\begin{array}{l}\text { Attawapiskat Chief Theresa Spence is officially ending her protest liquid diet in } \\
\text { Ottawa http://t.co/sS6yY2bw \#idlenomore \#NoKXL }\end{array}$ & \\
\hline 38 & 18 & $\begin{array}{l}\text { What is so awesome about my First Nations brothers and sisters is that they } \\
\text { made the improbable probable. \#IdleNoMore }\end{array}$ & Cultural Pride \\
\hline 39 & 11 & $\begin{array}{l}\text { @Min_Reyes CBC has fallen in other areas too, including this revealing } \\
\text { encounter yesterday regarding \#IdleNoMore:http://t.co/cA7f6Dq2 }\end{array}$ & Accountability \\
\hline 40 & 16 & $\begin{array}{l}\text { The Journey of Nishiyuu.Almost halfway to Chisasibi from Whapmagoostui. } \\
\text { Google map that. \#idlenomore (Photo: SJ George)http://t.co/sZ2OpBza }\end{array}$ & \\
\hline 41 & 21 & $\begin{array}{l}\text { Getting opposition to agree to sign a } 13 \text { point plan changes nothing. Idle No More } \\
\text { movement continues. \#INM \#idlenomore }\end{array}$ & \\
\hline 42 & 8 & Black \& Green \#ldleNoMore is for everyone poster! \#cdnpolihttp://t.co/jBTVrQpK & \\
\hline 43 & 25 & $\begin{array}{l}\text { If \#ldleNoMore is to grow and sustain, it will take the strength of women to help it } \\
\text { reach it's full potential. }\end{array}$ & Cultural Unity \\
\hline 44 & 73 & $\begin{array}{l}\text { Idle No More is not just an Indigenous movement, its for ALL } \\
\text { grassroots \#idlenomore }\end{array}$ & Cultural Unity \\
\hline 45 & 15 & $\begin{array}{l}\text { Exploring the Canadian constitution and treaty rights \#youtube\#IdleNoMore \& } \\
\text { Mainstream Media http://t.co/1anuJqR6 }\end{array}$ & Respect \\
\hline 46 & 24 & $\begin{array}{l}\text { RT @Min_Reyes: \#IdleNoMore Postcard! (not original } \\
\text { file/size)\#cdnpoli http://t.co/TgZe813T http://t.co/BOdPKIQb }\end{array}$ & \\
\hline 47 & 13 & \#IdleNoMore includes knowing your family history and ancestry. & Cultural Identity \\
\hline 48 & 10 & $\begin{array}{l}\text { Tonight on The Source: Chief Clarence Louie joins @EzraLevant to } \\
\text { discuss \#cdnpoli and \#IdleNoMore - 5PM ET, 7PM PT. }\end{array}$ & \\
\hline 49 & 56 & $\begin{array}{l}\text { \#IdleNoMore is } 4 \text { everyone. It is not just an 'Indian } \\
\text { thing'!!!http://t.co/ZA21FqnP \#cdnpoli \#canpoli \#J28 }\end{array}$ & Cultural Unity \\
\hline 50 & 18 & $\begin{array}{l}\text { "We took the lands from the Indians we will take the land from you!" Said to a } \\
\text { Neb.non \#ndn rancher by Keystone XL land agent.\#idlenomore }\end{array}$ & Respect \\
\hline
\end{tabular}


Top 50 Most Influential \#idlenomore Tweets from March 24-26, 2013. (Topsy, 2013)

\begin{tabular}{|c|c|c|c|}
\hline Influence & \# Tweets & Tweet Content & Theme \\
\hline 1 & 4 & $\begin{array}{l}\text { @krystalline_k: Tantoo Cardinal @tantooC speaks at Queen's } \\
\text { Park \#indigenous \#IdleNoMore rally in \#Toronto \#cdnpolihttp://t.co/yCcZBwVf5P }\end{array}$ & Empowerment \\
\hline 2 & $6 j$ & $\begin{array}{l}\text { @gmgtweet: Cree youth near Ottawa, end of Idle No More } \\
\text { journey http://t.co/wLEp2OOBmT \#goodmedicine \#IdleNoMore }\end{array}$ & Cultural Pride \\
\hline 3 & 2 & $\begin{array}{l}\text { @OrganicConsumer: Canadian and U.S. Natives Vow to Block Oil } \\
\text { Pipelines http://t.co/FmZjVyvKc8 \#IdleNoMore \#NOKXL! }\end{array}$ & Empowerment \\
\hline 4 & $3 i$ & $\begin{array}{l}\text { @OccupyPdx: Listen up Portland Actors! I wrote this and I'd love to see you in } \\
\text { it. \#IdleNoMore \#OregonFilm http://t.co/YChqhczZ47 }\end{array}$ & \\
\hline 5 & 21 & $\begin{array}{l}\text { @EllenGabriel110h had the line of the night @ \#N2Nn: "We need to assimilate } \\
\text { Canadians into the teachings of our elders."\#idlenomore }\end{array}$ & Education \\
\hline 6 & 24 & $\begin{array}{l}\text { @EllenGabriel110h had the line of the night @ \#N2Nn: "We need to assimilate } \\
\text { Canadians into the teachings of our elders."\#idlenomore }\end{array}$ & Education \\
\hline 7 & 7 & A giant round dance about to begin \#nishiyuu \#IdleNoMorehttp://t.co/3PUK5Krysn & Cultural Identity \\
\hline 8 & 1 & $\begin{array}{l}\text { @pmharper panda bears, much more important than Canada's citizens braving - } 50 \\
\text { and months of walking.\#getyourprioritiesstraight \#IdleNoMore }\end{array}$ & Respect \\
\hline 9 & 2 & $\begin{array}{l}\text { @AntDeRosa: Canada's PM snubs Nishiyuu youth for } \\
\text { pandashttp://t.co/TeeDtVO8vo \#IdleNoMore }\end{array}$ & Respect \\
\hline 10 & 3 & $\begin{array}{l}\text { \#FacePalm Harper greets pandas while \#Nishiyuu walkers } \\
\text { return\#IdleNoMore \#cdnpoli http://t.co/9cX9Ly8T6Y" }\end{array}$ & Respect \\
\hline 11 & 1 & $\begin{array}{l}\text { Thousands greeted the indigenous youth on the steps.....after their great trek..to bring a } \\
\text { message of equality \#IdleNoMore }\end{array}$ & Cultural Pride \\
\hline 12 & 5 & $\begin{array}{l}\text { Everyone should check out the \#IdleNoMore hash. The indigenous youth are accomplishing } \\
\text { great momentum to bring their message of equality. }\end{array}$ & Cultural Unity \\
\hline 13 & 1 & $\begin{array}{l}\text { @oliviachow: We are all equal. We are all one. Said the walker from James } \\
\text { Bay. \#idlenomore http://t.co/frsDol2XuR" }\end{array}$ & Cultural Unity \\
\hline 14 & 3 & $\begin{array}{l}\text { Chief Teresa Spence addressing } \\
\text { thousands \#nishiyuu \#IdleNoMorehttp://t.co/jeseCsEj7N }\end{array}$ & \\
\hline 15 & 140 & $\begin{array}{l}\text { A Bald eagle just circled over the marchers. All fingers point upward and } \\
\text { cheer. \#Nishiyuu \#idlenomore }\end{array}$ & Cultural Pride \\
\hline 16 & 94 & \#Nishiyuu \#idlenomore Yay! For First Nations youth! \#cdnpolihttp://t.co/Uglf2Wh275 & Cultural Pride \\
\hline 17 & 214 & $\begin{array}{l}\text { Proud to have met with and listened to the extraordinary Nishiyuu Walkers today. } \\
\text { These young leaders are \#IdleNoMore.http://t.co/Hwvmym78WT }\end{array}$ & Cultural Pride \\
\hline 18 & $4 \mathrm{~F}$ & RT if you're willing to put your body between a pipeline and stolen land. \#ldleNoMore & Empowerment \\
\hline 19 & 3 & $\begin{array}{l}\text { Pandas vs Cree } \\
\text { walkers... \#idlenomore \#Nishiyuu \#pandas \#harperhttp://t.co/qyMsAKqT1A }\end{array}$ & Respect \\
\hline 20 & $72 j$ & $\begin{array}{l}\text { \#Nishiyuu is trending in Canada. Here's some background about this epic } \\
\text { journey http://t.co/bp3NLGdrWc \#IdleNoMore \#cdnpoli }\end{array}$ & Cultural Pride \\
\hline 21 & 241 & $\begin{array}{l}\text { The Journey of Nishiyuu shows commitment to a better future for FN communities. } \\
\text { Let's equal that with real engagement. \#idlenomore\#Nishiyuu }\end{array}$ & Accountability \\
\hline 22 & 142 & $\begin{array}{l}\text { Everyone of my followers should RETWEET this and their followers } \\
\text { too! \#SHAMEONHARPER \#IDLENOMORE http://t.co/uH5Ykn5nTN }\end{array}$ & \\
\hline 23 & 2 & $\begin{array}{l}\text { Perhaps the pandas should have been welcomed by the real } \\
\text { Canadians... \#Nishiyuu \#IdleNoMore http://t.co/tF5pJmvK80 }\end{array}$ & Respect \\
\hline 24 & 2 & $\begin{array}{l}\text { Pandas vs Cree walkers...Harper makes me } \\
\text { ashamed.http://t.co/i2Pbrj7EN8 \#idlenomore \#Nishiyuu \#pandas \#pmharper\#canada }\end{array}$ & Frustration \\
\hline 25 & 5 & $\begin{array}{l}\text { Ashamed of our Prime Minister... \#pandas VS \#creewalkers\#Nishiyuu define Canada } \\
\text { in a way that Harper will never dream of.\#idlenomore }\end{array}$ & Frustration \\
\hline 26 & 4 & $\begin{array}{l}\text { So the \#mining industry/capital moves } \\
\text { to \#Canadahttp://t.co/c1zohktRoX \#idlenomore @Reservemining \#occupy\#vancouver } \\
\text { \#quebec \#skouries }\end{array}$ & Accountability \\
\hline 27 & 3 & $\begin{array}{l}\text { The \#IdleNoMore Daily is out! http://t.co/bgy8B5nv4Z • Top stories today } \\
\text { via@TweetSLC @jmrob@4oclockwhistle }\end{array}$ & \\
\hline 28 & 4 & $\begin{array}{l}\text { "Honour your word" -- Live on Parliament } \\
\text { Hill \#Nishiyuu \#Idlenomore\#cdnpoli http://t.co/fDPiVyoBRX }\end{array}$ & Accountability \\
\hline 29 & 37 & $\begin{array}{l}\text { Saw news headline, "forget diplomatic pandas, we're covering Journey } \\
\text { of @Nishiyuu" \#idlenomore GO Rabble.ca \& Nishiyuu@smhoule @CBC @CNN }\end{array}$ & Respect \\
\hline 30 & 17 & $\begin{array}{l}\text { Tar Sands Pipeline Bigger than Keystone XL \& Headed for the Great } \\
\text { Lakes http://t.co/vhXrXhg0ah \#idlenomore \#KXL \#NOKXL \#wiunion }\end{array}$ & Mistrust \\
\hline 31 & 8 & \#Nishiyuu means people in Cree. \#cdnpoli \#idlenomore & Cultural Identity \\
\hline
\end{tabular}




\begin{tabular}{|c|c|c|c|}
\hline 32 & 2 & $\begin{array}{l}\text { The Beginning is HERE! } \\
\sim \text { \#OccupyLove http://t.co/wvPhdxf7P3\#OWS \#IdleNoMore \#Occupy }\end{array}$ & \\
\hline 33 & & $\begin{array}{l}\text { A Bald eagle circled over the marchers. All fingers point upward and } \\
\text { cheer. \#Nishiyuu \#idlenomore @FirstPeoples }\end{array}$ & Cultural Pride \\
\hline 34 & 2 & $\begin{array}{l}\text { March now approaching Parliament } \\
\text { Hill. \#nishiyuu \#idlenomore\#cdnpoli http://t.co/zTtyOXbCRW }\end{array}$ & Cultural Pride \\
\hline 35 & 3 & $\begin{array}{l}\text { The pandas are not to blame. The idea that votes are more important than people is } \\
\text { to blame. \#idlenomore \#nishiyuu }\end{array}$ & Respect \\
\hline 36 & 5 & $\begin{array}{l}\text { The \#PropogandaPanda shows up } \\
\text { on @rickmercer:http://t.co/SCd3c8Cl7a | \#APC \#LPC \#CdnPoli |\#IdleNoMore }\end{array}$ & Respect \\
\hline 37 & 8 & $\begin{array}{l}\text { Tar Sands Pipeline Bigger than Keystone XL Headed for the Great } \\
\text { Lakes http://t.co/T6pn5VoTsq \#idlenomore \#wipolitics \#kxl }\end{array}$ & Mistrust \\
\hline 38 & 45 & $\begin{array}{l}\text { Huge crowd welcoming the Nishiyuu walkers on Parliament } \\
\text { Hill\#idlenomore \#cdnpoli http://t.co/7II6NWzyTw }\end{array}$ & Empowerment \\
\hline 39 & 28 & $\begin{array}{l}\text { The Journey of Nishiyuu. Young flagbearer. Chelsea, QC. } \\
\text { Today.\#idlenomore (photo:p.seesequasis) http://t.co/N2j2P4AR0n }\end{array}$ & Cultural Pride \\
\hline 40 & 2 & $\begin{array}{l}\text { Amazing grassroots-style live stream content for The Journey } \\
\text { of\#Nishiyuu on \#occupytoronto: http://t.co/pwABUZ1LMQ \#idlenomore }\end{array}$ & \\
\hline 41 & 2 & $\begin{array}{l}\text { Wishing I could be in Ottawa today for the arrival of The Journey of Nishiyuu. SUCH an } \\
\text { amazing trek with a great message.\#idlenomore }\end{array}$ & Cultural Unity \\
\hline 42 & 20 & $\begin{array}{l}\text { \#idlenomore \#toronto banner in support of Attawapiskat and against DeBeers } \\
\text { Mining http://t.co/ULdmwbashy }\end{array}$ & Empowerment \\
\hline 43 & 8 & $\begin{array}{l}\text { \#IdleNoMore RT @Megawitch Just posted the final schedule for\#Nishiyuu tomorrow } \\
\text { on FB https://t.co/m5g7ojV9HS ... \#ndnz\#indigenous \#cdnpoli }\end{array}$ & \\
\hline 44 & 26 & $\begin{array}{l}\text { The Journey of Nishiyuu. 'Made it.' Steps of Parliament. } \\
\text { 25/03/2013.\#idlenomore (photo:PS) http://t.co/eqvYTU3aPB }\end{array}$ & Cultural Unity \\
\hline 45 & 9 & $\begin{array}{l}\text { \#PMHarper imported \#Pandas so he can pretend } 2 \text { love \#animalsexcept those silly } \\
\text { Spirit Bears. \#Tarsands \#IdleNoMore \#Nishiyuu\#CdnPoli \#FN }\end{array}$ & Frustration \\
\hline 46 & 3 & $\begin{array}{l}\text { Another photo of the huge crowd on Parliament Hill in } \\
\text { Ottawa\#IdleNoMore \#INM \#Nishiyuu https://t.co/az5EYSjKch@CTV_Television }\end{array}$ & Cultural Pride \\
\hline 47 & 14 & $\begin{array}{l}\text { Canadian and U.S. Natives Vow to Block Oil } \\
\text { Pipelineshttp://t.co/sgwtRhN3T6 \#IdleNoMore \#NOKXL! }\end{array}$ & \\
\hline 48 & 2 & $\begin{array}{l}\text { Daily \#FN \#IdleNoMore \#CdnPoli is out! http://t.co/8teBPhZj9M • Top stories today } \\
\text { via @sas_robin @dj_agana @NancyFromCanada }\end{array}$ & \\
\hline 49 & 18 & $\begin{array}{l}\text { MT @CTVNews Cheers greet young Cree walkers after 1,600-kilometre trek to } \\
\text { Ottawa http://t.co/dn2P2rkWTq \#IdleNoMore\#Nishiyuu }\end{array}$ & \\
\hline 50 & 1 & $\begin{array}{l}\text { Homeless Edmontonians speak about impact of residential } \\
\text { schools http://t.co/2IJ9tKMvG2 \#idlenomore \#firstnations \#canpoli }\end{array}$ & Empowerment \\
\hline
\end{tabular}

